\title{
EFEITOS DA ADUBAÇÃO NPK NO CRESCIMENTO, NA PRODUTIVIDADE E NA EXPORTAÇÃO DE NUTRIENTES PELA SERINGUEIRA
}

\section{MARCOS ROBERTO MURBACH \\ Engenheiro Agrônomo}

Orientador: Prof. Dr. Antonio Enedi Boaretto

\begin{abstract}
Dissertação apresentada à Escola Superior de Agricultura "Luiz de Queiroz", da Universidade de São Paulo, para obtenção do título de Mestre em Agronomia, Área de concentração: Solos e Nutrição de Plantas
\end{abstract}

PIRACICABA

Estado de São Paulo - Brasil

Maio de 1997 
Dados Internacionais de Catalogação na Publicação (CIP) DIVISÃO DE BIBLIOTECA E DOCUMENTAÇÃO - Campus "Luiz de Queiroz"/USP

Murbach, Marcos Roberto Efeitos da adubação NPK no crescimento, na produtividade e na exportaçăo de nutrientes pela seringueira / Marcos Roberto Murbach. - - Piracicaba, 1997.

91 p. : il.

Dissertação (mestrado) - Escola Superior de Agricultura Luiz de Queiroz, 1997.

Bibliografia.

1. Adubação NPK (efeito) 2. Nutriente 3. Produtividade 4. São Paulo (estado) 5. Seringueira 1. Titulo

CDD 633.895 


\section{EFEITOS DA ADUBAÇÃO NPK NO CRESCIMENTO, NA PRODUTIVIDADE E NA EXPORTAÇÃO DE NUTRIENTES PELA SERINGUEIRA}

\section{MARCOS ROBERTO MURBACH}

Aprovado em 20/06/1997

Comissão julgadora:

Ondino Cleante Bataglia

Marcos Silveira Bernardes

Antonio Enedi Boaretto

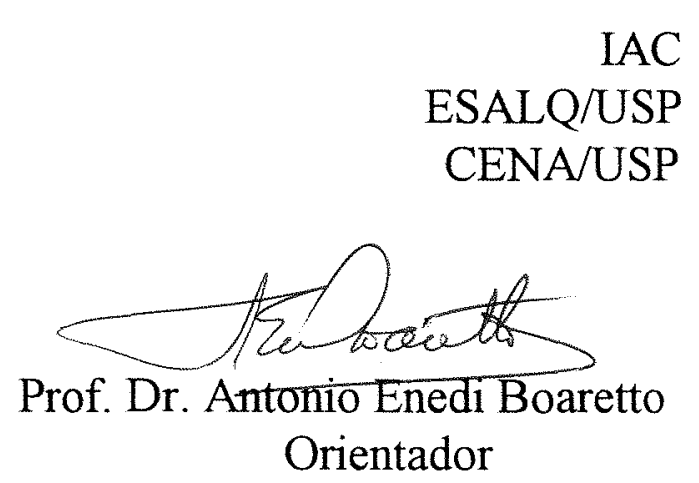


À Deus que me permitiu, Aos meus pais que sempre confiaram em mim, Aos meus irmãos Luis Antonio, Ana Lucia e

Lucimara, que sempre estiveram presentes

\section{OFEREÇO}

À minha esposa Claudia

e minha filha Jaqueline, razão da minha vida,

\section{DEDICO}




\section{Agradecimentos}

- À Escola Superior de Agricultura "Luiz de Queiroz" (ESALQ/USP) e ao Centro de Energia Nuclear na Agricultura (CENA) pela oportunidade de realizar este curso.

- Os autores agradecem à FAPESP pelo auxílio financeiro para a realização do projeto e pela bolsa de mestrado (6 meses) e ao CNPq pelas bolsas de mestrado e de iniciação científica.

- Ao IBAMA e a EMBRAPA pelo apoio financeiro no início do projeto.

- Ao Prof. Dr. Antonio Enedi Boaretto pela orientação, compreensão, amizade e confiança depositada em minha pessoa.

- Ao Prof. Dr. Ronaldo Ivan Silveira, pela colaboração.

- Ao Prof. Dr.Takashi Muraoka, pela colabaração e pelo laboratório de fertilidade do solo do CENA/USP.

- Ao prof. Dilermando Perecin pela proveitosa assessoria nas análises estatísticas.

- Ao Engenheiro Agrícola Luís Roberto Takitane, gerente da Fazenda Mundo Novo, ao Sr.Hissashi e ao Grupo Sassazaki, pelo apoio e colaboração cedendo a área para a execuçãodo presente trabalho.

- Aos técnicos de laboratório: Henriqueta, Marileuza, Sandra, João Salvador; e aos estagiários: Felipe, Margarette, Rodrigo, Reimar.

- À amiga Maria Aparecida Calegaro (Cidinha) pela amizade, paciência e dedicação na digitação da Dissertação.

- Aos amigos de pós-graduação: Adonias de Castro Virgens Filho, Newton Falcão, Eduardo Scarpari Spolidorio, Cássio Hamilton Abreu Junior, Valquiria Scivittaro, Ila Cardin, Edgar Fernando de Luca e Anita.

- À bibliotecaria Marília Ribeiro Garcia Henyei pela correção das referências bibliográficas.

- À todos que direta ou indiretamente ajudaram na realização deste trabalho. 


\section{SUMÁRIO}

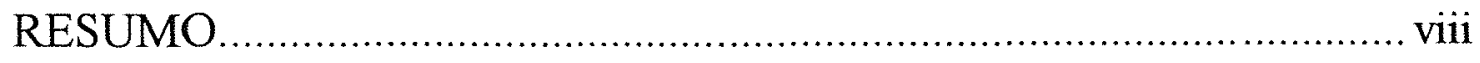

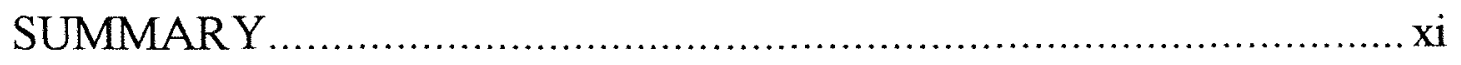

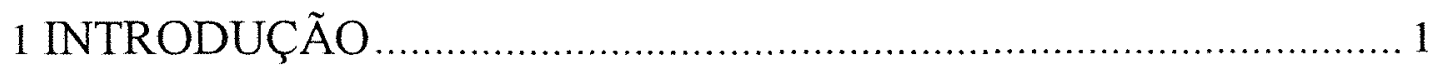

2 REVISÃO DE LITERATURA .................................................. 4

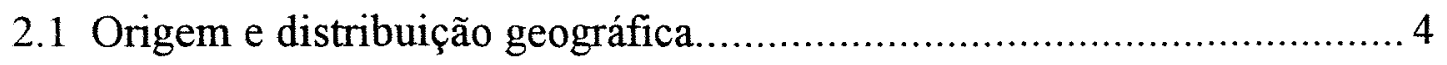

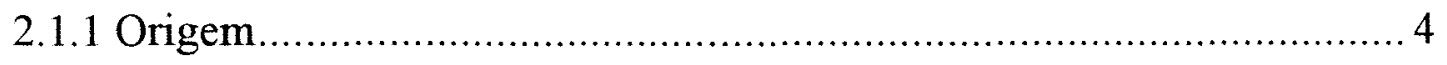

2.1.2 Distribuição geográfica ............................................................ 5

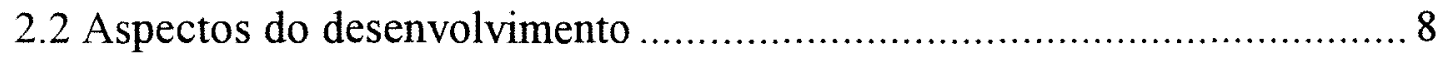

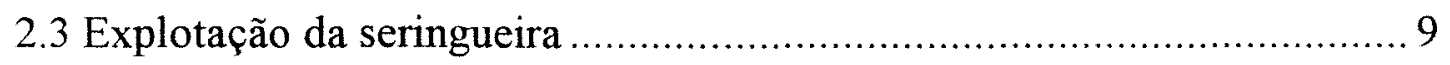

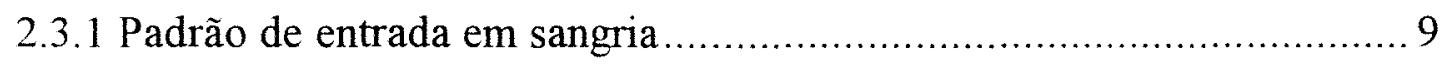

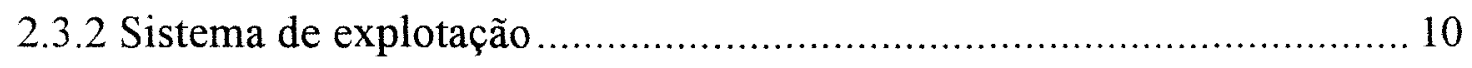

2.4 Efeito da adubação sobre o desenvolvimento ......................................... 11

2.5 Efeito da adubação sobre a produção ………...................................... 15

2.6 Composição bioquímica do látex da seringueira.................................. 15

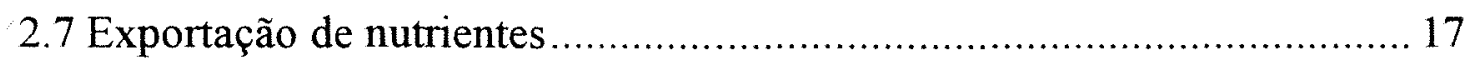

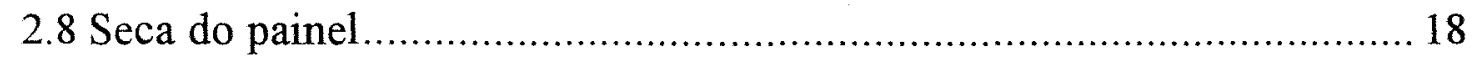




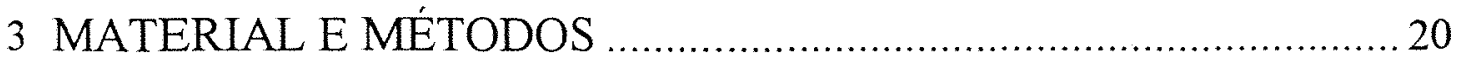

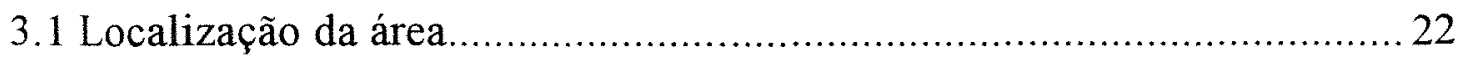

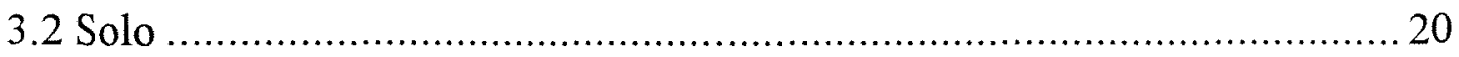

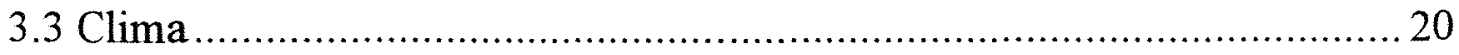

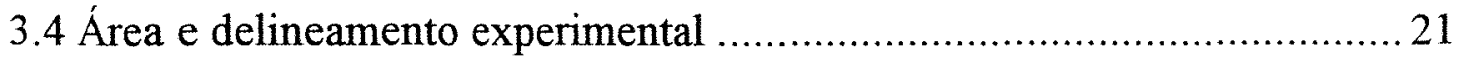

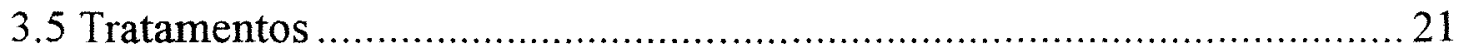

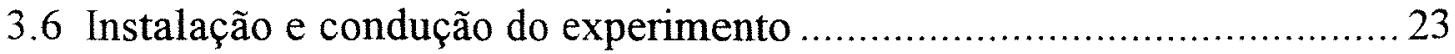

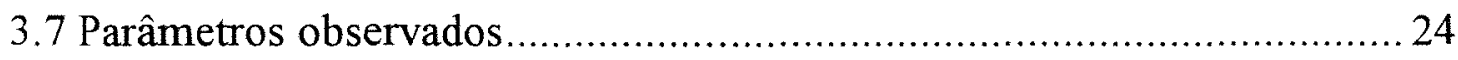

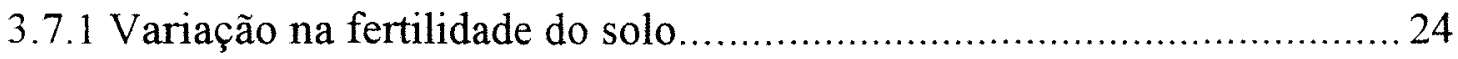

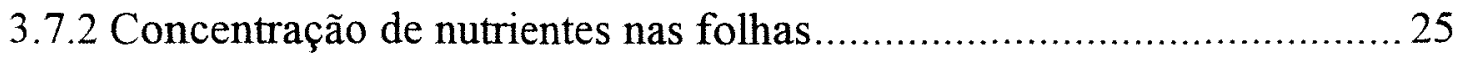

3.7.3 Perímetro do tronco, Espessura da casca e seca do painel ...................2 25

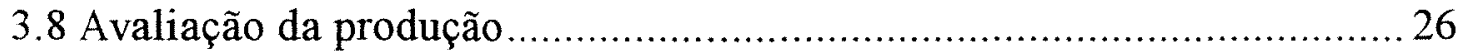

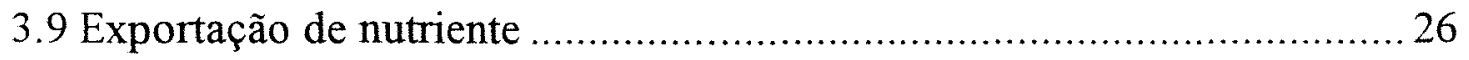

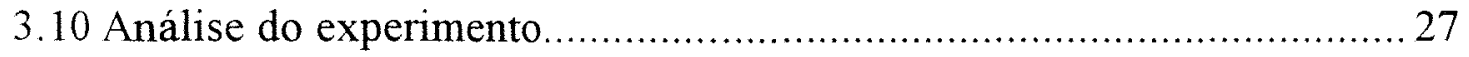

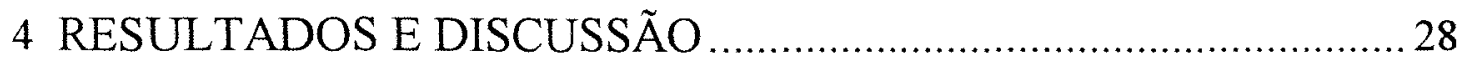

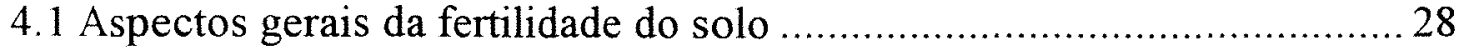

4.2 Efeito da adubação N, P, K sobre a fertilidade do solo...........................2 29

4.3 Efeito da adubação nitrogenada, fosfatada e potássica no estado nutricional das plantas.................................... 43 
4.4 Efeito da adubação nitrogenada, fosfatada e potássica no perímetro do caule e na espessura da casca do caule da seringueira............................55

4.5 Flutuação mensal da produção de borracha seca.................................61

4.6 Influência da adubação NPK na produtividade de borracha seca e

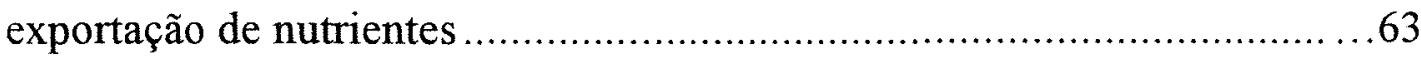

4.7 Influência da adubação NPK na \% de corte seco do painel.............. 75

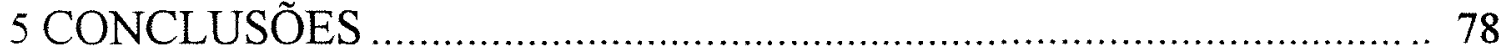

REFERÊNCIAS BIBLIOGRÁFICAS............................................... 79 


\title{
EFEITOS DA ADUBAÇÃO NPK NO CRESCIMENTO, NA PRODUTIVIDADE E NA EXPORTAÇÃO DE NUTRIENTES PELA SERINGUEIRA.
}

\author{
Autor: Marcos Roberto Murbach \\ Orientador: Antonio Enedi Boaretto
}

\section{Resumo}

Com o objetivo de avaliar os efeitos da adubação nitrogenada, fosfatada e potássica sobre o crescimento, produção de borracha seca, exportação de nutrientes e seca do painel da seringueira (clone PB235), foi conduzido um experimento num seringal de 12 anos de idade, localizado no município de Garça (SP), em solo Latossolo Vermelho escuro A moderado álico textura arenosa.

$\mathrm{O}$ experimento foi instalado em blocos ao acaso, em esquema fatorial fracionário $(1 / 4) 4^{3}$, totalizando 16 tratamentos e 4 repetições. Cada parcela, de $480 \mathrm{~m}^{2}$, continha 20 plantas, sendo que 6 delas foram consideradas na obtenção dos resultados,

Os tratamentos foram constituídos pela combinação de doses $\left(\mathrm{kg} \mathrm{ha}^{-1}\right)$ de $\mathrm{N}(0$; $80 ; 160$ e 320), de $\mathrm{P}_{2} \mathrm{O}_{5}(0 ; 40 ; 80$ e 160$)$ e de $\mathrm{K}_{2} \mathrm{O}(0 ; 80 ; 160$ e 320), nas combinações: $\mathrm{N}_{0} \mathrm{P}_{0} \mathrm{~K}_{0} ; \mathrm{N}_{1} \mathrm{P}_{1} \mathrm{~K}_{0} ; \mathrm{N}_{1} \mathrm{P}_{0} \mathrm{~K}_{1} ; \mathrm{N}_{0} \mathrm{P}_{1} \mathrm{~K}_{1} ; \mathrm{N}_{1} \mathrm{P}_{1} \mathrm{~K}_{1} ; \mathrm{N}_{2} \mathrm{P}_{1} \mathrm{~K}_{1} ; \mathrm{N}_{3} \mathrm{P}_{1} \mathrm{~K}_{1} ; \mathrm{N}_{1} \mathrm{P}_{2} \mathrm{~K}_{1} ; \mathrm{N}_{1} \mathrm{P}_{3} \mathrm{~K}_{1} ; \mathrm{N}_{1} \mathrm{P}_{1} \mathrm{~K}_{2} ;$ $\mathrm{N}_{1} \mathrm{P}_{1} \mathrm{~K}_{3} ; \mathrm{N}_{2} \mathrm{P}_{1} \mathrm{~K}_{2} ; \mathrm{N}_{3} \mathrm{P}_{1} \mathrm{~K}_{2} ; \mathrm{N}_{2} \mathrm{P}_{1} \mathrm{~K}_{3} ; \mathrm{N}_{2} \mathrm{P}_{2} \mathrm{~K}_{2}$ e $\mathrm{N}_{3} \mathrm{P}_{3} \mathrm{~K}_{3}$. As fontes de nutrientes utilizadas foram: uréia $(45 \% \mathrm{~N})$, superfosfato simples $\left(18 \%\right.$ de $\left.\mathrm{P}_{2} \mathrm{O}_{5}\right)$ e cloreto de potássio $(60 \%$ de $\mathrm{K}_{2} \mathrm{O}$ ). A adubação do experimento, desde a sua instalação, foi crescente com a idade do seringal, sendo que as doses citadas foram aplicadas a partir de 1992 e os resultados foram obtidos em 1996 e 1997. 
A produção foi avaliada mensalmente, obtendo-se o peso da borracha (seca a $65^{\circ} \mathrm{C}$ ) em $\mathrm{kg} / \mathrm{ha} / \mathrm{ano}$. O perimetro do tronco, o percentual de corte seco e a espessura de casca foram avaliados anualmente. A exportação de nutrientes pelo látex foi avaliada analisando-se amostra de látex coletada em junho de 96. As amostras de solo, das camadas de $0-20$ e $20-40 \mathrm{~cm}$, foram obtidas em outubro de 1995 e a amostragem de folhas foi feita em fevereiro de 1996.

A adubação nitrogenada provocou diminuição do $\mathrm{pH}$ em $\mathrm{CaCl}_{2}$ do solo, do $\mathrm{Mg}$ trocável, da soma de bases, da saturação por bases e aumentou a acidez potencial $\left(\mathrm{H}^{+}+\mathrm{Al}^{+++}\right)$, A adubação fosfatada aumentou a CTC, o $\mathrm{pH}$ em $\mathrm{CaCl}_{2}$ (nas amostras de solo retiradas a $0-20 \mathrm{~cm}$ ) e aumentou a saturação por bases (na camada de $20-40 \mathrm{~cm}$ ) e em amostras de solo das duas camadas verificaram-se aumentos dos teores de $\mathrm{Ca}$ e de $\mathrm{P}$ extraídos pela resina trocadora de íons. A adubação potássica aumentou a disponibilidade de $\mathrm{K}$ para as plantas em ambas as camadas de solo amostradas.

Os teores de $\mathrm{N}$ e $\mathrm{K}$ foliares foram aumentados pela adubação nitrogenada $\mathrm{e}$ potássica, respectivamente. A adubação fosfatada não alterou os teores foliares de $\mathrm{P}$ mas aumentou os teores de Ca na folha.

O perímetro do tronco da seringueira, medido aos 12 e 13 anos de idade, foi aumentado significativamente pela adubação potássica. A taxa de crescimento anual do perímetro do tronco, a partir do $4^{0}$ ano, é decrescente até o $13^{\circ}$ ano após o plantio, quando a última medida foi efetuada. A adubação potássica provocou aumento da espessura da casca medida quando a seringueira tinha 12 anos de idade.

O clone PB235 mostrou-se suscetivel a seca do painel mas este fenômeno não teve qualquer relação com a adubação de nitrogênio, fósforo e potássio aplicada.

A produtividade de borracha foi crescente de outubro a fevereiro, de fevereiro a abril manteve-se constante e a partir de maio decresceu até junho, quando a sangria foi interrompida. A adubação potássica promoveu aumento de produção anual de borracha seca, sendo o efeito quadrático significativo ao nível de $10 \%$. A dose de $155 \mathrm{~kg} \mathrm{ha}^{-1}$ de $\mathrm{K}_{2} \mathrm{O}$ proporcionou a maior produtividade (1444 kg ha ${ }^{-1}$ de borracha seca). Os teores de $\mathrm{K}$ 
nas folhas e no solo $(0-20 \mathrm{~cm})$ associados a esta adubação foram respectivamente de $12, \mathrm{gkg}^{-1}$ e $3,2 \mathrm{mmol}_{\mathrm{c}} / \mathrm{dm}^{3}$.

Com $1000 \mathrm{~kg}$ de borracha seca são exportados $6,6 \mathrm{~kg}$ de $\mathrm{N} ; 3,9 \mathrm{~kg}$ de $\mathrm{P} ; 6,1 \mathrm{~kg}$ de $\mathrm{K} ; 190 \mathrm{~g}$ de $\mathrm{Ca} ; 1,1 \mathrm{~kg}$ de $\mathrm{Mg} ; 540 \mathrm{~g}$ de $\mathrm{S} ; 18 \mathrm{~g}$ de $\mathrm{Cu} ; 57 \mathrm{~g}$ de Fe; $3 \mathrm{~g}$ de $\mathrm{Mn}$ e $257 \mathrm{~g}$ de $\mathrm{Zn}$. 


\title{
NPK FERTILIZATION AFFECTING GROWTH, YIELD AND NUTRIENT REMOVAL ON RUBBER TREE
}

\author{
Author: Marcos Roberto Murbach \\ Adviser: Prof. Antonio Enedi Boaretto
}

\section{SUMMARY}

This experiment was carried out to study the effects of nitrogen, phosphorous and potassium fertilization on growth, dry rubber yield, nutrient removal and "brown bast" of rubber trees (clone PB 235) in a Dark Red Latosol sandy fase located in Garça, state of São Paulo, Brazil.

The experimental design was a randomized blocks, with a fractional factorial scheme $\left(1 / 4\right.$ of $\left.4^{3}\right)$, with 16 treatments and 4 replications. The $480 \mathrm{~m}^{2}$ plots, had 20 trees and data was collected from 6 plants.

The treatments were based in the combination of 4 dosis of $N(0,80,160$, and $\left.320 \mathrm{~kg} \mathrm{ha}^{-1}\right)$, of $\mathrm{P}_{2} \mathrm{O}_{5}\left(0 ; 40 ; 80\right.$ and $\left.160 \mathrm{~kg} \mathrm{ha}^{-1}\right)$ and $\mathrm{K}_{2} \mathrm{O}\left(0 ; 80 ; 160\right.$ and $\left.320 \mathrm{~kg} \mathrm{ha}^{-1}\right)$, in the following combinations: $\mathrm{N}_{0} \mathrm{P}_{0} \mathrm{~K}_{0} ; \mathrm{N}_{1} \mathrm{P}_{1} \mathrm{~K}_{0} ; \mathrm{N}_{1} \mathrm{P}_{0} \mathrm{~K}_{1} ; \mathrm{N}_{0} \mathrm{P}_{1} \mathrm{~K}_{1} ; \mathrm{N}_{1} \mathrm{P}_{1} \mathrm{~K}_{1} ; \mathrm{N}_{2} \mathrm{P}_{1} \mathrm{~K}_{1}$; $\mathrm{N}_{3} \mathrm{P}_{1} \mathrm{~K}_{1} ; \mathrm{N}_{1} \mathrm{P}_{2} \mathrm{~K}_{1} ; \mathrm{N}_{1} \mathrm{P}_{3} \mathrm{~K}_{1} ; \mathrm{N}_{1} \mathrm{P}_{1} \mathrm{~K}_{2} ; \mathrm{N}_{1} \mathrm{P}_{1} \mathrm{~K}_{3} ; \mathrm{N}_{2} \mathrm{P}_{1} \mathrm{~K}_{2} ; \mathrm{N}_{3} \mathrm{P}_{1} \mathrm{~K}_{2} ; \mathrm{N}_{2} \mathrm{P}_{1} \mathrm{~K}_{3} ; \mathrm{N}_{2} \mathrm{P}_{2} \mathrm{~K}_{2}$ e $\mathrm{N}_{3} \mathrm{P}_{3} \mathrm{~K}_{3}$. Urea, simple superphosphate, and potassium chloride were used as source of $\mathrm{N}, \mathrm{P}$ and $\mathrm{K}$, respectively. The fertilization started in 1992 and the data were collected from 1996 to 1997

The yield of dry rubber was evaluated monthly, and summed to obtain annual yield of dry rubber in $\mathrm{kg} / \mathrm{ha} / \mathrm{year}$. Trunk perimeter, bark thickness and percentage of "brown bast" were estimated annually. The removal of nutrients by latex was determined by analyzing latex samples collected in June 1996. Soil and leaf samples for chemical analysis were taken on October 1995, and on February 1996, respectively.

Soil $\mathrm{pH}\left(\mathrm{CaCl}_{2}\right)$, exchangeable $\mathrm{Mg}$, sum of bases and base saturation decreased with increasing nitrogen fertilization, while exchangeable acidity increased $\mathrm{CEC}$ and $\mathrm{pH}$ in soil samples collected in $0-20 \mathrm{~cm}$ layer increased with phosphate 
application and base saturation increased in the $20-40 \mathrm{~cm}$ layer. Exchangeable $\mathrm{Ca}$ and available $\mathrm{P}$ increased in both layers. Exchangeable $\mathrm{K}$ increased with potassium dosis at both layers $(0-20$ and $20-40 \mathrm{~cm})$.

$\mathrm{N}$ and $\mathrm{K}$ leaf levels significantly increased with nitrogen and potassium fertilization. On the other hand, leaf $\mathrm{Ca}$ content increased with phosphorous application.

Trunk perimeter and bark thickness of rubber trees, significantly increased with potassium fertilization, and the annual rate of trunk growth was decreased from the $4^{\text {th }}$ to $13^{\text {th }}$ year of the experiment.

The "brown bast" incidence was not affected by any fertilization applied, but the clone PB 235 seemed to be susceptible to this phenomenon.

The following pattern of dry rubber production was observed: increased from October to February, stable from February to April, and decrease from May to June, when tapping is was discontinued..

Potassium application had a quadratic effect on annual dry rubber production, reading a maximum with the application of $155 \mathrm{~kg} \mathrm{~K}_{2} \mathrm{O} \mathrm{ha}^{-1}$. At this rate, soil content of $\mathrm{K}$ was $3.2 \mathrm{mmo}_{\mathrm{c}} / \mathrm{dm}^{3}$ and leaf content of $\mathrm{K}$ was $12.1 \mathrm{~g} \mathrm{~kg}^{-1}$.

The nutrients removal by $1,000 \mathrm{~kg}$ dry rubber produced were: $6.6 \mathrm{~kg}$ of $\mathrm{N}$; $3.9 \mathrm{~kg}$ of $\mathrm{P} ; 6.1 \mathrm{~kg}$ of $\mathrm{K} ; 190 \mathrm{~g}$ of Ca; $1.1 \mathrm{~kg}$ of Mg; $540 \mathrm{~g}$ of S; $18 \mathrm{~g}$ of Cu; $57 \mathrm{~g}$ of Fe; $3 \mathrm{~g}$ of $\mathrm{Mn}$ and $257 \mathrm{~g}$ of $\mathrm{Zn}$. 


\section{INTRODUÇÃO}

Originária da Amazônia, a seringueira (Hevea brasiliensis Muell. Arg.) é cultura de grande interesse para as zonas tropicais, devido a importância econômica da borracha e a alta produtividade obtida, quando são empregados materiais melhorados e tratos culturais adequados

O Brasil já ocupou lugar de destaque como exportador de borracha natural, proveniente de plantas nativas localizadas em determinadas áreas da planície Amazônica. Entretanto, com o passar dos anos, de exportador o Brasil tornou-se importador desse produto, apesar de possuir condições edafoclimáticas adequadas para o desenvolvimento e expansão da heveicultura (Miranda, et al., 1975).

Nos últimos trinta anos, o mercado mundial de borracha natural tem sido dominado pelos asiáticos. Dados de 1996 mostram que a Tailândia, seguida da Indonésia e da Malásia são os principais países produtores desse produto, com uma produção de $1.784 .400,1.456 .800$ e $1.089 .300 \mathrm{t}$ respectivamente, enquanto que o Brasil, nesse mesmo ano, produziu apenas 32.000 t (International Rubber Study Group, 1996).

A produção anual brasileira de borracha natural nos períodos de 1960/69; $1970 / 79$ e 1980/89, foi de $23.800,22.600$ e 32.500 t respectivamente, mantendo-se por volta de $30.000 \mathrm{t}$ em meados da década de 1990. O consumo nacional nesses mesmos períodos foi da ordem de $35.600,57.600$ e 95.000 e 140.000 t respectivamente, indicando ao longo dessas quatro décadas uma flutuação na produção e um aumento linear no consumo. Observa-se que, para o período 1960/69, a produção atendia a $67 \%$ da demanda nacional, enquanto que em 1995 a produção nacional supria somente $22,3 \%$ da necessidade interna do país (International Rubber Study Grup,1996). 
Para reverter esse quadro, alguns programas foram criados pelo governo brasileiro. O primeiro foi, o Programa de Incentivo à Produção de Borracha Natural (PROBOR I) em 1972, com meta de implantação de 18.000 ha de seringais de cultivo até 1976. Em 1977 foi lançado o PROBOR II com o objetivo de tornar o Brasil autosuficiente em borracha natural, com meta de implantação de 120.000 ha de seringais de cultivo até 1981. Em 1982 foi lançado o PROBOR III, com o objetivo de consolidar a auto-suficiência e criar excedentes exportáveis de borracha natural, com implantação de 250.000 ha de seringais de cultivo até 1987.

Apesar de todos esses programas de incentivo, as áreas implantadas com seringais de cultivo não atingiram as metas programadas, sobretudo nos projetos conduzidos na Amazônia. No Estado de São Paulo o crescimento da heveicultura teve duas fases: a primeira via incentivos governamental com a distribuição de mudas por parte da Secretaria da Agricultura, quando houve um direcionamento para a região do Litoral. A segunda fase, a partir dos anos 80 , sendo caracterizada pela ação empresarial suportada no apoio tecnológico a partir dos trabalhos de pesquisa conduzidos pelo Instituto Agronômico de Campinas, Instituto Biológico, Escola Superior de Agricultura Luiz de Queiroz, entre outras instituições. Estes seringais predominam na região do planalto paulista, onde vem apresentando bom desenvolvimento. No entanto, algumas limitações ao desenvolvimento das plantas exigem esforços concentrados de pesquisa para superá-las, destacando-se neste contexto, aqueles referentes a área de adubação e nutrição da cultura, que objetivam tornar mínimo e/ou anular os efeitos negativos dos fatores edáficos que podem limitar o desenvolvimento e a produção da seringueira.

A literatura ainda sobre a adubação da seringueira, mostra que muitas vezes a resposta dessa planta à aplicação de fertilizantes tem sido inconsistente, particularmente para alguns nutrientes como o nitrogênio e o potássio. Tal fato, leva a conclusão precipitada de que a adubação seria desnecessária para a seringueira, e portanto, não pode ser tomada como definitiva. Há entretanto, resultados experimentais que evidenciam o efeito benéfico da aplicação de fertilizantes, não somente na fase de desenvolvimento como também na fase produtiva. 
Pode-se afirmar que é necessário estudar, para as condições do Estado de São Paulo, as possíveis limitações de ordem nutricional, durante a fase de produção, pois nesta situação a seringueira tem duas fontes de dreno de nutrientes, uma para o crescimento e outra para a produção de borracha seca.

O objetivo do presente trabalho é o de avaliar a influência de diferentes doses de nitrogênio, fósforo e potássio na fertilidade do solo, no estado nutricional das plantas, no desenvolvimento, na produção de borracha seca, na exportação de nutrientes e na seca do painel da seringueira cultivada no Planalto Ocidental do Estado de São Paulo. 


\section{REVISÃO DE LITERATURA}

\subsection{Origem e distribuição geográfica}

\subsubsection{Origem}

A divulgação de produtos fabricados a partir da borracha antecedeu em muito a primeira descrição de uma espécie do gênero Hevea. Desde a chegada de Cristóvão Colombo à América, informações dão conta da utilização de objetos de borracha pelos nativos do Haiti. No México, relatos de colonizadores espanhóis sobre civilizações indígenas, por volta dos anos 1525 e 1529, registraram a utilidade da borracha como produto de uso nos costumes locais (Gonsalves et al.,1983). Em 1625, colonizadores espanhóis na América vestiam casaco de borracha para protegerem-se da chuva (Reis, 1953). Em 1749, F. Fresnau descreveu a primeira espécie do gênero Hevea, a qual foi posteriormente identificada, em 1775, por J. B. Fusèe Aublet como sendo a Hevea guianensis, (Bouychou, 1963).

Muitas descobertas foram relevantes para o conhecimento das múltiplas utilidades da borracha. Entre estas, mencionasse o apagador de riscos no papel de onde tem origem o nome inglês "RUBBER" (rub - esfregar). Joseph Prestley, químico inglês, usou a borracha com esse propósito em 1770 e em 1772 pequenos cubos de borracha foram comercializados com esta finalidade em Londres e Paris. Em 1761 com Grossart e em 1880 com Francisco Xavier de Oliveira, realizou-se estudos com a borracha do Pará, possibilitando a utilização deste produto na fabricação de objetos cirúrgicos (Gonsalves et al., 1983; RRII, 1980; Reis, 1953). 
Charles Macintosh, em 1823, baseando-se na sua técnica para impermeabilização de tecidos com o uso da borracha realizou uma proposição para a instalação da primeira fábrica de tecidos impermeáveis. Em 1839 foi descoberto o processo fundamental da vulcanização da borracha pelo uso do enxofre, através dos trabalhos realizados independentemente por Goodyear nos Estados Unidos e Hancock na Grã-Bretanha (Wisniewsky, 1979). Esta técnica possibilitou à borracha maior resistência quanto às variações de temperatura, sendo um grande impulso na fabricação de pneumáticos. A partir desta descoberta, ampliou-se o número de artigos e usos da borracha e à medida em que desenvolvia-se a indústria automobilística, era incrementada a demanda na produção de pneumáticos e câmaras de ar, (Gonsalves, et al., 1983).

Esta fase decorria simultaneamente aos tempos áureos das regiões extrativas da Amazônia, uma vez que a produção de borracha não acompanhava sua crescente demanda, elevando-se assim o preço do produto. Tal situação permaneceu sustentando riquezas até que as crescentes produções do sudeste asiático, a partir da segunda década deste século, provocassem uma tendência de declínio nos preços por aumento da oferta, tornando a produção extrativa menos competitiva com reflexos de natureza econômica e social para região Amazônica, (India, 1980).

\subsubsection{Distribuição geográfica}

No ecossistema da Região Amazônica nenhuma outra espécie possui melhor identidade com as suas fronteiras que as espécies do gênero Hevea. O mapa fitogeográfico da floresta hileana superpõe ao do gênero Hevea (Carvalho,1980). A distribuição do gênero nesta região abrange uma área em torno de 6 milhões de $\mathrm{km}^{2}$, onde a Hevea, sem dúvida, localiza seus extremos tendo como limites na América do Sul, aproximadamente $6^{\circ} \mathrm{N}, 15^{\circ} \mathrm{S}, 46^{\circ} \mathrm{L}$ e $77^{\circ}$ Oeste de Gr. W., também reconhecidos como limites extremos na Floresta Amazônica (Brasil,1971).

Nas condições do habitat original na Amazônia, as diversas espécies estão distribuídas harmonicamente com as suas necessidades ecológicas. Hevea pauciflora, $H$. 
guianensis, $H$. rigidifolia e $H$. brasiliensis ocorrem em terras preferencialmente úmidas nas regiões da mata pluvial de terra firme, precisamente ao longo das margens de pequenos riachos. A $H$. brasilienesis também pode ser encontrada em áreas relativamente altas das várzeas causadas pelas enchentes dos grandes rios e lagos.

As possibilidades de exploração econômicas da Hevea, notadamente com relação a espécie $H$. brasiliensis, motivou a sua dispersão pelo Brasil, de maneira que em 1908, durante a gestão do Dr. Miguel Calmon do Ministério da Agricultura, foi procedida a sua introdução na Bahia a partir de 200 mudas trazidas da Ilha de Java pelo Dr. Leo Zehntner, técnico suíço contratado na Escola de Batavia para dirigir a Escola Agrícola de São Bento das Lages, situado no Recôncavo Baiano. No ano seguinte, foram introduzidas aproximadamente 30.000 mudas, resultante de um embarque de 150.000 mudas do Ceilão. Este material foi distribuído no sul baiano, onde, 5 décadas após e por imperativo esforço do governo estadual, foi difundida a atividade heveícola, de maneira que logrou a este estado a maior área de seringal de cultivo do país na época (Bahia, 1959; Menezes, et al., 1975).

No Estado de São Paulo, com a colaboração do Marechal Cândido Rondon, em 1914, foi procedida a implantação da seringueira na Fazenda do Coronel José Procópio Ferraz no Município de Gavião Peixoto, próximo a Araraquara. Todavia, só em 1950 foram desenvolvidas maiores plantações da cultura que são hoje encontradas nas Regiões de Ribeirão Preto e São José do Rio Preto. No litoral paulista também são encontrados plantios nos municípios de Registro, Jacupiranga, Sete Barras e Ubatuba (Camargo, 1958; São Paulo, 1958).

No Amazonas, foram feitas tentativas de se implantar a cultura na década de 30 em Manaus, através da implantação de sementes de seringais nativos pelo Sr. José Cláudio de Mesquita, e na localidade de Aleixo pelo Sr. Cosme Ferreira Filho que implantou 100 ha de seringueiras a partir da enxertia do clone Fx 25 e alguns clones da série IAN. No Pará, apesar de pequenos plantios realizados em Belém, nas três primeiras décadas deste século, a experiência de um grande plantio só foi realizada por norteamericanos através da Companhia Ford, em Fordlândia, culminando com 0 
estabelecimento de 3.000 ha, interrompidos em 1933, com surgimento do Microcyclus ulei, patógeno causador do "mal-das-folhas". Seguiu-se a esta façanha, os plantios de Belterra que posteriormente sofreriam as mesmas conseqüências. Anos após, iniciaram-se os primeiros trabalhos de melhoramento da seringueira nesta região. No Mato Grosso, cerca de 3.000 ha de seringueiras foram estabelecidos na década de 50 nas regiões de Porto dos Gaúchos, Diamantino e Rio Ferro, (Gonçalves, et al.,1983).

Com o estímulo a produção de borracha natural, outros Estados brasileiros têm sido contemplados com o estabelecimento da Heveicultura, a exemplo de Minas Gerais, Pernambuco, Maranhão, Goiás, além do Espírito Santo onde existem áreas com boa produtividade.

$\mathrm{Na}$ América do Sul, outros países apresentam-se como produtores de borracha natural, sobretudo Bolívia, Peru, Trinidad e Tobago, Colômbia, Equador, Venezuela, Guiana e Suriname (Cortez e Black,1954). Na América do Norte, o México destaca-se como produtor. Na África, são produtores o Zaire, Costa do Marfim, Nigéria, Libéria, Camarões e Gana (Bouychou, 1951).

Mas, o mais extraordinário caminho percorrido pela seringueira refere-se a sua ida para o sudeste asiático, tendo início em 1870, quando Sir Henry A. Wickmam embarcou 70.000 sementes de Hevea brasiliensis selecionadas nas proximidades de Boim, uma pequena ilha do rio Tapajós. Estas sementes foram conduzidas pelo cargueiro Amazonas com destino a Liverpool e posteriormente ao Kews Garden, onde se pôde obter 2.397 seedlings que após selecionados deram origem a 1.191 mudas (Wisniewsky, 1979). A quase totalidade destas mudas foram transportadas para Sri Lanka, algumas para Malásia e somente 2 delas para o Culturtuin Butenzorg situado a oeste de Java. Há referências de que toda a borracha produzida na Malásia teve como fonte de germoplasma, 27 sementes da coleção de Wickham que foram levadas para Singapura em 1826. Outras introduções tardias também são mencionadas (Dÿckman, 1951).

A princípio a atividade heveícola não foi dinamizada em razão da prosperidade do café e do chá e das informações contraditórias com respeito aos 
requerimentos ecológicos da seringueira. A partir do início do século, essa situação foi invertida tendo vista a queda dos preços do chá e a ocorrência de Hemileia vastatrix nos cafezais. Sob o impacto de constantes aumentos nos preços da borracha houve um grande impulso no cultivo da seringueira de maneira que em 1913 o sudeste asiático, com 54.000 toneladas de borracha já superava a produção da área extrativa do Brasil (39.750 t), que já experimentava decréscimos anuais (São Paulo, 1958).

Outros países asiáticos também são detentores de grandes áreas plantadas e entre estes, o Vietnam, Cambodja, Tailândia e Índia. Na Indonésia, apesar de uma rápida introdução ocorrida em 1876, a partir de seedlings oriundos de Kew, admite-se terem havido outras introduções a partir do Ceilão e da Malásia.

Na China, a seringueira foi introduzida em 1904, nas llhas Taiwan e Hainam e província de Yunam, por chineses que residiam fora do país. Por longo período, a heveicultura permaneceu inexplorada, até que a partir de clones oriundos do Camboja e Sri Lanka e, posteriormente, a partir de clones desenvolvidos no País com características voltadas à resistência ao vento e ao frio (Barros e Castro, 1983).

Atualmente cerca de $90 \%$ da borracha produzida no mundo é oriunda do sudeste asiático/a partir de clones produtivos que tiveram como germoplasma básico, seedlings introduzidos pela expedição de Wickham.

\subsection{Aspectos do desenvolvimento da seringueira}

Nos três primeiros anos de crescimento a seringueira apresenta sucessivos fluxos de lançamentos, experimentando o caule rápidas e periódicas alongações, alternandas com períodos de latência. Esta seqüência tem relação com um período de atividade cambial, seguido por período de inatividade, havendo estreita correlação com a intensidade de freqüência e número de anéis de vasos lacíferos no caule (Moraes, 1977). E um periodo de intenso crescimento vegetativo com grande demanda de nutrientes para formação de tecidos no caule, galhos, folhas e raizes (Haag, 1973). 
Aproximadamente, a partir do terceiro ano de idade a seringueira modifica seu ritmo, deixando de produzir fluxos sucessivos de lançamentos, e passando a ter periodicidade anual, caracterizada pela senescência e queda de folhas, seguida de novo fluxo após um período 2 a 6 semanas, em que a planta fica desfolhada. Este comportamento é típico de $H$. brasilensis, $H$. benthamiana e $H$. microphylla, cujo grau de uniformidade varia com as condições ambientais e com a variação individual ou clonal. A descrição do periodo em que as plantas permanecem sem folhas depende de sua constituição genética, da intensidade e duração do déficit hídrico e das condições nutricionais. A inflorescência, tem início após a queda de folhas, antes ou posteriormente ao seu pleno desenvolvimento inicial. (Ortolani et al., 1983).

\subsection{Explotação da seringueira}

\subsubsection{Padrão de entrada de sangria}

Virgens Filho et al. (1990) consideram válida a estratégia adotada no Brasil de iniciar a exploração do seringal quando $50 \%$ das plantas apresentam perímetro mínimo de 45 centímetros à altura de 150 a 130 centímetros, respectivamente, a partir do solo ou da união enxerto x porta enxerto. Já Rodrigues \& Tinoco (1984) recomendam uma avaliação econômica ou seja considerar o preço da borracha e o custo da mão-de-obra da sangria, para decisão do início de exploração e consideram que o limite mínimo, na época do estudo, era de 125 árvores aptas $(45 \mathrm{~cm})$ por tarefa de sangria para dar início a explotação do seringal. Ressaltam porém que sendo a seringueira uma planta perene, a resposta da produção não pode ser vista em função da produção esperada para um único ano de sangria, mas da produção esperada ao longo da vida útil da planta.

O perímetro de tronco mínimo de 45 centímetros parece ser limite aceitável em termos de comprometimento da produtividade futura das plantas. Por outro lado em clones com produção inicial alta, o incremento em perímetro do tronco de árvores é muito reduzido em comparação com árvores não sangradas, de mesma idade. Como a copa continua crescendo, ocorre uma disparidade entre o desenvolvimento da copa e do 
tronco, ficando assim a árvore em sangria mais susceptível a quebra por vento (Bernardes et al, 1996). Caso deste tipo foi relatado por Rubber Research Institute of Malaysia (1959) onde o cultivar RRIM 501, quando colocado experimentalmente, em sangria com perímetro do tronco de aproximadamente $63,5 \mathrm{~cm}$ apresentou resistência a quebra provocada por vento e posteriormente posto em sangria comercialmente com perímetro do tronco de 50 centímetros mostrou-se altamente susceptível à quebra.

\subsubsection{Sistema de explotação}

Tradicionalmente o sistema utilizado no Brasil é a sangria em meia espiral, realizada em dias alternados, exceto aos domingos ( $S / 2, d / 2,6 d / 7)$ com intensidade relativa de $85,7 \%$. Ultimamente, em função do alto custo da mão de obra, se tem optado por sistemas de menor freqüência, como o $d / 4$ ou $d / 7$, significando, sangria a cada 4 ou a cada 7 dias, repectivamente. Na Malásia o sistema $\mathrm{S} / 2, \mathrm{~d} / 2$ é largamente usado, mas são praticadas outras alternativas de explotação, sendo o mesmo registrado no Sri - Lanka.

$\mathrm{Na}$ Costa do Marfim os sistemas de sangria mais utilizados são os de corte em meia espiral (S/2) a cada 3,4 ou 7 dias, iniciando a sangria nas plantas $c 0 \mathrm{~m} 50 \mathrm{~cm}$ ou mais de perímetro de tronco. A definição de um sistema de explotação é efetuada com a escolha de um sistema de sangria e de estimulação (aplicação de ethephon sobre o corte de sangria para aumentar o fluxo de látex). O sistema de sangria é a combinação da forma, do tamanho e do número de incisões e da freqüência da sangria. $\mathrm{O}$ objetivo é a rentabilidade máxima, durante todo o período de explotação do seringal. É necessário obter a cada ano a produção ótima que permita manter o equilibrio fisiológico entre a produção de borracha e a capacidade de crescimento e regeneração de uma árvore Existem também diferentes fatores sócio econômicos que podem influenciar na escolha de um sistema de explotação: os preços da borracha, o custo, disponibilidade e qualificação de mão de obra, tipo de plantação, entre outros Montano, $(1984)^{1}$, citado por Bernardes et al.; (1990). 


\subsection{Efeito da adubação sobre o desenvolvimento}

A análise do crescimento e do conteúdo total de nutrientes de uma planta em seus diversos estádios de crescimento é um procedimento básico para a resolução de problemas nutricionais. A análise química do solo tem sido a técnica mais usada para diagnosticar a fertilidade dos solos e determinar as necessidades de adubação. Por outro lado, a análise foliar, como técnica de diagnose permite, também, identificar deficiências nutricionais, considerando-se os teores de nutrientes nas folhas. Assim, as análises do solo e foliar, têm sido usadas pelo Rubber Research Institute of Malaya, (RRIM), desde 1963, para determinar o estado nutricional e diagnosticar nutrientes requeridos pela seringueira (Pushparajah \& Cunha, 1968)

Haag \& Dechen (1982) estudando a marcha de absorção de plantas de seringueiras de 1 a 4 anos de idade, observaram que o incremento de matéria seca do primeiro para o segundo ano foi muito pequeno, enquanto que, a partir do terceiro ano, o crescimento foi estimulado, com o incremento de matéria seca quase triplicando em relação ao ano anterior, o mesmo acontecendo do quarto ano em relação ao terceiro. É nessa fase de crescimento intenso que a seringueira necessita de quantidades suficientes de nutrientes para que crescimento não seja prejudicado.

Resultados sobre o crescimento da seringueira jovem na Malásia, após cinco anos de ensaio com fertilizantes em um Latossolo Amarelo, com cobertura do solo com leguminosa, mostraram que incrementos de circunferência foram obtidos pela aplicação de nitrogênio e fósforo, somente até quatro anos após o plantio. Para o potássio, não foi observada resposta durante o período de imaturidade da planta, isto é, até cinco anos após o plantio. Resultado semelhante foi observado também na Índia, quando quatro diferentes clones foram submetidos a diferentes níveis de fertilizantes (Kalam, 1970; Pannoje \& Potty, 1975; Syvanadian, 1975)

Na Malásia, até aproximadamente 1960, as recomendações de fertilizantes para a seringueira foram baseadas principalmente nas diferenças de textura dos solos. Uma mistura completa de nitrogênio, fósforo, potássio e magnésio, com quantidade alta 
de potássio era recomendada para solos de textura arenosa, enquanto que a mesma mistura, porém com quantidade relativamente baixa de potássio, era recomendada para solos de textura argilosa (Pushparajah, 1977). Contudo, outros resultados, em solos diferentes, mostraram que uma recomendação geral de fertilizantes nem sempre proporcionava crescimento e produção de borracha adequados, principalmente em razão de desequilibrio entre nutrientes aplicados (Bolton, 1964; Cunha \& Yeow, 1966; Wong, 1977).

Tendo em vista a formulação geral dos programas de adubação, os solos da Malásia foram agrupados em três classes principais: solos costeiros aluviais argilosos, onde o cultivo da seringueira responde principalmente às aplicações de fertilizantes principalmente nitrogenados; solos continentais barrentos e argilo-barrentos onde os seringais respondem às aplicações de fertilizantes nitrogenados e fosfatados, e por fim os solos continentais arenosos onde o cultivo da seringueira responde às aplicações de fertilizantes nitrogenados, fosfatados e principalmente potássicos (Shorrocks, 1979).

Trabalhos realizados na Malásia tem demonstrado que uma adubação apropriada pode antecipar a exploração do látex devido ao maior diâmetro de tronco em relação a idade da planta. Também, demonstraram a interação positiva de $\mathrm{N} x \mathrm{~K}$ sobre o crescimento do diâmetro do tronco e a produção.

$O$ interesse pela adubação da seringueira no Brasil era pequeno até algum tempo em razão da exploração do látex se limitar às populações naturais ou plantios em áreas recém-desbravadas, onde normalmente, a disponibilidade de nutrientes minerais no solo é relativamente elevado, em virtude da matéria orgânica remanescente (Barros \& Alves, 1985). Em geral os seringais no Brasil encontram-se implantados em Oxissois que são pobres e ácidos. Apesar da seringueira ser adaptada a solos de baixa fertilidade, responde bem a aplicação de fertilizantes e extrai quantidades elevadas de nutrientes (Miranda et al., 1975). Provavelmente esta espécie consegue suprir as suas exigências nutricionais nesses solos, em virtude de possuir um sistema radicular muito desenvolvido.

O solo mais indicado para o plantio da seringueira é aquele que apresenta boa fertilidade, $\mathrm{pH}$, situando-se na faixa de 5.5 e 6.5 , e algumas propriedades físicas de 
importância, tais como: porosidade, capilaridade e poder de retenção de água (Cardoso, 1980)

Bataglia \& Cardoso (1990) em um estudo da situação nutricional e desenvolvimento dos seringais do Estado de São Paulo com média de 11 anos de idade, verificaram que quando os mesmos eram cultivados em solos de maior fertilidade, como Latossolo Roxo do Planalto Paulista, se desenvolveram mais, com 95\% das plantas estavam aptas para entrar em sangria, em comparação aos solos do Litoral, como PodzólicoVermelho Amarelo-orto e Latossolo Vermelho amarelo- fase rasa, com somente $40 \%$ das plantas áptas a sangria.

O cultivo da seringueira tem se intensificado com grande expressão no Sul da Bahia. Santana et al. (1978) avaliando o nível de fertilidade desses solos, observaram que os mesmos são pobres em nutrientes e apresentam elevada acidez. A seringueira tem sido uma espécie tolerante a acidez do solo e o uso de calcário ou outra fonte de $\mathrm{Ca}$ e $\mathrm{Mg}$, serviria apenas para supri-las desses elementos, quando seus teores são muito baixos no solo.

Syvanadyan et al. (1975) observou que a necessidade de K para a seringueira pode variar de acordo com o seu estádio de desenvolvimento. A carência desse elemento durante a fase de crescimento pode limitar a área foliar e reduzir a atividade fotossintética das folhas, resultando em incremento muito mais lento do diâmetro do caule e consequentemente demorando mais tempo para atingir o tamanho ideal para sangria.

No Pará, Berniz (1987), constatou-se que aplicação de fósforo e potássio não incrementou a espessura da casca e circunferência do tronco. Por outro lado Reis \& Cabala- Rosand (1988) avaliando a eficiência dos fertilizantes aplicados nas fases pré e pós sangria da seringueira, observaram que o fósforo foi o nutriente que provocou maiores respostas no desenvolvimento da circunferência do tronco e na produção de borracha. No Mato Grosso do Sul, Kitamura (1992), observou que a adubação fosfatada proporcionou incrementos significativos da circunferência do tronco da seringueira. 
Viegas (1985) trabalhando com seringueira na fase de viveiro em casa de vegetação e em solução nutritiva, analisaram a concentração de nutrientes nas folhas, caule e raiz. Os teores médios de macro e micronutrientes estão apresentados na Tabela 1.

Tabela 1. Concentração média de nutrientes nas folhas, no caule e na raiz de plântulas de seringueira.

\begin{tabular}{lcccccccccc}
\hline Órgãos & $\mathrm{N}$ & $\mathrm{P}$ & $\mathrm{K}$ & $\mathrm{Ca}$ & $\mathrm{Mg}$ & $\mathrm{S}$ & $\mathrm{B}$ & $\mathrm{Fe}$ & $\mathrm{Mn}$ & $\mathrm{Zn}$ \\
& - & & & & & & \\
Folha & 33.4 & 5.7 & 15.0 & 7.1 & 3.1 & 2.5 & 81 & 81 & 577 & 30 \\
Caule & 21.0 & 6.2 & 11.4 & 4.0 & 3.3 & 2.4 & 18 & 18 & 54 & 26 \\
Raiz & 26.0 & 10.3 & 19.2 & 2.5 & 4.0 & 2.6 & 23 & 23 & 1045 & 39 \\
\hline
\end{tabular}

Através destes dados observa-se que os teores de nutrientes encontrados em outros órgãos que não as folhas apresentam-se consideravelmente altos, mostrando que a seringueira necessita de quantidades consideráveis de nutrientes para o seu desenvolvimento.

Através de trabalho de seleção de método e delimitação de faixas de disponibilidade, para as condições de solos do sul da Bahia, ficou comprovado que $5 \mathrm{mg} / \mathrm{kg}$ de $\mathrm{P}$ no solo, extraído pelo extrator de Mehlich, representa um valor acima do qual diminuem as probabilidades de resposta à adição desse elemento(Cabala-Rosand \& Maia,1973). No sul da Bahia o cultivo vem sendo implantado predominantemente em solos de baixa fertilidade, com teores de fósforo inferiores a $5 \mathrm{mg} / \mathrm{kg}$. Nestes solos têm sido verificadas a resposta à adição desse elemento tanto em viveiro (Cabala-Rosand \& Maia, 1973) como nas diferentes fases de desenvolvimento da plantação (Santana, et al.,1978; Reis, 1979). Os efeitos adição de nitrogênio, na fase de desenvolvimento, têm sido significativos, enquanto que o potássio tem ocasionado reduções no desenvolvimento, até mesmo em solos com teores baixos ou médios deste elemento. 


\subsection{Efeito da adubação sobre a produção}

Bataglia \& Cardoso (1990) comparando seringais com diferentes níveis de produtividade, verificou através da análise foliar que os nutrientes $\mathrm{N}$ e $\mathrm{K}$, foram os que mais estiveram relacionados com as maiores produtividade.

Reis et al. (1984a )verificaram a influência da calagem e da adubação N, P e $\mathrm{K}$ sobre a produção da seringueira no sul da Bahia. Observaram que, embora os tratamentos com a adubação e calagem e a combinação de ambos não tenham apresentado efeitos estastisticamente significativos na produtividade, os níveis de produtividade alcançados foram bastantes elevados em relação a produção média anual da região, evidenciando a importância da adubação entre as práticas agronômicas recomendadas para esta cultura. Reis \& Cabala-Rosand (1988) em um estudo da influência do fósforo na produção de borracha e recuperação da casca em seringal no sul da Bahia, verificou que não houve aumento na produtividade de borracha devido a adubação fosfatada, mas houve efeito da adubação fosfatada na renovação da casca. Atenção especial deve ser dada aos seringais que estão em produção pois possuem duas fontes de drenagem dos nutrientes, uma para suprir o desenvolvimento da planta e a outra destina-se a produção de látex. Pushparajah (1977) mostra que uma adubação inadequada faz com que haja um desequilíbrio nutricional das árvores, quando estas são muito explotadas.

\subsection{Composição bioquímica do látex da seringueira}

Pakianathan (1980) através de revisões bibliográficas concluiu que o látex consistia em três fases distintas obtidas por centrifugação. Considerou a primeira camada constituida de partículas de borracha predominantemente esféricas e com diâmetro de 5-6 micras. Seguia-se um soro claro ao qual denominaram Soro-C (centrifugado). 
Finalmente, substâncias que se organizavam no fundo e eram constituídas de partículas não borracha.

Outros trabalhos resultaram em novas contribuições, de maneira que a constituição do látex, citada por Virgens Filho (1986), é assim caracterizada:

a) Partículas de Borracha envoltas por dupla membrana lipoprotéica com espessura em torno de 10 nanomicra, predominantemente esféricas nos laticíferos mais novos e piriformes nos mais velhos, diâmetro podendo variar de 5-6 micras . Ocupam de 24 a $45 \%$ do volume do látex e após centrifugação deslocam-se para a fração superior por serem mais leves

b) Partículas maiores, envolvidas por membrana lipoprotéica, diâmetro 5-6 micros sendo denominadas de Frey Wyssling (FW). Em sua constituição apresentam carotenóides, lipídeos, resinas e polifenoxidases (enzimas). A presença de carotenóides em maior conteúdo confere ao látex uma característica cor amarela ou laranja. Alto teor de resina também é responsável por características tecnológicas não recomendadas tais como: alto adesividade, plasticidade e maior viscosidade. Estas partículas encontram-se em torno de 1 a $3 \%$ do volume total do látex.

c) Um soro aquoso (soro C) no interior do qual estão substâncias hidrosolúveis como açúcares, ácidos orgânicos, sais minerais, aminoácidos, peptídeos, proteínas e material nucleotídico. $\mathrm{O}$ pH nesta fração está em torno de 6,9 .

d) Uma camada de aspecto gelatinoso de coloração pardo avermelhada constituindo a fração de fundo, onde encontram-se os lutóides . Estes, são partículas esféricas que estão em maior abundância no látex após as partículas de borracha, com 2 a 10 micros de diâmetro e envoltos por uma membrana simples de 8 a 10 nanomicra. $\mathrm{O}$ soro possui $\mathrm{pH}$ em torno de 5,5. A face interna da membrana dos lutóides tem carga positiva enquanto a externa tem carga negativa. Na constituição do soro dos lutóides existem cátions bivalentes, principalmente cálcio e magnésio, além de 60 a $80 \%$ das peroxidases do látex e fosfatases ácidas. Os lutóides podem ocupar um volume de até 9 a $20 \%$ do látex. 


\subsection{Exportação de nutrientes}

Em geral, plantas que apresentam maior capacidade fotossintética apresentam maior consumo de nutrientes para o seu crescimento e produção. $O$ consumo de nutrientes destinados à formação dos diferentes órgãos da seringueira é muito elevada quando comparado com a quantidade de nutrientes exportados pelo látex.

Pushparajah (1977) avaliando a necessidade de nutrientes da seringueira quando submetida a diferentes tipos de estimulantes de produção de látex e quantidades diferentes de fertilizantes NPK e Mg, observou que a quantidade de nutrientes exportados foi maior quando se aplicou o Ethephon a $10 \%$. As quantidades de $\mathrm{N}, \mathrm{P}, \mathrm{K}$ e Mg exportados foram 14, 5, 14 e $2 \mathrm{~kg} /$ ha/ano a mais, em relação às da testemunha, mostrando que a estimulação pode levar a uma depressão do estado nutricional das plantas. As plantas estimuladas com ethephon a 10\% apresentaram um acréscimo de produção da ordem de $1150 \mathrm{~kg}$ de borracha seca /ha/ano comparada com as plantas não estimuladas. $O$ autor mostrou que a adubação inadequada faz com que haja "empobrecimento" das árvores e verificou que, mesmo considerando as reservas de nutrientes do solo ocorria um déficit de até $80 \mathrm{~kg}$ de $\mathrm{N}, 10,2 \mathrm{~kg}$ de $\mathrm{P}$ e $71 \mathrm{~kg}$ de $\mathrm{K}$, no caso das árvores estimuladas. Isto acontecia porque o solo, mesmo recebendo adubação não satisfazia a exigência nutricional da seringueira. Nas seringueiras não sangradas existe aparentemente um equilibrio entre os nutrientes, o crescimento e a formação do látex. Este equilíbrio é afetado quando as árvores são sangradas para a retirada do látex. Este desbalanço é indicado primeiramente pela alteração da composição do látex extraído e finalmente por um retardamento no crescimento da árvore em peso de matéria seca $\mathrm{e}$ diâmetro do caule.

De acordo com Miranda et al. (1975), para cada tonelada de borracha seca produzida, são exportados aproximadamente $7,5 \mathrm{~kg}$ de $\mathrm{N} ; 3,0 \mathrm{~kg}$ de $\mathrm{P}$ e $6,0 \mathrm{~kg}$ de $\mathrm{K}$. Seringueiras com idade média de 17 anos apresentam consumo médio anual de $293 \mathrm{~g}$ de $\mathrm{N} ; 29 \mathrm{~g}$ de $\mathrm{P} ; 125 \mathrm{~g}$ de $\mathrm{K} ; 46 \mathrm{~g}$ de $\mathrm{Mg} ; 178 \mathrm{~g}$ de $\mathrm{Ca}$ e $36 \mathrm{~g}$ de $\mathrm{S}$. Esses dados mostram que os elementos $\mathrm{P}$ e $\mathrm{S}$ são os requeridos em menores quantidades. 
Haag et al. (1987) analisando amostras de borracha seca provenientes de um experimento com diferentes sistemas de sangria da seringueira nas condições do Planalto Paulista, verificaram que houve uma acentuada variação na concentração dos macro e micronutrientes na borracha seca em função dos diversos tratamentos e da época de coleta do material. Observaram ainda baixa concentração de $\mathrm{Ca}$ e de $\mathrm{K}$ em todos os tratamentos. A concentração de N e S foram altas. Para os micronutrientes, observou que o teor de Fe é o mais elevado seguido do $\mathrm{Zn}$. A concentração de $\mathrm{Cu}$ é baixa chegando em alguns tratamentos a se apresentar apenas traços. Admitindo-se a produção média de uma tonelada de borracha seca, a extração dos nutrientes seria da seguinte ordem de grandeza: N-6,1 kg; P-0,53kg; K-0,18kg; Ca-0,03kg; Mg-0,73kg; S-1,42kg; B-5,15kg; Cu-1,05kg; Fe-39,20kg; Mn-0,99kg; Zn-20,36kg

A drenagem de nutrientes, através da produção de látex, varia conforme os clones, sistema de exploração e solos. Se não houver uma adubação extra por ocasião da sangria efeitos adversos ocorrerão no crescimento da árvore com conseqüênte baixa produção de borracha seca ( Syvanadyan, 1979).

Para uma produtividade de $2600 \mathrm{~kg}$ de borracha seca/ha/ano em plantio com sangria estimulada, com Ethephon a $10 \%$, as quantidades anualmente removidas com a exportação do látex foram de $23,9 \mathrm{~kg} \mathrm{ha}^{-1}$ de $\mathrm{N}, 7,2 \mathrm{~kg} \mathrm{ha}^{-1}$ de $\mathrm{P}, 22,3 \mathrm{~kg} \mathrm{ha}^{-1}$ de $\mathrm{K}$ e 4,1 $\mathrm{kg} \mathrm{ha}{ }^{-1}$ de $\mathrm{Mg}$, enquanto que tratamentos não estimulados, nos quais obteve-se produtividade de $1390 \mathrm{~kg}$ de borracha seca/ha/ano, as quantidades de nutrientes removidos no látex foram de $9,4 \mathrm{~kg} / \mathrm{ha}$ de $\mathrm{N}, 2,3 \mathrm{Kg} / \mathrm{ha}$ de $\mathrm{P}, 8,3 \mathrm{~kg} / \mathrm{ha}$ de $\mathrm{K} \mathrm{e} 1,7 \mathrm{~kg} / \mathrm{ha}$ de Mg (RRIM, 1972).

\subsection{Seca do painel}

O seca do painel, é uma anomalia causada por distúrbios nas árvores em exploração, podendo ainda estar associada a outros agentes causadores, como intensidade de sangria, déficit hídrico, situação nutricional, e principalmente a adubação potássica (Souza, 1986). A seca do painel não induz a árvore a morte, mas a perda da 
produção constitui sério problema para produtores de látex. Não há ainda uma causa definitiva para o aparecimento da seca. Existe um conjunto de pontos de vista sobre a maneira possível pelo qual o distúrbio pode ser iniciado (Boaventura et al., 1989). Parajonthy et al. $(1975)^{2}$, sugeriram que a maior incidência da seca do painel durante ou após o periodo de hibernação poderia indicar que o estresse nutricional é um fator de desenvolvimento do secamento. Observaram também que uma possível causa do secamento, seja uma conseqüência de repetidas e intensas remoções de látex conduzindo a um estresse nutricional, ao nível de casca explorada.

A estimulação da produção com o correspondente aumento na drenagem de nutrientes inibe a proliferação de raízes, retarda a renovação de casca, reduz o índice de área foliar e conseqüente crescimento da planta. Com a adição de fertilizantes, minimizam-se os efeitos adversos do estimulante (Dolmat, 1980). Um dos métodos de convivência com a seca do painel em plantas com alta incidência, segundo Virgens Filho (1986),é deixar as plantas em repouso por um período de seis meses, testando-se a seguir novo corte $15 \mathrm{~cm}$ abaixo da região afetada.

De acordo com Bernardes et al.(1990), a incidência de secamento torna-se maior com o incremento da intensidade de sangria sendo que a frequência de sangria tem maior influência do que o comprimento do corte na indução ao secamento. A combinação da intensificação da freqüência de sangria e do aumento do comprimento do corte resulta em incidência severa de secamento e queda na produção.

\footnotetext{
${ }^{2}$ Parajonthy, K.; Gomes, J.B. \& Yeang, H.Y. Physiological aspects of brow bast development. Proc. Rubber Research Institute of Malaysia Planter's conference. Kuala Lumpur, p 1-22,1975.
} 


\section{MATERIAL E MÉTODOS}

\subsection{Localização da área}

O estudo foi conduzido em um seringal com 11 anos de idade, na fazenda Mundo Novo, localizada no município de Garça (latitude de $22^{\circ} 24^{\prime} \mathrm{S}$, longitude de $49^{\circ}$ $40^{\prime} \mathrm{W}$ e altitude de $663 \mathrm{~m}$ ), no sudoeste do Estado de São Paulo, Planalto Ocidental Paulista. Nesta região se encontra uma alta concentração de seringais em fase de desenvolvimento ou produção.

\subsection{Solo}

O solo da área experimental é um Latossolo Vermelho Escuro a moderado álico textura arenosa.

\subsection{Clima}

De acordo com a classificação internacional de Köppen, a área do experimento encontra-se em tipos climáticos Aw (Clima tropical úmido com estação chuvosa no verão e seca no inverno. $O$ índice pluviométrico deste tipo climático varia entre 1100 e $1300 \mathrm{~mm}$ ) e Cwa (Clima mesotérmico de inverno seco em que a temperatura média do mês mais frio é inferior a $18^{\circ} \mathrm{C}$ e a do mês mais quente ultrapassa 
$22^{\circ} \mathrm{C}$, o total das chuvas do mês mais seco não ultrapassa $30 \mathrm{~mm}$ e o índice pluviométrico deste tipo climático varia entre 1100 e $1700 \mathrm{~mm}$ ). A estação seca nesta região ocorre entre os meses de abril e setembro, sendo julho o mês em que atinge a máxima intensidade. $\mathrm{O}$ mês mais chuvoso oscila entre janeiro e fevereiro. A temperatura do mês mais quente oscila entre 22 e $24^{\circ} \mathrm{C}$ (BRASIL, 1960).

\section{4. Área e delineamento experimental}

A área total do experimento consta de $30720 \mathrm{~m}^{2}$, subdividida em 4 blocos, sendo cada bloco constituído de 16 parcelas experimentais de $480 \mathrm{~m}^{2}$. O espaçamento adotado foi $11 \times 5 \times 3$, totalizando 20 plantas dispostas em duas linhas com 10 plantas. As avaliações foram efetuadas nas 6 plantas centrais de cada parcela. $O$ experimento foi instalado em blocos ao acaso, em esquema fatorial fracionário $(1 / 4) 4^{3}$, totalizando 16 tratamentos e 4 repetições (Box et al., 1973; Gomes, 1978).

\subsection{Tratamentos}

Os tratamentos foram constituídos pela combinação dos quatro niveis de $\mathrm{N}$, $\mathrm{P}_{2} \mathrm{O}_{5}$ e $\mathrm{K}_{2} \mathrm{O}$. As fontes utilizadas foram: uréia $(45 \%$ de $\mathrm{N})$, superfosfato simples ( $18 \%$ de $\left.\mathrm{P}_{2} \mathrm{O}_{5}\right)$ e cloreto de potássio $\left(60 \%\right.$ de $\left.\mathrm{K}_{2} \mathrm{O}\right)$. Os tratamentos de adubação foram: $\mathrm{N}_{0} \mathrm{P}_{0} \mathrm{~K}_{0}, \mathrm{~N}_{1} \mathrm{P}_{1} \mathrm{~K}_{0}, \mathrm{~N}_{1} \mathrm{P}_{0} \mathrm{~K}_{1}, \mathrm{~N}_{0} \mathrm{P}_{1} \mathrm{~K}_{1}, \mathrm{~N}_{1} \mathrm{P}_{1} \mathrm{~K}_{1}, \quad \mathrm{~N}_{2} \mathrm{P}_{1} \mathrm{~K}_{1}, \mathrm{~N}_{3} \mathrm{P}_{1} \mathrm{~K}_{1}, \mathrm{~N}_{1} \mathrm{P}_{2} \mathrm{~K}_{1}, \mathrm{~N}_{1} \mathrm{P}_{3} \mathrm{~K}_{1}, \mathrm{~N}_{1} \mathrm{P}_{1} \mathrm{~K}_{2}$, $\mathrm{N}_{1} \mathrm{P}_{1} \mathrm{~K}_{3}, \mathrm{~N}_{2} \mathrm{P}_{1} \mathrm{~K}_{2}, \mathrm{~N}_{3} \mathrm{P}_{1} \mathrm{~K}_{2}, \mathrm{~N}_{2} \mathrm{P}_{1} \mathrm{~K}_{3}, \mathrm{~N}_{2} \mathrm{P}_{2} \mathrm{~K}_{2}, \mathrm{~N}_{3} \mathrm{P}_{3} \mathrm{~K}_{3}$.

As doses de $\mathrm{N}, \mathrm{P}_{2} \mathrm{O}_{5}$ e $\mathrm{K}_{2} \mathrm{O}$ foram constantes do quarto ao sexto ano agrícola. No sétimo ano agrícola as doses de $\mathrm{N}$ foram acrescidas em $50 \%$ e as doses de $\mathrm{K}_{2} \mathrm{O}$ sofreram um acréscimo de $15 \%$. No oitavo, ano agrícola as doses de $\mathrm{N}$ sofreram um acréscimo de $90 \%$, as de $\mathrm{P}_{2} \mathrm{O}_{5}$ continuaram constantes e as de $\mathrm{K}_{2} \mathrm{O}$ foram aumentadas em $43 \%$. A partir do nono ano agrícola as doses de $\mathrm{N}, \mathrm{P}_{2} \mathrm{O}_{5}$ e $\mathrm{K}_{2} \mathrm{O}$ foram elevadas em $100 \%, 14 \%$ e $130 \%$, respectivamente. Todos esses acréscimos foram feitos 
baseados nas doses utilizadas no primeiro ano. A tabela 2 apresenta o cronograma de adubação dos últimos 10 anos. O estabelecimento dessas doses foi baseado nas recomendações do boletim 100 do IAC (Raij et al., 1985).

O superfosfato simples foi aplicado na sua totalidade por ocasião da primeira aplicação da uréia e do cloreto de potássio no início do período chuvoso (novembro), de cada ano agrícola. A segunda dose da uréia e do cloreto de potássio foi aplicada normalmente no mês de janeiro. Variações na época de aplicação dos fertilizantes ocorreram em função das condições climáticas. Entretanto, tais variações não comprometeram o cronograma de atividade do projeto.

Procedeu-se calagens em julho de 1989, agosto de 1991 e em março de 1993, nas dosagens de 1,0 t/ha; $2,5 \mathrm{t} / \mathrm{ha}$ e de $1,5 \mathrm{t} / \mathrm{ha}$, respectivamente, de calcário dolomítico em toda a área experimental, o calcário tinha as seguintes características fisicas e químicas: $30,24 \%$ de $\mathrm{CaO}, 18,55 \%$ de $\mathrm{MgO}, \mathrm{PN}\left(\% \mathrm{ECaCO}_{3}\right)=100, \mathrm{RE}=89 \%$, PRNT $=89 \%$. 


\subsection{Instalação e Condução do Experimento}

O plantio foi efetuado em janeiro de 1984 e até meados de 1985 procedeu-se o replantio. O experimento foi instalado no ano agrícola $1987 / 1988$, época em que o seringal apresentava cerca de 3 a 4 anos de idade.

Tabela 2. Quantidades de nitrogênio, fósforo e potássio aplicados no período $1987 / 1997$

\begin{tabular}{|c|c|c|c|c|c|c|c|c|c|c|c|c|}
\hline \multirow[t]{2}{*}{ Ano agrícola } & \multicolumn{4}{|c|}{$\mathrm{N}$} & \multicolumn{4}{|c|}{$\mathrm{P}_{2} \mathrm{O}_{5}$} & \multicolumn{4}{|c|}{$\mathrm{K}_{2} \mathrm{O}$} \\
\hline & $\mathrm{N}_{0}$ & $N_{1}$ & $\mathrm{~N}_{2}$ & $\mathrm{~N}_{3}$ & $\mathrm{P}_{0}$ & $P_{1}$ & $P_{2}$ & $\mathrm{P}_{3}$ & $\mathrm{~K}_{0}$ & $\mathrm{~K}_{1}$ & $\mathrm{~K}_{2}$ & $\mathrm{~K}_{3}$ \\
\hline & & 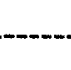 & $\cdots$ & 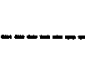 & 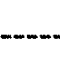 & $\cdots$ & $h a^{-1}-$ & & & & $\cdots$ & \\
\hline $87 / 88(4)^{*}$ & 0 & 40 & 80 & 160 & 0 & 35 & 70 & 140 & 0 & 35 & 70 & 140 \\
\hline $88 / 89(5)$ & 0 & 40 & 80 & 160 & 0 & 35 & 70 & 140 & 0 & 35 & 70 & 140 \\
\hline $89 / 90(6)$ & 0 & 60 & 120 & 240 & 0 & 35 & 70 & 140 & 0 & 35 & 70 & 140 \\
\hline $90 / 91(7)$ & 0 & 75 & 150 & 300 & 0 & 35 & 70 & 140 & 0 & 40 & 80 & 160 \\
\hline $91 / 92(8)$ & 0 & 80 & 160 & 320 & 0 & 35 & 70 & 140 & 0 & 50 & 100 & 200 \\
\hline $92 / 93(9)$ & 0 & 80 & 160 & 320 & 0 & 40 & 80 & 160 & 0 & 80 & 160 & 320 \\
\hline $93 / 94(10)$ & 0 & 80 & 160 & 320 & 0 & 40 & 80 & 160 & 0 & 80 & 160 & 320 \\
\hline $94 / 95(11)$ & 0 & 80 & 160 & 320 & 0 & 40 & 80 & 160 & 0 & 80 & 160 & 320 \\
\hline $95 / 96(12)^{* *}$ & 0 & 80 & 160 & 320 & 0 & 40 & 80 & 160 & 0 & 80 & 160 & 320 \\
\hline $96 / 97(13)$ & 0 & 80 & 160 & 320 & 0 & 40 & 80 & 160 & 0 & 80 & 160 & 320 \\
\hline
\end{tabular}

*anos após o plantio;

**ano em que o ensaio foi realizado; 
O clone utilizado foi o PB 235, resultante do cruzamento intra-específico de Hevea brasiliensis (PB 5/51 x PB 5/78) de origem malaia. De acordo com Gonsalves (1983), trata-se de um clone que apresenta baixa incidência de árvores secas nas condições do Estado de São Paulo, alta produção nos primeiros anos e crescimento de casca virgem superior aos clones mais plantados nesta região como o RRIM 600 e o GT 1.

O sistema de sangria utilizado foi em meia espiral, a cada quatro dias com seis dias de sangria por semana, sem balanceamento anual de painel, estimulação com Ethrel $2,5 \%$, aplicação de $1 \mathrm{~g} /$ planta em faixa de $1 \mathrm{~cm}$ sobre o painel de sangria e em 2 aplicações anuais (1/2S d/4 6d/7 ET 2,5\% Pa 1/1 2/y).

Nos três primeiros anos agrícolas as adubações foram efetuadas a lanço em faixas, a $1,00 \mathrm{~m}$ das plantas. Nos dois últimos anos agrícolas as adubações nitrogenada e potássica foram efetuadas a lanço, em faixas a $1,50 \mathrm{~m}$ das plantas..

\subsection{Parâmetros observados}

\subsubsection{Variação na fertilidade do solo}

Amostras de solo foram coletadas em outubro de 1995, nas profundidades de $0-20 \mathrm{~cm}$ e $20-40 \mathrm{~cm}$. Em cada parcela experimental retirou-se 15 amostras simples, em ziguezague, sendo posteriormente homogeneizadas e coletada uma amostra composta para cada profundidade.

As determinações analíticas foram realizadas, segundo métodos descritos por Raij \& Quaggio (1983): (a) índice de acidez ( $\mathrm{pH}$ em $\mathrm{CaCl}_{2}$ 0,01M); (b) P; $\mathrm{K}$; $\mathrm{Ca}$ e $\mathrm{Mg}$, extraídos em resina trocadora de íons; ( c ) acidez potencial ( $\mathrm{H}+\mathrm{Al}$ ), extraída em solução de $\mathrm{KCl} 1 \mathrm{~N}$ e determinado por titulação com $\mathrm{NaOH} 0,02 \mathrm{~N}$ e a matéria orgânica (\% M.O.). Com essas variáveis calculou-se os seguintes parâmetros: soma de bases 
de $\mathrm{KCl}$ IN e determinado por titulação com $\mathrm{NaOH} 0,02 \mathrm{~N}$ e a matéria orgânica (\% M.O.). Com essas variáveis calculou-se os seguintes parâmetros: soma de bases trocáveis (SB); capacidade de troca de cátions; percentagem de saturação de bases da CTC $(\mathrm{V} \%)$.

\subsubsection{Concentração de nutrientes nas folhas}

A coleta foi realizada no verão (início de fevereiro de 1996), época em que as folhas lançadas no início da primavera completavam seis meses de idade e nessa fase atingiram sua maturidade fisiológica. As folhas selecionadas foram as quatro basais, sem pecíolos, localizadas no último lançamento maduro de ramos sombreados no interior da copa. De cada parcela foram tomadas 20 folhas, coletadas de 6 plantas úteis. (Shorrocks, 1962; Pushpadas \& Ahammed, 1980). Após a lavagem, secagem e moagem, as amostras foram analisadas quanto aos teores de macronutrientes $(\mathrm{N}, \mathrm{P}, \mathrm{K}, \mathrm{Ca}, \mathrm{Mg}$ e S) e micronutrientes ( $\mathrm{Fe}, \mathrm{Cu}, \mathrm{Zn}, \mathrm{Mn}$ e B).

O nitrogênio total foi extraído por digestão ácida à quente, seguida de destilação em aparelho semi-micro Kjeldahl e titulação (Bremmer, 1965). Os macronutrientes $\mathrm{P}, \mathrm{K}, \mathrm{Ca}, \mathrm{Mg}$, e $\mathrm{S}$ e os micronutrientes $\mathrm{Fe}, \mathrm{Cu}, \mathrm{Zn}$ e $\mathrm{Mn}$ foram extraidos por digestão nitro-perclórica, sendo que o $\mathrm{P}$ foi determinado por colorimetria de molibdato vanadato; o $\mathrm{K}$ por fotometria de chama, o $\mathrm{Ca}, \mathrm{Mg}, \mathrm{Fe}, \mathrm{Cu}, \mathrm{Zn}$ e $\mathrm{Mn}$ por espectrofotometria de absorção atômica, o S por turbidimetria de sulfato de bário, e o B analisado pelo método da curcumina (Sarruge \& Haag, 1974).

\subsubsection{Perímetro do tronco, espessura da casca seca do Painel}

A determinação do perimetro do tronco, espessura de casca e seca do painel foram efetuadas em abril de 96 e fevereiro de 97. 
A espessura da casca foi tomada com auxilio de um paquímetro, com aproximação de $1 / 10$ de $\mathrm{mm}$, na mesma altura em que realizou-se a medida dạ perímetro do tronco e em um ponto pré-determinado da casca virgem.

O secamento do painel foi avaliado visualmente imediatamente após uma sangria, onde se observava a porcentagem (\%) do corte no painel em que não havia fluxo do látex. Estes dados foram coletados das 6 plantas úteis de cada parcela e a \% média de secamento da parcela foi calculada, semelhante a metodologia proposta por Jobbe Durval (1986), que estima o comprimento do corte seco em porcentagem.

\subsubsection{Avaliação da produção}

A produção foi avaliada mensalmente a partir de outubro de 1995. A produção também foi referente às 6 plantas úteis de cada parcela. Os coágulos foram pendurados em arames ( arame 14), que estavam presos as árvores. A pesagem da produção foi realizada em balança digital e os resultados finais foram expressos em $\mathrm{kg}$ de borracha seca/ha/mês e $\mathrm{kg}$ de borracha seca/ha/ano, considerando 400 plantas/ha. A produção também foi expressa em $\mathrm{g} /$ planta/mês e em $\mathrm{g} /$ planta/sangria. A cada pesagem era coletada uma amostra representativa de coágulos, trazida ao laboratório e levada a estufa para se obter o peso seco da borracha.

\subsubsection{Exportação de nutrientes}

Em junho de 1996 coletou-se amostras compostas de látex das 6 plantas úteis de cada parcela, para a determinação dos teores de nutrientes do látex. Foram feitas duas amostragens, sendo uma para se determinar o nitrogênio e outra para se determinar os demais nutrientes com exceção do boro. Para a primeira amostra foram coletadas 12 gotas de látex em um frasco de $10 \mathrm{ml}$, sendo 2 gotas de cada planta. Os frascos foram previamente tarado e identificados e após a coleta foram pesados novamente, sendo 
levados a estufa com temperatura a $65^{\circ} \mathrm{C}$ para se obter o peso constante. Esta amostra foi usada para se fazer a digestão sulfúrica onde posteriormente se obteve o teor de $\mathrm{N}$, semelhante a determinação do teor de $\mathrm{N}$ foliar.

A segunda amostra foi composta por 18 gotas de látex, coletadas em frascos de $15 \mathrm{ml}$, juntando-se a $9 \mathrm{ml}$ do ácido tricloro acético a $2,5 \%$, que também foram préviamente tarados e identificados, usados para a digestão nitro-perclórica. Esta digestão foi realizada para se obter o extrato para se determinar os teores de $\mathrm{P}, \mathrm{K}, \mathrm{Ca}$, $\mathrm{Mg}, \mathrm{S}, \mathrm{Fe}, \mathrm{Cu}, \mathrm{Mn}$ e $\mathrm{Zn}$, determinação esta semelhante a utilizada para se obter os teores foliares dos mesmos nutrientes. Com base nos teores de nutrientes do látex, o peso seco deste látex, e a produção anual calculou-se o quanto de nutriente foi exportado por ano.

\subsection{Análise estatística do experimento}

Os dados obtidos foram analisados estatisticamente através de análise de variância (teste $\mathrm{F}$ ) segundo o delineamento em blocos casualizados com 16 tratamentos (fatorial fracionado com 3 nutrientes (NPK) e quatro doses). Para identificar tratamentos com melhor resposta, foram realizadas as comparações dos tratamentos pelo teste de Tukey ao n'vel de 5\%. Para complementar a análise das diferenças entre tratamentos realizou-se análises segundo uma superficie de resposta de segunda ordem, nos tratamentos $\mathrm{N}, \mathrm{P}$ e K.

Realizou-se também uma análise de variância das regressões para identificar o grau de correlação entre as doses dos diferentes nutrientes e os parâmetros avaliados, sendo que, quando a regressão foi significativa na análise de variância, as regressões foram usadas para a elaboração das curvas de resposta. Todas as análises supracitadas foram efetuadas utilizando-se o programa SAS - Sistema de Análises Estatísticas. 


\section{RESULTADOS E DISCUSSÃO}

\subsection{Aspectos gerais da fertilidade do solo}

A Tabela 3 encontram-se os resultados analíticos de algumas caracteristicas químicas do solo, obtidas antes da instalação do experimento (amostra 1) e 9 anos após a condução do mesmo (amostra 2), no tratamento controle, na profundidade de $0-20 \mathrm{~cm}$.

Tabela 3. Características quimicas do solo da área experimental antes da instalação do experimento e após 9 anos à condução do mesmo no tratamento controle , na profundidade de $0-20 \mathrm{~cm}$.

\begin{tabular}{lcccccccccc}
\hline Amostras & $\mathrm{pH}$ & $\mathrm{M} . \mathrm{O}$. & P resina & $\mathrm{K}^{+}$ & $\mathrm{Ca}^{++}$ & $\mathrm{Mg}^{++}$ & $\mathrm{H}^{+}+\mathrm{Al}^{+++}$ & $\mathrm{S}$ & $\mathrm{T}$ & $\mathrm{V}$ \\
\hline & $\mathrm{CaCl}_{2}$ & $\mathrm{~g} \mathrm{dm}^{-3}$ & $\mathrm{mg} \mathrm{dm}{ }^{-3}$ & & & & & & & \\
$1^{(1)}$ & 4,4 & 15 & 11 & 0,8 & 6,9 & 5,6 & 22,5 & 13,3 & 36 & 37 \\
$2^{(2)}$ & 4,7 & 12 & 5 & 1,0 & 9,9 & 6,0 & 20 & 16,8 & 37 & 46 \\
\hline
\end{tabular}

(1)- Coletada antes da instalação do experimento;

(2)- Coletada 9 anos após o início do experimento.

Observa-se que, apesar de uma pequena elevação dos valores de $\mathrm{pH}$, o solo apresenta condições ácidas, com baixos teores de $\mathrm{K}$ e $\mathrm{P}$ disponiveis e os teores de $\mathrm{Ca}$ e $\mathrm{Mg}$, segundo Raij et al.(1996) estão nos seus níveis altos e médios. O decréscimo no conteúdo de $\mathrm{H}^{+}+\mathrm{Al}^{+++}$e o acréscimo nos teores de $\mathrm{Ca}^{++}, \mathrm{Mg}^{++}$e $\mathrm{K}^{+}$ determinados nove anos após a condução do ensaio, contribuíram para a ligeira variação na capacidade de troca de cations potencial (CTC) e a saturação por bases, 
que aumentou de $37 \%$ para $46 \%$. Estas variações se devem ao efeito residual da calagem, que foi realizada em março de 1993 com aplicação de 1 tonelada/ha do calcário dolomítico em toda a área experimental.

As características químicas do calcário utilizado mostra que o mesmo apresenta efeito residual, considerando que a amostra 2 foi coletada 2,5 anos após a ultima calagem. Os teores de $\mathrm{P}$ no solo diminuíram, provavelmente devido à absorção das plantas, à fixação deste elemento na fase coloidal do solo e a não reposição do mesmo ao solo.

Houve uma pequena diminuição no teor de matéria orgânica no solo, fato este não muito comum na camada de $0-20 \mathrm{~cm}$ em uma cultura de seringueira, pois nesta, há a queda de folhas e galhos (liteira). Entretanto essa diminuição reflete a importância da introdução de leguminosas de cobertura em seringais, principalmente na fase de desenvolvimento. Murbach (1994), trabalhando com diferentes manejos na entrelinha da seringueira, verificou que, após 2 anos de cultivo da Puerária, houve uma grande incorporação de material orgânico, o mesmo não sendo observado em outros tratamentos onde se utilizou gradagem, roçagem, cultura anual e mucuna anã

\subsection{Efeito da adubação com $N, P, K$ sobre a fertilidade do solo.}

Nas tabelas 4 e 5 são apresentados valores do teste $F$ das regressões, médias gerais e coeficientes de variação, obtidos mediante análises de variância para os resultados analíticos das amostras coletadas nas profundidades de $0-20 \mathrm{~cm}$ e $20-40$ $\mathrm{cm}$ respectivamente. $\mathrm{Na}$ Tabela 4 observa-se que o $\mathrm{pH}, \mathrm{H}+\mathrm{Al}, \mathrm{Mg}, \mathrm{SB}$ e V\% foram afetados linearmente pela adubação nitrogenada. A adubação fosfatada causou efeito linear no teor de $\mathrm{P}$ e Ca disponíveis e na CTC do solo. A adubação potássica causou efeito linear nos teores de $\mathrm{K}$ disponíveis no solo. 


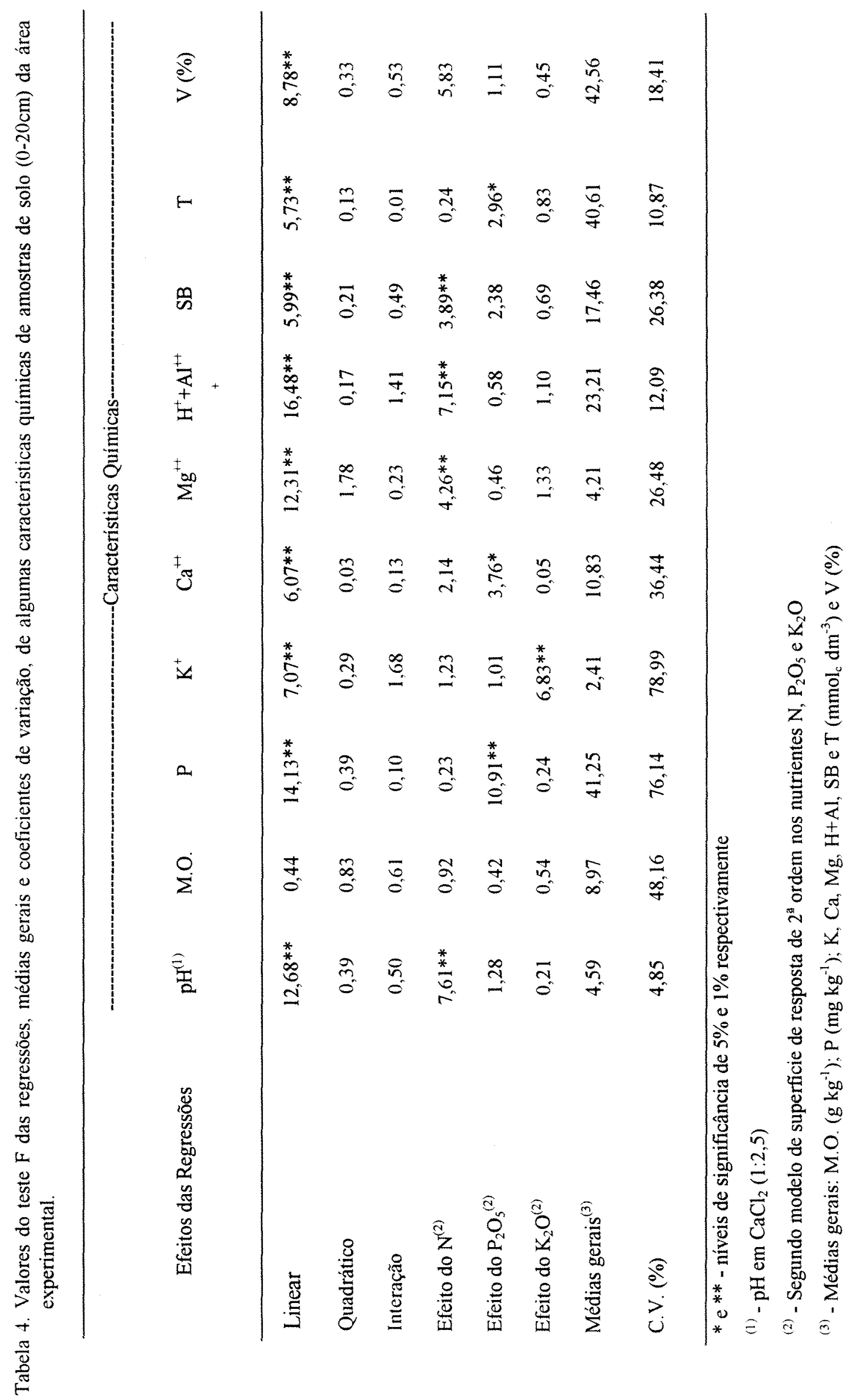




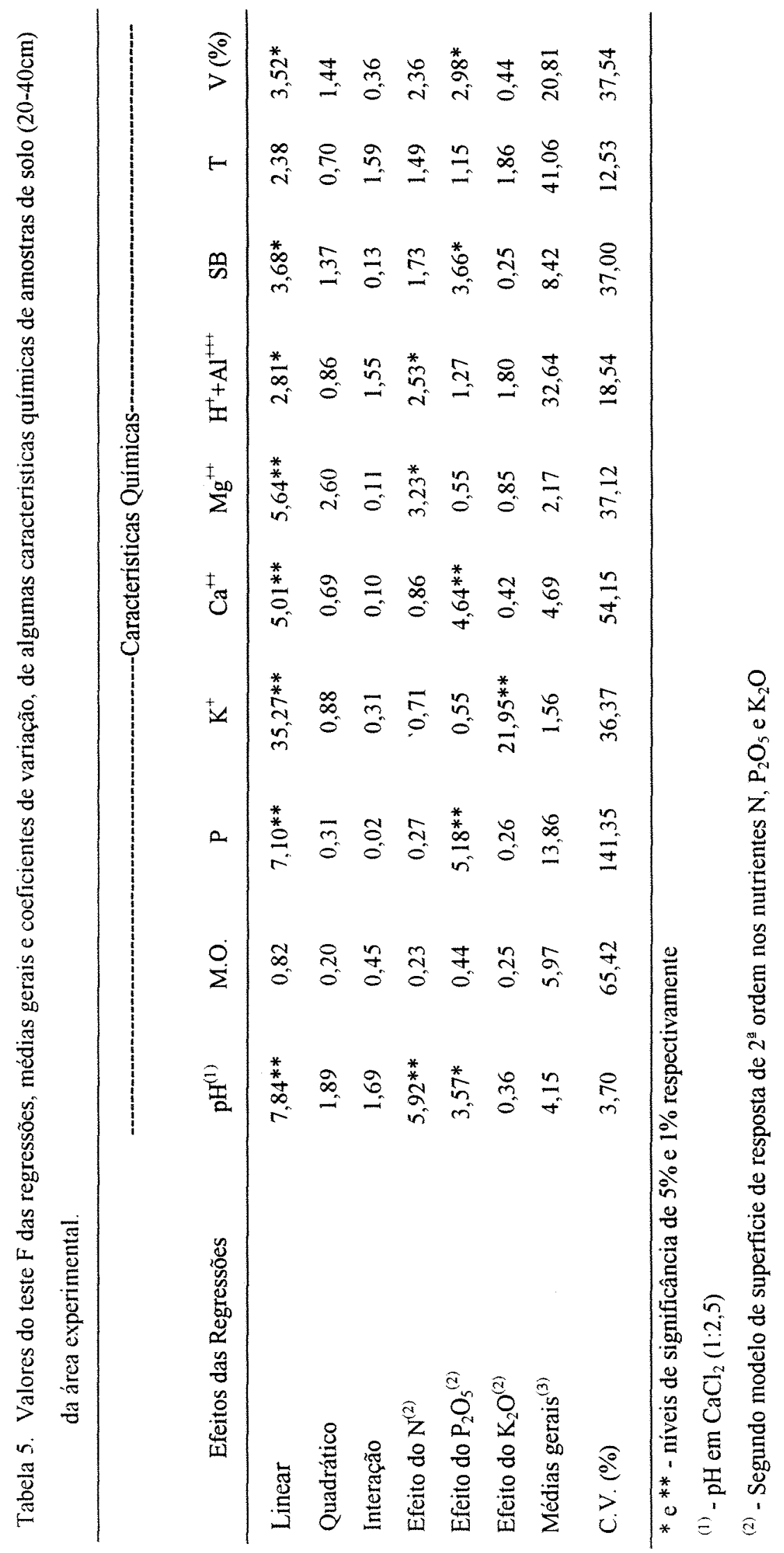


A Tabela 5 apresenta os resultados alcançados na camada subsuperficial $(20-40 \mathrm{~cm})$, onde se verificou que a adubação nitrogenada causou efeito linear no pH do solo, no $\mathrm{H}+\mathrm{Al}$ e no teor de $\mathrm{Mg}$ disponível. A adubação fosfatada causou efeito linear no pH, na disponibilidade de $\mathrm{P}, \mathrm{Ca}, \mathrm{SB}$ e na saturação por bases. A adubação potássica afetou linearmente os teores de $\mathrm{K}$ disponíveis.

A Figura 1A ilustra a elevação da acidez, com as doses de $\mathrm{N}$ cuja regressão estatisticamente significativa pelo teste F. Na Figura $1 \mathrm{~B}$ se observa que a disponibilidade de $\mathrm{Mg}$ foi afetada significativamente pelas doses de $\mathrm{N}$, promovendo a diminuição do mesmo que passou de um nível médio para um nível baixo, segundo indices dados por (Raij, 1991).

A Figura 1C ilustra a elevação da acidez potencial $\mathrm{H}^{+}+\mathrm{Al}^{+++}$e a conseqüente diminuição da soma de bases com as doses de N. A Figura ID ilustra a consequiência de doses elevadas de $\mathrm{N}$ no solo, promovendo uma acentuada queda da saturação por bases.

As doses de nitrogênio influenciaram também algumas características na camada $20-40 \mathrm{~cm}$ como ilustram a Figura 2, provocando uma elevação na acidez (Figura 2A, elevação do $\mathrm{H}^{+}+\mathrm{Al}^{+++}$trocável Figura $2 \mathrm{~B}$ e diminuição do $\mathrm{Mg}$ trocável Figura 2C).

Estas variações provocadas pela adubação nitrogenada, são motivadas por deixar um residuo ácido no solo, principalmente quando a fonte é uréia (Raij, 1991) Segundo o mesmo autor, quando se aplica $100 \mathrm{~kg} / \mathrm{ha}$ de $\mathrm{N}$ na forma de uréia, necessita-se uma adição de $180 \mathrm{~kg} /$ ha de $\mathrm{CaCO}_{3} \operatorname{com}(\mathrm{PRNT}=100)$, para que o solo não se acidifique.

Resultados similares foram obtidos em solos da Malásia por Bolton (1964) e Pushparajah et al. (1983) e no Brasil por Viegas (1985), onde a aplicação de sulfato de amônio causou uma redução no índice de pH, acarretando em diminuição da CTC potencial, e possibilitando, uma lixiviação de cálcio, magnésio e potássio. 

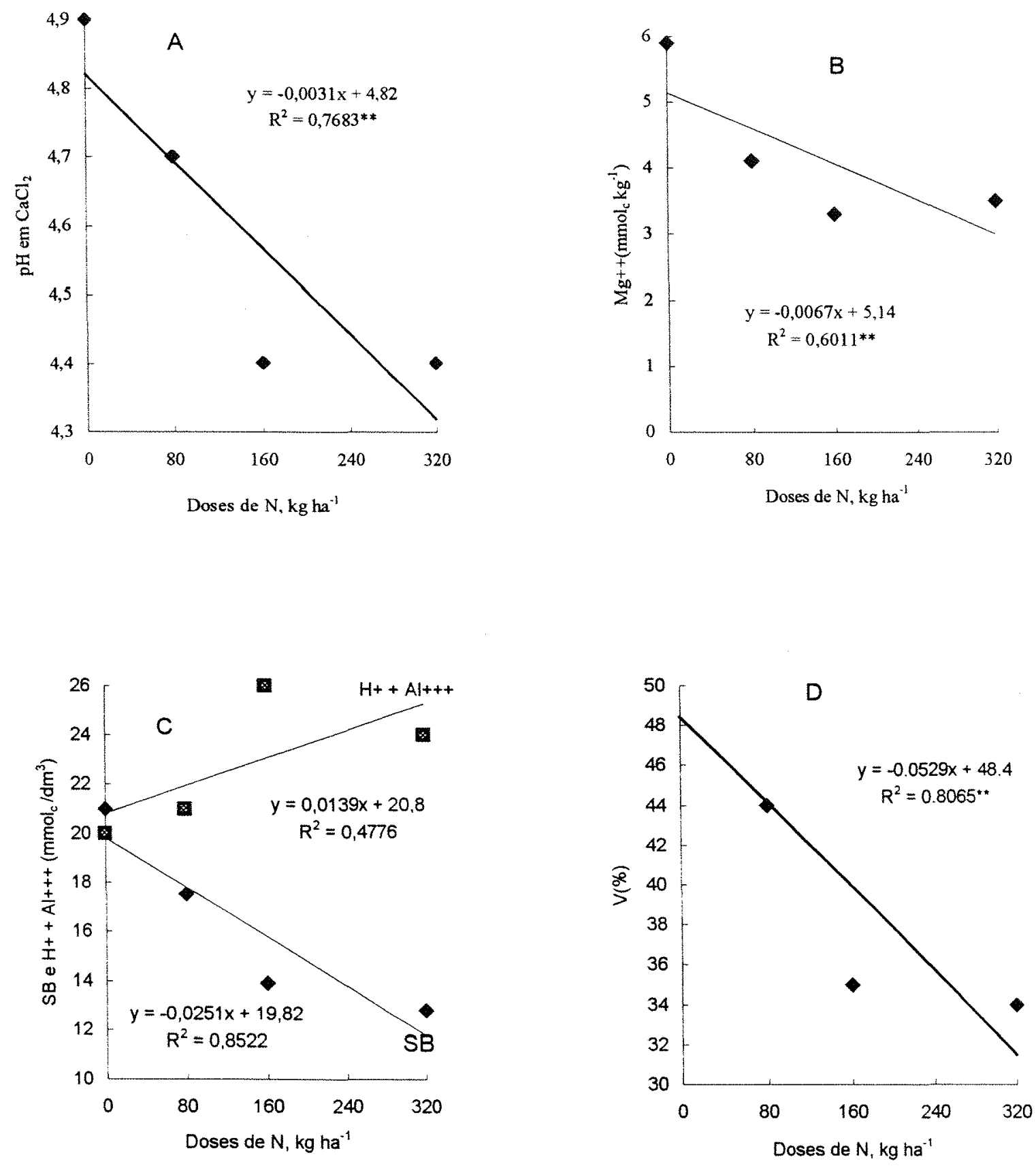

Figura 1- Efeito da adubação nitrogenada no $\mathrm{pH}$ em $\mathrm{CaCl}_{2}$ (A); nos teores de $\mathrm{Mg}(\mathrm{B})$; na soma de bases $\left(\mathrm{H}^{+}+\mathrm{Al}^{++}\right)(\mathrm{C})$ e na saturacão por bases (D) na camada de 0 $20 \mathrm{~cm}$. 

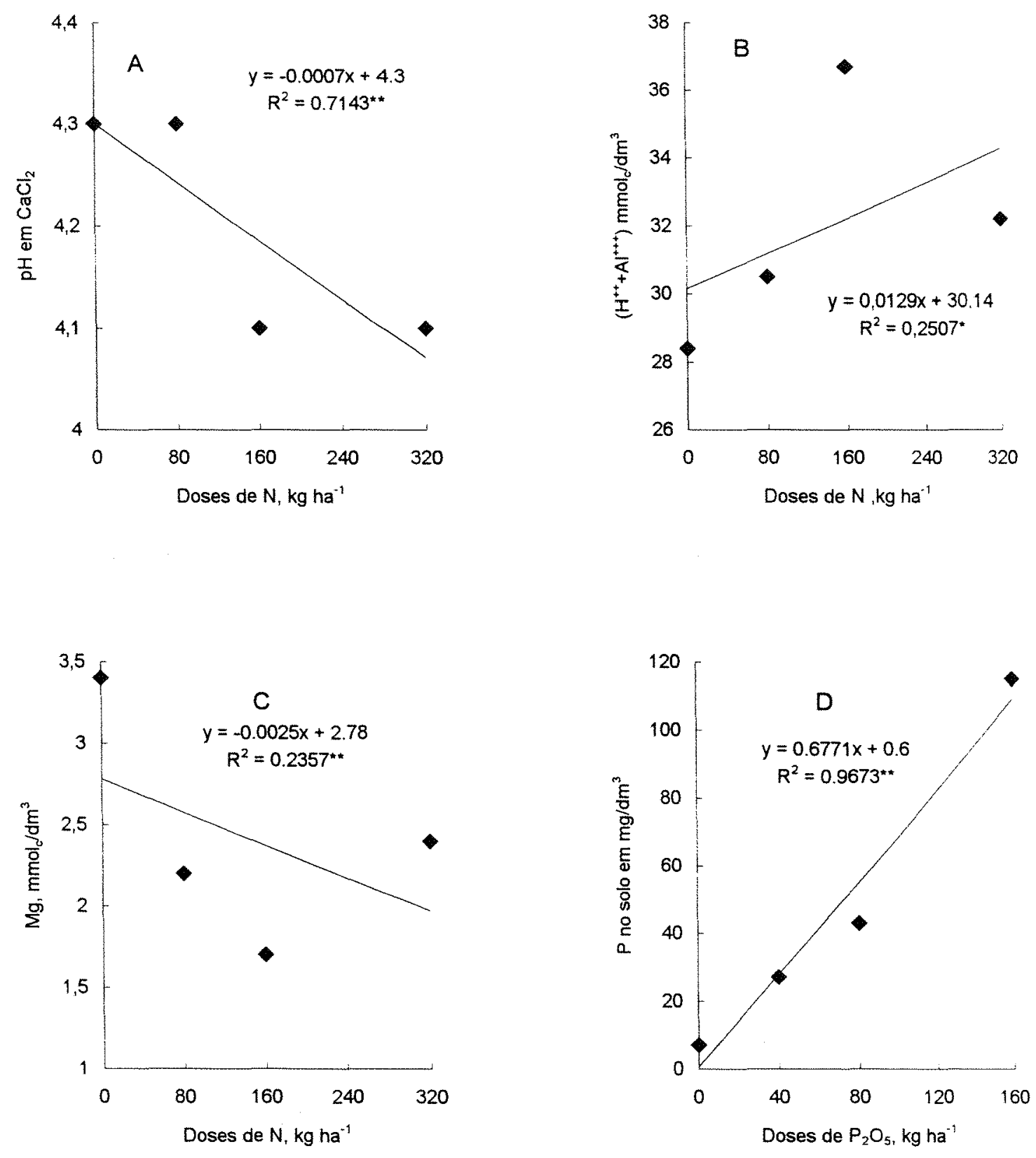

Figura 2. Alterações do $\mathrm{pH}$ em $\mathrm{CaCl}_{2}(\mathrm{~A}) ;\left(\mathrm{H}^{+}+\mathrm{Al}^{+++}\right)$trocável (B) e no $\mathrm{Mg}$ Trocável do solo(C) $(20-40 \mathrm{~cm}$ de profundidade $)$ provocadas pela adubação nitrogenada e alterações do $\mathrm{P}$ disponivel (D) no solo $(0-20 \mathrm{~cm})$ provocadas pela adubação fosfatada, ambas aplicadas em superfície. 
O incremento nas doses de fósforo resultou no aumento da disponibilidade deste elemento na camada de $0-20 \mathrm{~cm}$ do solo (figura 2D), no teor de cálcio trocável (figura 3A), e na CTC (figura3B).

Segundo Raij (1991) a grande vantagem do superfosfato simples é o seu conteúdo de enxofre (13\%) e de cálcio $(26 \%$ de $\mathrm{CaO})$ em forma móvel de sulfato.

Observou-se também na camada de $20-40 \mathrm{~cm}$, uma elevação do pH (figura 3C), aumento na disponibilidade de Ca e Soma de Bases (figura 3D) e, nesta mesma camada observou-se, o efeito da adubação fosfatada que aumentou o P disponível (figura 4A) e a saturação por bases (figura 4B).

A elevação da saturação por bases e da soma de bases na camada de 0-40 $\mathrm{cm}$ se deve exclusivamente ao $\mathrm{Ca}^{++}$, que como foi mencionado, é proveniente do superfosfato simples, que é móvel no solo.

A figura $4 \mathrm{C}$, ilustra o aumento na disponibilidade de $\mathrm{K}$ na camada de 0 $20 \mathrm{~cm}$ com a adubação potássica na camada de $0-20 \mathrm{~cm}$ e a figura $4 \mathrm{D}$ ilustra este aumento na camada $20-40 \mathrm{~cm}$. Raij (1991), verificou que amostras de solos do horizonte $B$ são mais importantes que a camada arável em liberar potássio não trocavel. A mobilidade deste nutriente deve provavelmente aumentar a sua disponibilidade para as plantas, pois a seringueira apresenta um sistema radicular profundo.

A comparação das médias pelo teste de Tukey ao nível de $5 \%$ de probabilidade (Tabelas $6 \mathrm{e}$ 7) revelam que o efeito dos tratamentos foi significativo para os teores de potássio, cálcio e magnésio trocáveis, determinados na camada de 0 $20 \mathrm{~cm}$ do solo. Considerando que o nível médio de $\mathrm{K}$ no solo é de 1,6-3,0 (Raij, 1996) se verifica que os tratamentos que receberam a dose 2 deste elemento $(160 \mathrm{~kg}$ $\left.\mathrm{K}_{2} \mathrm{O} / \mathrm{ha}\right)$ ou $3\left(320 \mathrm{~kg} \mathrm{~K} \mathrm{~K}_{2} \mathrm{O} / \mathrm{ha}\right.$ ), foram os que apresentaram teores altos desse elemento no solo. 

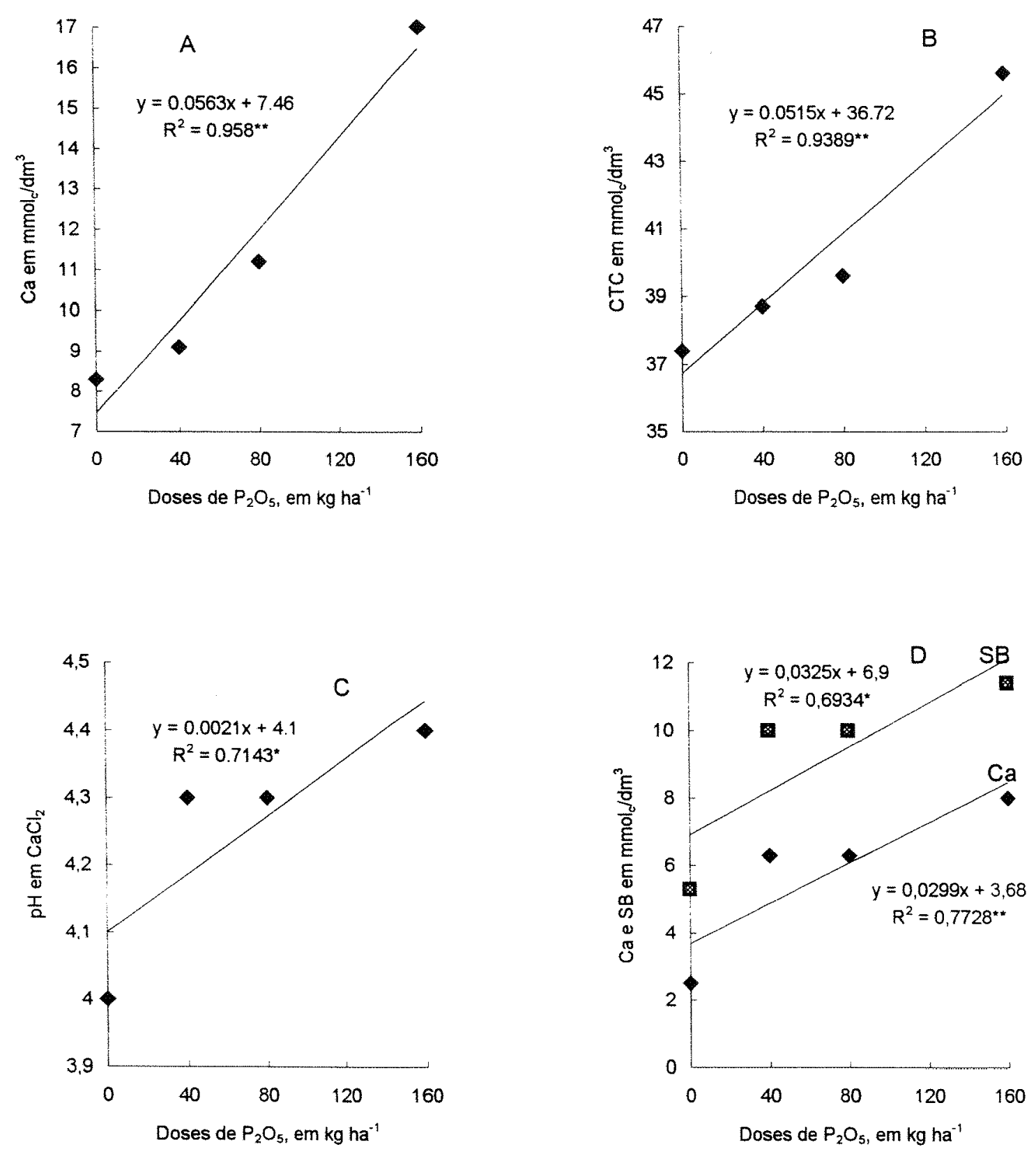

Figura 3. Alterações no teor de $\mathrm{Ca}^{++}$trocável (A); CTC do solo (B) $(0-20 \mathrm{~cm}$ de profundidade) e alterações no $\mathrm{pH}$ em $\mathrm{CaCl}_{2}(\mathrm{C}) ; \mathrm{Ca}^{++}$trocável e Soma de Bases do solo (D) $(20-40 \mathrm{~cm}$ de profundidade) provocados pela adubação fosfatada. 

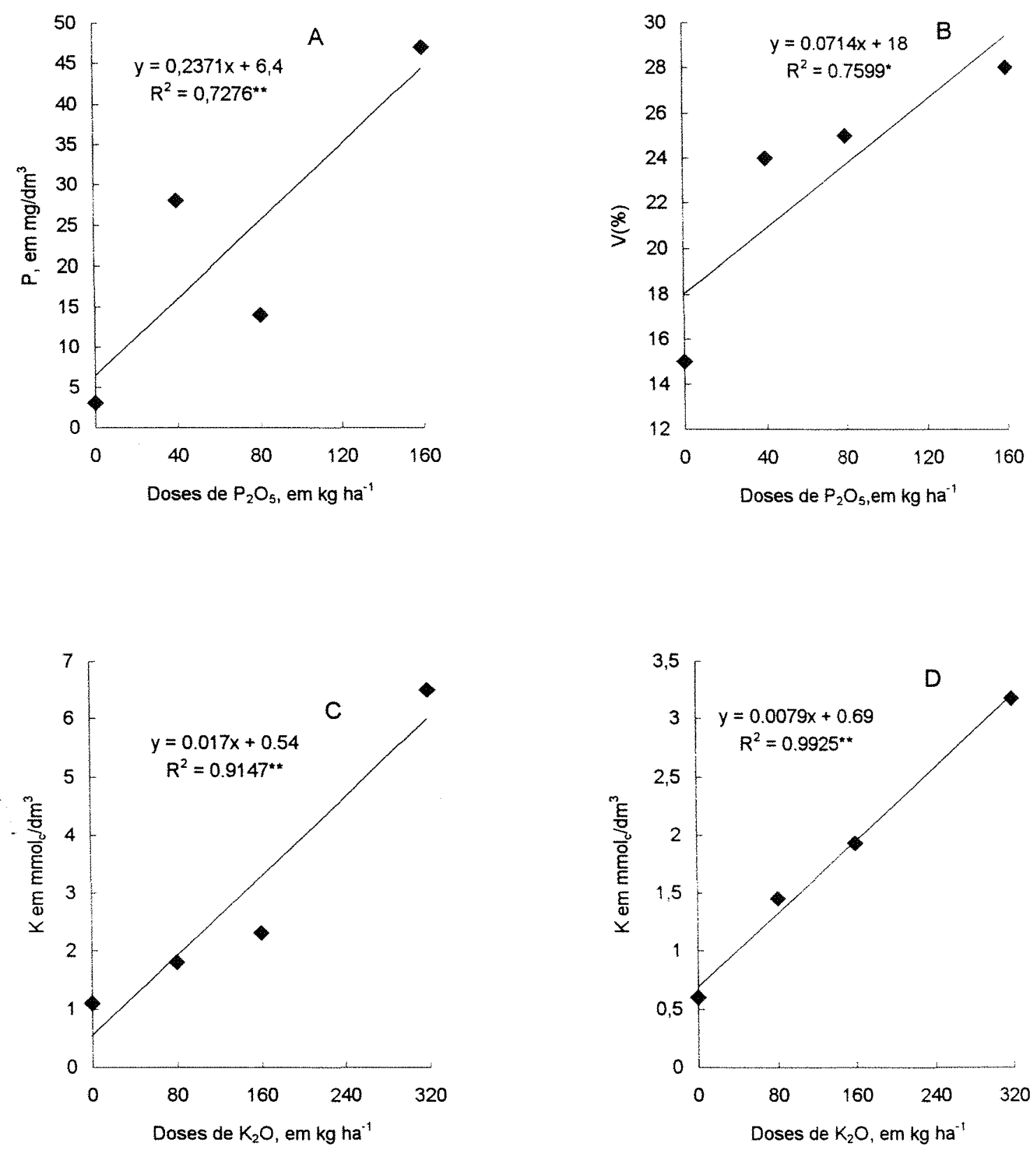

Figura 4- Alterações provocadas no teor P disponível (A) e Saturação por bases (B) na camada de $20-40 \mathrm{~cm}$ pela adubação fosfatada e as alterações provocadas no teor de $\mathrm{K}$ trocável na camada de $0-20 \mathrm{~cm}$ (C) e $20-40 \mathrm{~cm}$ (D) devido a adubação potássica. 
Tabela 6. Influência dos níveis de nitrogênio, fósforo e potássio sobre algumas caracteristicas químicas do solo na profundidade de $(0-20 \mathrm{~cm})$, amostras efetuadas em outubro de 1995.

\begin{tabular}{|c|c|c|c|c|c|c|c|c|c|c|c|}
\hline & & \multicolumn{10}{|c|}{ Características Químicas } \\
\hline \multicolumn{2}{|c|}{ Tratamentos } & \multicolumn{2}{|l|}{$\mathrm{K}^{+}$} & \multicolumn{2}{|l|}{$\mathrm{Ca}^{+}$} & \multicolumn{2}{|l|}{$\mathrm{Mg}^{+}$} & \multicolumn{2}{|l|}{$\mathrm{H}+\mathrm{Al}^{+++}$} & SB & $\mathrm{T}$ \\
\hline $\mathrm{T}_{1}$ & $\mathrm{~N}_{0} \mathrm{P}_{0} \mathrm{~K}_{0}$ & 1,0 & $\mathrm{~b}$ & 9,9 & $a b$ & 6,0 & $\mathrm{a}$ & 20 & c & 16,8 & 37,0 \\
\hline $\mathrm{T}_{4}$ & $\mathrm{~N}_{0} \mathrm{P}_{1} \mathrm{~K}_{1}$ & 1,8 & $\mathrm{~b}$ & 13,4 & $a b$ & 5,9 & $\mathrm{a}$ & 20 & c & 21,0 & 41,1 \\
\hline $\mathrm{T}_{5}$ & $\mathrm{~N}_{1} \mathrm{P}_{1} \mathrm{~K}_{1}$ & 1,8 & b & 11,6 & $a b$ & 4,1 & $\mathrm{ab}$ & 21 & c & 17,5 & 38.7 \\
\hline $\mathrm{T}_{6}$ & $\mathrm{~N}_{2} \mathrm{P}_{1} \mathrm{~K}_{1}$ & 1,5 & b & 9,1 & $\mathrm{ab}$ & 3,3 & $a b$ & 26 & $a b c$ & 13,9 & 39,7 \\
\hline $\mathrm{T}_{7}$ & $\mathrm{~N}_{3} \mathrm{P}_{1} \mathrm{~K}_{1}$ & 1,5 & b & 7,8 & b & 3,5 & $a b$ & 24 & $a b c$ & 12,8 & 37,2 \\
\hline $\mathrm{T}_{3}$ & $\mathrm{~N}_{1} \mathrm{P}_{0} \mathrm{~K}_{1}$ & 3,5 & $a b$ & 8,3 & $a b$ & 5,1 & $a b$ & 21 & $\mathrm{c}$ & 16,9 & 37.4 \\
\hline$T_{5}$ & $\mathrm{~N}_{1} \mathrm{P}_{1} \mathrm{~K}_{1}$ & 1,8 & $\mathrm{~b}$ & 11,6 & $a b$ & 4,1 & $a b$ & 21 & c & 17,5 & 38,7 \\
\hline $\mathrm{T}_{8}$ & $\mathrm{~N}_{1} \mathrm{P}_{2} \mathrm{~K}_{1}$ & 1,6 & b & 11,2 & $a b$ & 4,1 & $a b$ & 23 & $a b c$ & 16,8 & 39,6 \\
\hline $\mathrm{T}_{9}$ & $\mathrm{~N}_{1} \mathrm{P}_{3} \mathrm{~K}_{1}$ & 1,6 & b & 17,0 & $\mathrm{a}$ & 4,7 & $a b$ & 22 & $a b c$ & 23,2 & 45.6 \\
\hline $\mathrm{T}_{2}$ & $\mathrm{~N}_{1} \mathrm{P}_{1} \mathrm{~K}_{0}$ & 1,1 & $b$ & 13,3 & $a b$ & 5,1 & $a b$ & 20 & $c$ & 19,5 & 39.7 \\
\hline $\mathrm{T}_{5}$ & $\mathrm{~N}_{1} \mathrm{P}_{1} \mathrm{~K}_{1}$ & 1,8 & $\mathrm{~b}$ & 11,6 & $a b$ & 4,1 & $a b$ & 21 & $b c$ & 17,5 & 38.7 \\
\hline$T_{10}$ & $\mathrm{~N}_{1} \mathrm{P}_{1} \mathrm{~K}_{2}$ & 2,3 & $a b$ & 12,4 & $a b$ & 5,0 & $a b$ & 21 & c & 19,7 & 40.4 \\
\hline$T_{11}$ & $\mathrm{~N}_{1} \mathrm{P}_{1} \mathrm{~K}_{3}$ & 6,5 & $\mathrm{a}$ & 11,2 & $a b$ & 3,6 & $a b$ & 22 & $a b c$ & 21,2 & 43.5 \\
\hline $\mathrm{T}_{12}$ & $\mathrm{~N}_{2} \mathrm{P}_{1} \mathrm{~K}_{2}$ & 3,3 & $a b$ & 11,0 & $a b$ & 4,2 & $a b$ & 25 & $a b c$ & 18,6 & 43,2 \\
\hline$T_{13}$ & $\mathrm{~N}_{3} \mathrm{P}_{1} \mathrm{~K}_{2}$ & 2,4 & $a b$ & 7,3 & b & 2,8 & $\mathrm{~b}$ & 29 & $a$ & 12,7 & 40,6 \\
\hline$T_{14}$ & $\mathrm{~N}_{2} \mathrm{P}_{1} \mathrm{~K}_{3}$ & 3,0 & $a b$ & 8,2 & $a b$ & 3,1 & $b$ & 24 & $a b c$ & 14,3 & 38.9 \\
\hline $\mathrm{T}_{15}$ & $\mathrm{~N}_{2} \mathrm{P}_{2} \mathrm{~K}_{2}$ & 2,7 & $a b$ & 10,2 & $a b$ & 4,0 & $a b$ & 24 & $a b c$ & 16,8 & 41,1 \\
\hline$T_{16}$ & $\mathrm{~N}_{3} \mathrm{P}_{3} \mathrm{~K}_{3}$ & 3,2 & $a b$ & 11,7 & $a b$ & 3,0 & b & 28 & $a b$ & 17,8 & 46.1 \\
\hline
\end{tabular}

Médias seguidas pela mesma letra não diferem entre si estatisticamente pelo teste de Tukey ao nivel de $5 \%$ de probabilidade. 
Tabela 7. Influência dos níveis de nitrogênio, fósforo e potássio sobre algumas caracteristicas químicas do solo na profundidade de $(0-20 \mathrm{~cm})$, amostras efetuadas em outubro de 1995.

\begin{tabular}{|c|c|c|c|c|c|c|c|}
\hline \multirow{2}{*}{\multicolumn{2}{|c|}{ Tratamentos }} & \multicolumn{6}{|c|}{ Caracteristicas Químicas } \\
\hline & & \multirow{2}{*}{\multicolumn{2}{|c|}{$\frac{\mathrm{pH}}{\mathrm{CaCl}_{2}}$}} & \multirow{2}{*}{$\frac{\text { M.O. }}{\mathrm{g} \mathrm{kg}^{-1}}$} & \multicolumn{2}{|l|}{$\mathrm{P}$} & \multirow{2}{*}{$\begin{array}{l}\mathrm{V} \\
\%\end{array}$} \\
\hline & & & & & $m g k^{-1}$ & & \\
\hline$T_{1}$ & $\mathrm{~N}_{0} \mathrm{P}_{0} \mathrm{~K}_{0}$ & 4,7 & $a b$ & 12 & 5 & $\mathrm{c}$ & 46 \\
\hline $\mathrm{T}_{4}$ & $\mathrm{~N}_{0} \mathrm{P}_{1} \mathrm{~K}_{1}$ & 4,9 & $\mathbf{a}$ & 8 & 33 & $b c$ & 51 \\
\hline$T_{5}$ & $\mathrm{~N}_{1} \mathrm{P}_{1} \mathrm{~K}_{1}$ & 4,7 & $a b$ & 10 & 57 & $a b c$ & 44 \\
\hline$T_{6}$ & $\mathrm{~N}_{2} \mathrm{P}_{1} \mathrm{~K}_{1}$ & 4,4 & $a b$ & 12 & 35 & $\mathrm{bc}$ & 35 \\
\hline $\mathrm{T}_{7}$ & $\mathrm{~N}_{3} \mathrm{P}_{1} \mathrm{~K}_{1}$ & 4,4 & $a b$ & 8 & 24 & bc & 34 \\
\hline $\mathrm{T}_{3}$ & $\mathrm{~N}_{1} \mathrm{P}_{0} \mathrm{~K}_{1}$ & 4,6 & $a b$ & 10 & 7 & c & 45 \\
\hline $\mathrm{T}_{5}$ & $\mathrm{~N}_{1} \mathrm{P}_{1} \mathrm{~K}_{1}$ & 4,7 & $a b$ & 10 & 57 & $a b c$ & 44 \\
\hline $\mathrm{T}_{8}$ & $\mathrm{~N}_{1} \mathrm{P}_{2} \mathrm{~K}_{1}$ & 4,6 & $\mathrm{ab}$ & 6 & 43 & bc & 42 \\
\hline $\mathrm{T}_{9}$ & $\mathrm{~N}_{1} \mathrm{P}_{3} \mathrm{~K}_{1}$ & 4,9 & a & 9 & 115 & $\mathrm{a}$ & 50 \\
\hline $\mathrm{T}_{2}$ & $\mathrm{~N}_{1} \mathrm{P}_{1} \mathrm{~K}_{0}$ & 4,8 & $\mathrm{ab}$ & 9 & 30 & $b c$ & 49 \\
\hline $\mathrm{T}_{5}$ & $\mathrm{~N}_{1} \mathrm{P}_{1} \mathrm{~K}_{1}$ & 4,7 & $a b$ & 10 & 57 & $a b c$ & 44 \\
\hline $\mathrm{T}_{10}$ & $\mathrm{~N}_{1} \mathrm{P}_{1} \mathrm{~K}_{2}$ & 4,8 & a & 8 & 41 & $b c$ & 47 \\
\hline $\mathrm{T}_{11}$ & $\mathrm{~N}_{1} \mathrm{P}_{1} \mathrm{~K}_{3}$ & 4,7 & $a b$ & 7 & 35 & $b c$ & 49 \\
\hline $\mathrm{T}_{12}$ & $\mathrm{~N}_{2} \mathrm{P}_{1} \mathrm{~K}_{2}$ & 4,5 & $a b$ & 10 & 27 & $\mathrm{bc}$ & 43 \\
\hline$T_{13}$ & $\mathrm{~N}_{3} \mathrm{P}_{1} \mathrm{~K}_{2}$ & 4,2 & $\mathrm{~b}$ & 6 & 36 & $\mathrm{bc}$ & 32 \\
\hline $\mathrm{T}_{14}$ & $\mathrm{~N}_{2} \mathrm{P}_{1} \mathrm{~K}_{3}$ & 4,5 & $a b$ & 10 & 20 & $b c$ & 37 \\
\hline$T_{15}$ & $\mathrm{~N}_{2} \mathrm{P}_{2} \mathrm{~K}_{2}$ & 4,6 & $a b$ & 11 & 67 & $a b c$ & 41 \\
\hline$T_{16}$ & $\mathrm{~N}_{3} \mathrm{P}_{3} \mathrm{~K}_{3}$ & 4,4 & $a b$ & 8 & 87 & $\mathrm{ab}$ & 39 \\
\hline
\end{tabular}

Médias seguidas de mesma letra não diferem entre si estatisticamente pelo teste de Tukey ao nivel de $5 \%$ de probabilidade 
Verifica-se que todos os tratamentos apresentaram altos teores de cálcio no solo, considerando o nível alto a partir de $6 \mathrm{mmol}_{\mathcal{c}} / \mathrm{dm}^{3}$. É importante frisar que, o maior teor de Ca foi obtido no tratamento $9\left(\mathrm{~N}_{1} \mathrm{P}_{3} \mathrm{~K}_{1}\right)$ e os menores foram obtidos nos tratamentos $7\left(\mathrm{~N}_{3} \mathrm{P}_{1} \mathrm{~K}_{1}\right)$ e $13\left(\mathrm{~N}_{3} \mathrm{P}_{1} \mathrm{~K}_{2}\right)$, onde se aplicou a maior dose de $\mathrm{N}$, e este pode ter provocado a lixiviação do $\mathrm{Ca}^{++}$.

Os teores de $\mathrm{H}^{+}+\mathrm{Al}^{+++}$trocável foram influenciados pelas aplicações de fertilizantes nitrogenados e potássicos, apresentando diferença significativa a $5 \%$ de probabilidade pelo teste de Tukey. $O$ tratamento $T_{1}\left(N_{0} P_{0} K_{0}\right)$ foi o que apresentou menor teor de $\mathrm{H}^{+}+\mathrm{Al}^{+++}$.

O valor da CTC (Tabelas 6 e 8) variou de 37,2 a $45,9 \mathrm{mmol} / \mathrm{kg}$ (níveis baixos) na profundidade de $0-40 \mathrm{~cm}$, indicando que este solo apresenta baixa capacidade de reter cátions, refletindo ainda que, as argilas deste solo são de baixa atividade, formadas provavelmente por caulinitas e/ou óxidos e hidróxidos de ferro e alumínio. O baixo conteúdo de matéria orgânica, entre 3,9 a 9,2 $\mathrm{g} \mathrm{kg}^{-1}$ (Tabela 9)na camada de 20 a $40 \mathrm{~cm}$, reforça a suposição de que este solo apresenta alto grau de perdas de nutrientes por lixiviação e/ou percolação, devido a sua textura arenosa.

A adubação fosfatada afetou significativamente os teores de $\mathrm{P}$ no solo, pelo teste de Tukey ao nivel de $5 \%$ (Tabela 7) na camada de $0-20 \mathrm{~cm}$. Apresentando desde teores baixos (0-5 $\mathrm{mg} \mathrm{dm}^{-3}$ ), até teores altos. (maior que $60 \mathrm{mg} \mathrm{dm}^{-3}$ ).

$\mathrm{Na}$ Tabela 8 , pode-se observar, que o $\mathrm{K}$ é lixiviado no solo arenoso, pois este elemento é aplicado em superficie, aparece em altos teores na camada de 20-40 $\mathrm{cm}$, nos tratamentos de maior dose desse nutriente.

O pH na camada de $20-40 \mathrm{~cm}$ está muito baixo aliado a uma alta concentração de $\mathrm{H}^{+}+\mathrm{Al}^{+++}$trocável, baixos teores de bases e baixa saturação por bases, problemas estes comuns na camada de $20-40 \mathrm{~cm}$ de profundidade, em solos sob culturas perenes, devido a dificuldade de incorporação do calcário nas camadas profundas do solo (Tabela 9). 
Tabela 8. Influência dos niveis de nitrogênio, fósforo e potássio sobre algumas características quimicas do solo na profundidade de $(20-40 \mathrm{~cm})$, amostras efetuadas em outubro de 1995.

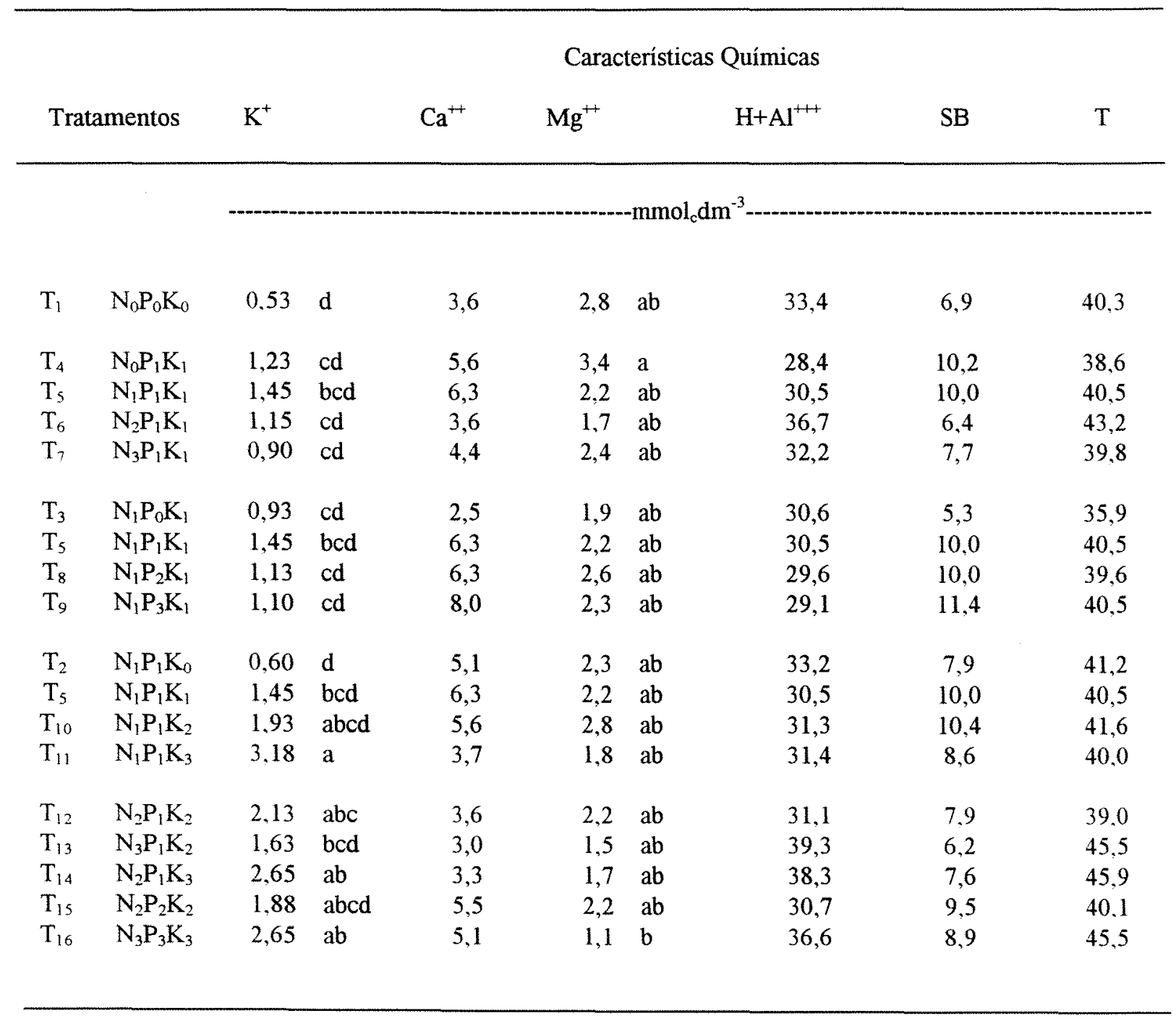

Médias seguidas de mesma letra não diferem entre si estatisticamente pelo teste de Tukey ao nível de $5 \%$ de probabilidade 
Tabela 9. Influência dos níveis de nitrogênio, fósforo e potássio sobre algumas características quimicas do solo na profundidade de $(20-40 \mathrm{~cm})$, amostras efetuadas em outubro de 1995.

\begin{tabular}{|c|c|c|c|c|c|c|}
\hline & & \multicolumn{5}{|c|}{ Características Químicas } \\
\hline \multicolumn{2}{|c|}{ Tratamentos } & \multicolumn{2}{|l|}{$\mathrm{pH}$} & \multirow{2}{*}{$\frac{\text { M.O. }}{\mathrm{g} \mathrm{kg}^{-1}}$} & \multirow{2}{*}{$\frac{\mathrm{P}}{\mathrm{mg} \mathrm{kg}{ }^{-1}}$} & \multirow{2}{*}{$\frac{\mathrm{V}}{\%}$} \\
\hline & & & & & & \\
\hline $\mathrm{T}_{1}$ & $\mathrm{~N}_{0} \mathrm{P}_{0} \mathrm{~K}_{0}$ & 4,2 & $\mathrm{ab}$ & 7,4 & 2 & 18 \\
\hline $\mathrm{T}_{4}$ & $\mathrm{~N}_{0} \mathrm{P}_{1} \mathrm{~K}_{1}$ & 4,3 & $a b$ & 6,4 & 5 & 27 \\
\hline $\mathrm{T}_{5}$ & $\mathrm{~N}_{1} \mathrm{P}_{1} \mathrm{~K}_{1}$ & 4,3 & $a b$ & 7,8 & 28 & 24 \\
\hline $\mathrm{T}_{6}$ & $\mathrm{~N}_{2} \mathrm{P}_{1} \mathrm{~K}_{1}$ & 4,1 & $a b$ & 9,2 & 12 & 15 \\
\hline $\mathrm{T}_{7}$ & $\mathrm{~N}_{3} \mathrm{P}_{1} \mathrm{~K}_{1}$ & 4,1 & $a b$ & 7,1 & 5 & 20 \\
\hline $\mathrm{T}_{3}$ & $\mathrm{~N}_{1} \mathrm{P}_{0} \mathrm{~K}_{1}$ & 4,0 & $a b$ & 6,0 & 3 & 15 \\
\hline $\mathrm{T}_{5}$ & $\mathrm{~N}_{1} \mathrm{P}_{1} \mathrm{~K}_{1}$ & 4,3 & $a b$ & 7,8 & 28 & 24 \\
\hline $\mathrm{T}_{8}$ & $\mathrm{~N}_{1} \mathrm{P}_{2} \mathrm{~K}_{1}$ & 4,3 & $a b$ & 3,9 & 14 & 25 \\
\hline $\mathrm{T}_{9}$ & $\mathrm{~N}_{1} \mathrm{P}_{3} \mathrm{~K}_{1}$ & 4,4 & $\mathrm{a}$ & 6,4 & 47 & 28 \\
\hline $\mathrm{T}_{2}$ & $\mathrm{~N}_{1} \mathrm{P}_{1} \mathrm{~K}_{0}$ & 4,1 & $a b$ & 4,9 & 9 & 20 \\
\hline $\mathrm{T}_{5}$ & $\mathrm{~N}_{1} \mathrm{P}_{1} \mathrm{~K}_{1}$ & 4,3 & $\mathrm{ab}$ & 7,8 & 28 & 24 \\
\hline $\mathrm{T}_{10}$ & $\mathrm{~N}_{1} \mathrm{P}_{1} \mathrm{~K}_{2}$ & 4,2 & $a b$ & 7,4 & 10 & 25 \\
\hline$T_{11}$ & $\mathrm{~N}_{1} \mathrm{P}_{1} \mathrm{~K}_{3}$ & 4,2 & $a b$ & 6,0 & 7 & 22 \\
\hline $\mathrm{T}_{12}$ & $\mathrm{~N}_{2} \mathrm{P}_{1} \mathrm{~K}_{2}$ & 4,2 & $a b$ & 3,9 & 4 & 21 \\
\hline $\mathrm{T}_{13}$ & $\mathrm{~N}_{3} \mathrm{P}_{1} \mathrm{~K}_{2}$ & 4,0 & $\mathrm{~b}$ & 6,0 & 7 & 14 \\
\hline $\mathrm{T}_{14}$ & $\mathrm{~N}_{2} \mathrm{P}_{1} \mathrm{~K}_{3}$ & 4,1 & $\mathrm{ab}$ & 5,0 & 5 & 18 \\
\hline $\mathrm{T}_{15}$ & $\mathrm{~N}_{2} \mathrm{P}_{2} \mathrm{~K}_{2}$ & 4,2 & $a b$ & 4,6 & 31 & 23 \\
\hline$T_{16}$ & $\mathrm{~N}_{3} \mathrm{P}_{3} \mathrm{~K}_{3}$ & 4,0 & $b$ & 3,9 & 34 & 19 \\
\hline
\end{tabular}

Médias seguidas de mesma letra não diferem entre si estatisticamente pelo teste de Tukey ao nivel de $5 \%$ de probabilidade 


\subsection{Efeito da adubação nitrogenada, fosfatada e potássica no estado nutricional das plantas}

As Tabelas 10 e 11 apresentam, valores do teste $\mathrm{F}$ das regressões, médias gerais de todas as parcelas dos tratamentos e coeficientes de variação referente aos teores de nutrientes encontrados nas folhas, coletadas em fevereiro de 1996, quando as plantas estavam com 12 anos de idade. Observa-se que a adubação nitrogenada aumentou linearmente os teores de N, Ca e B nas folhas. A adubação fosfatada aumentou linearmente os teores de $\mathrm{N}, \mathrm{Ca}, \mathrm{Cu}$ e $\mathrm{Mn}$, e a adubação potássica incrementou linearmente os teores de $\mathrm{K}, \mathrm{Mg}, \mathrm{Cu}$ e $\mathrm{Mn}$.

O estabelecimento de faixas adequadas de concentração de macronutrientes e micronutrientes nas folhas da seringueira tem sido sugerida por diversos autores (Tabela 12). Para efeito de comparação e discussão dos resultados encontrados no presente estudo, elaborou-se a tabela 13 caracterizando faixas adequadas de concentração de macronutrientes, contidos nas folhas da seringueira na fase de produção, adaptada dos valores pré estabelecidos por Bataglia \& Cardoso (1990), Malavolta et al. (1989) e Shorrocks (1979). 
Tabela 10. Valores do teste $\mathrm{F}$ das regressões, médias gerais e coeficientes de variação, dos teores de macronutrientes nas folhas de seringueiras com 12 anos de idade.

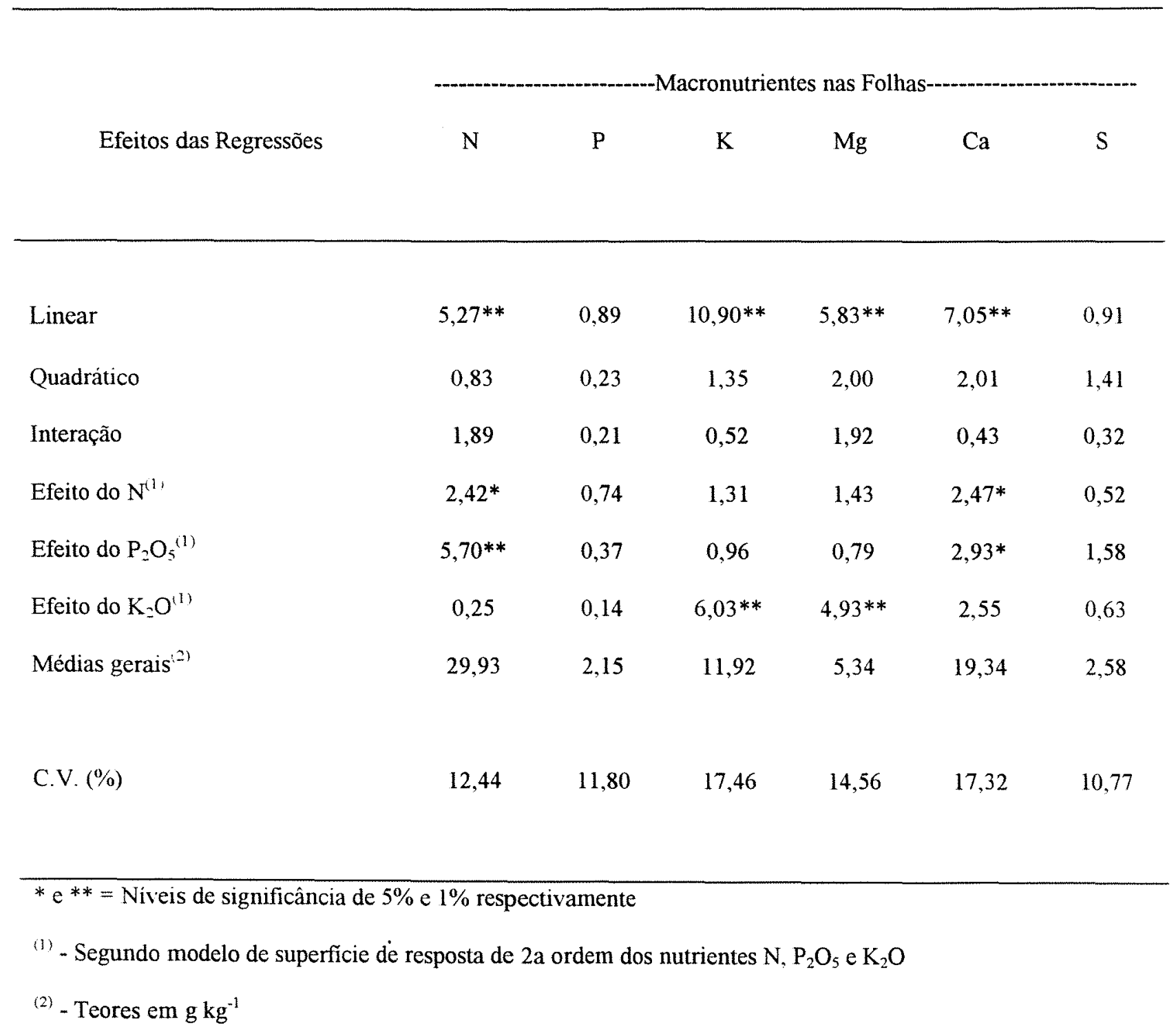


Tabela 11. Valores do teste $\mathrm{F}$ das regressões, médias gerais e coeficientes de variação, dos teores de micronutrientes nas folhas de seringueiras com 12 anos de idade

B

$\mathrm{Cu}$

$\mathrm{Fe}$

$\mathrm{Mn}$

Zn

\begin{tabular}{lccccc}
\hline Linear & 1,40 & $3,40^{*}$ & 0,87 & $3,40^{*}$ & 1,57 \\
Quadrático & 0,33 & 0,73 & 1,12 & 1,92 & $2,91^{*}$ \\
Interação & $3,30^{*}$ & 1,01 & 0,49 & 1,60 & 0,34 \\
Efeito do $\mathrm{N}^{(1)}$ & $2,64^{*}$ & 1,20 & 1,15 & 1,05 & 1,92 \\
Efeito do $\mathrm{P}_{2} \mathrm{O}_{5}^{(1)}$ & 0,48 & 0,96 & 0,44 & $3,32^{*}$ & 1,22 \\
Efeito do $\mathrm{K}_{2} \mathrm{O}^{(1)}$ & 1,88 & $3,51^{*}$ & 1,21 & $2,86^{*}$ & 2,09 \\
Médias gerais & & & & & \\
& 22,77 & 10,81 & 177,97 & 561,22 & 146,51 \\
C.V. (\%) & & & & & \\
& 20,15 & 9,34 & & 18,90 & 40,28 \\
\hline
\end{tabular}

${ }^{*} \mathrm{e}^{* *}=$ Niveis de significância de $5 \%$ e $1 \%$ respectivamente

(1) - Segundo modelo de superficie de resposta de $2 \mathrm{a}$ ordem dos nutrientes $\mathrm{N}, \mathrm{P}_{2} \mathrm{O}_{5}$ e $\mathrm{K}_{2} \mathrm{O}$

(2) - Teores em $\mathrm{mg} \mathrm{kg}^{-1}$ 

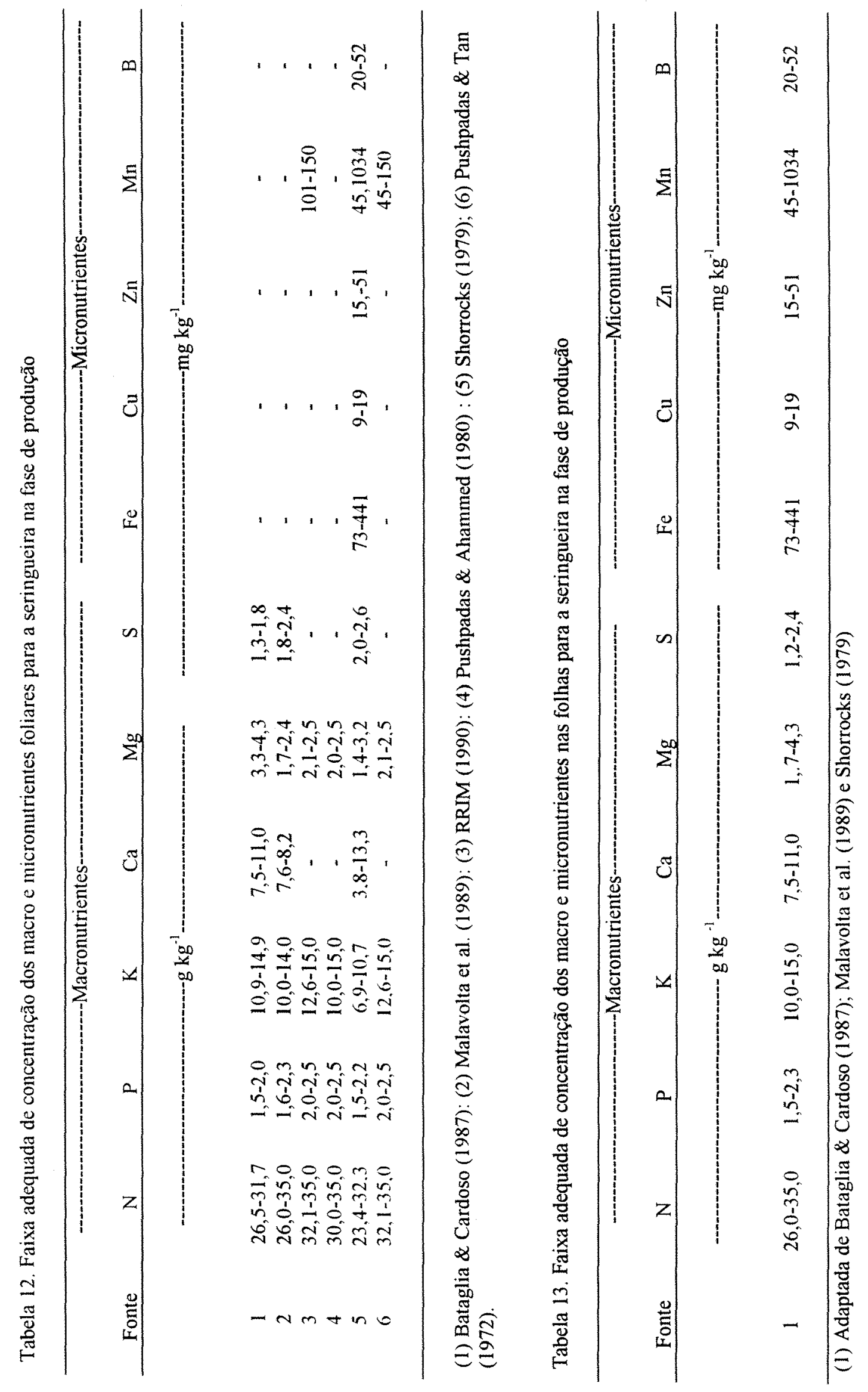
A figura 5A ilustra a elevação significativa dos teores foliar de $\mathrm{N}$ pelas doses de $\mathrm{N}$ aplicadas ao solo. Embora este efeito seja crescente, se verifica que houve um pequeno decréscimo no teor de $\mathrm{N}$ foliar na maior dose de $\mathrm{N}$.

A Figura 5B demonstra a significativa diminuição dos teores de $\mathrm{Ca}$ foliar, com aumento das doses de $\mathrm{N}$ aplicadas ao solo o que não concorda com Malavolta. (1989). Quando se analisou o solo foi verificado que as doses de $\mathrm{N}$ provocaram diminuição dos teores de Ca disponíveis, devendo ser este o provável motivo para a explicação de tal fato.

A Figura 5C, que apresenta o efeito das doses de superfosfato simples aplicadas no solo, mostra aumento dos teores de $\mathrm{Ca}$ nas folhas, devido aos altos teores de $\mathrm{Ca}$ contidos neste fertilizante, concordando com EMBRAPA (1979), que observou que a aplicação de $\mathrm{P}$ no solo na forma de super fosfato simples aumenta o teor foliar de Ca.

Analisando os teores de Mn na planta, se observou que houve um incremento significativo dos seus teores, com incremento da adubação fosfatada (Figura 5D).

Os teores de $\mathrm{K}$ foliar foram afetados significativamente pelas doses de $\mathrm{K}$ aplicadas ao solo, observando uma elevação dos mesmos, (Figura 6A). Esta mesma adubação provocou diminuição dos teores de $\mathrm{Mg}$ foliar (Figura 6B), concordando com Malavolta (1989), Explica-se a inibição competitiva entre o Mg e K, que é provocada quando dois nutrientes competem pelo mesmo sítio ativo do carregador. Estudos realizados por Malavolta 1989, demonstram que um excesso de potássio no meio pode causar carência de cálcio e magnésio. Falcão (1996), observou que doses crescentes de potássio reduziu as concentrações de $\mathrm{Ca}$ e $\mathrm{Mg}$ contidas nas folhas das seringueiras com onze anos de idade. Este antagonismo entre potássio e magnésio na cultura da seringueira, tem sido mencionado por diversos pesquisadores, enfatizando a redução do $\mathrm{Mg}$ nas folhas, principalmente nos maiores níveis de K (Viegas, 1985) Os teores de $\mathrm{Cu}$ foliar aumentaram de forma linear com as doses de potássio aplicadas. 

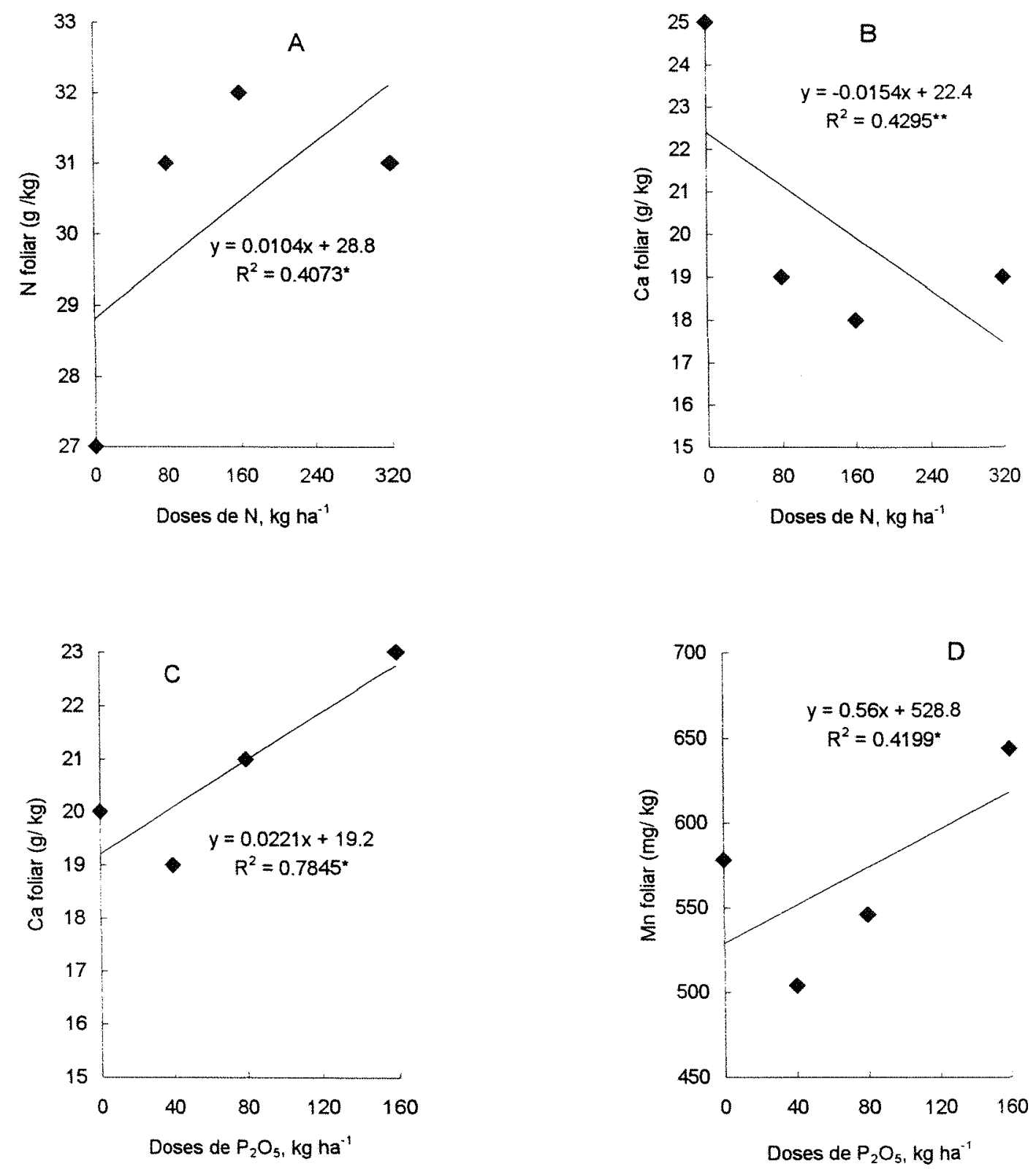

Figura 5 - Efeito da adubação nitrogenada no teor foliar de $\mathrm{N}(\mathrm{A})$ e $\mathrm{Ca}(\mathrm{B})$, e o efeito da adubação fosfatada no teor foliar de $\mathrm{Ca}$ ( C ) e de $\mathrm{Mn}$ (D). 

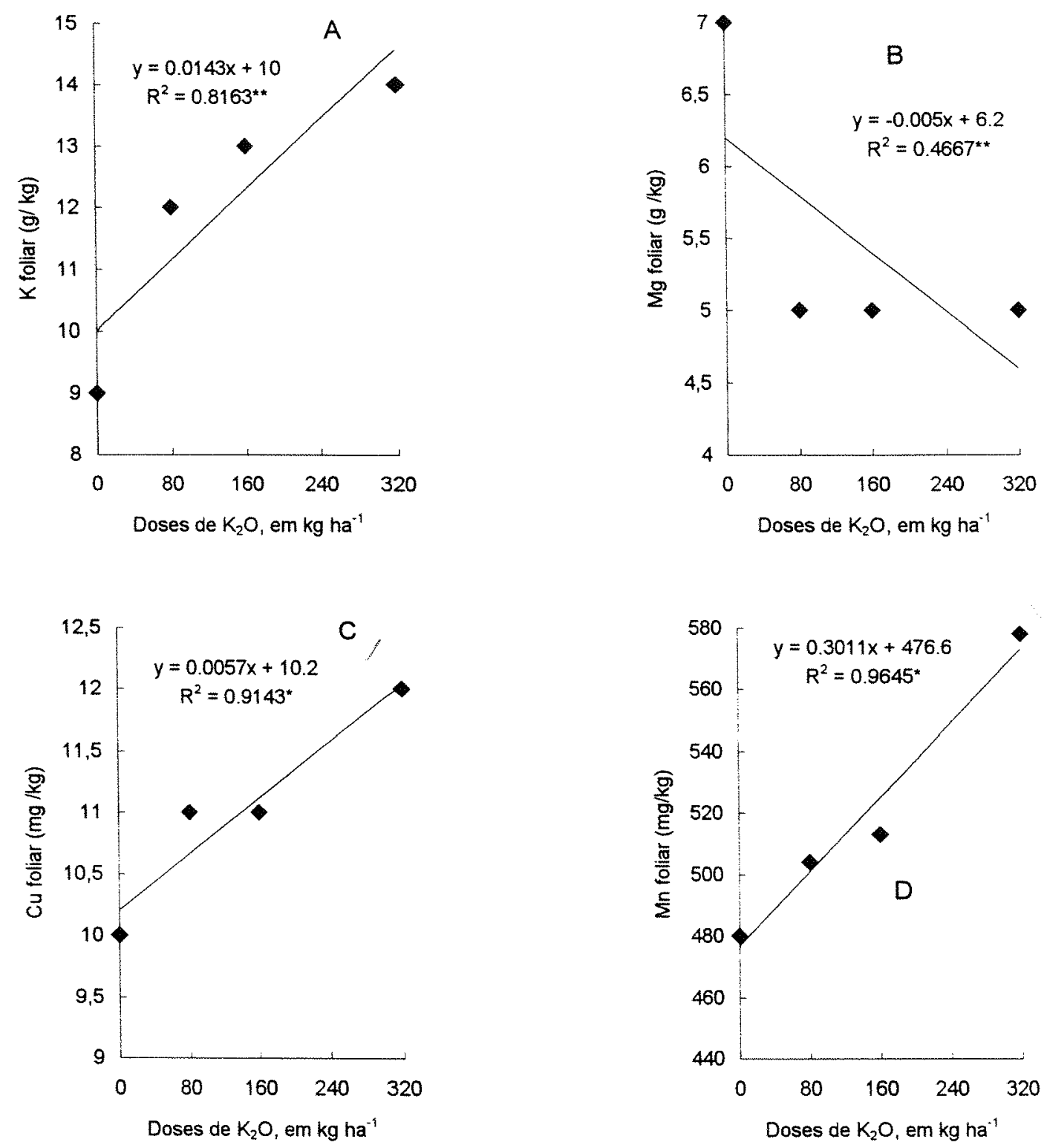

Figura 6. Efeito de adubação potássica nos teores foliares de $\mathrm{K}(\mathrm{A}), \mathrm{Mg}(\mathrm{B}), \mathrm{Cu}(\mathrm{C})$ e $\mathrm{Mn}(\mathrm{D})$. 
As Tabelas 14 e 15, apresentam os resultados do teste de Tukey ao nível de $5 \%$, para os teores foliares dos macro e micronutrientes, respectivamente. Os teores de $\mathrm{N}$ foliar foram afetados significativamente pela adubação nitrogenada, e os teores médios de $\mathrm{N}$ encontrados em todos os tratamentos estão dentro da faixa adequada que varia de 26 a $35 \mathrm{~g} \mathrm{~kg}^{-1}$, mesmo no $\mathrm{T}_{9}\left(\mathrm{~N}_{1} \mathrm{P}_{3} \mathrm{~K}_{1}\right)$ e no $\mathrm{T}_{13}\left(\mathrm{~N}_{3} \mathrm{P}_{1} \mathrm{~K}_{2}\right)$ onde se verificou o menor teor foliar, conforme tabelas elaboradas por Bataglia \& Cardoso (1990), Malavolta et al. (1989), RRIM (1990), Pushpadas \& Ahammed (1980), Shorrocks (1979).

Pusparajah \& Tan (1972) verificaram aumento da produção de borracha com a aplicação de fertilizantes nitrogenados, quando os teores foliares de $\mathrm{N}$ estavam na faixa de $35-37 \mathrm{~g} \mathrm{~kg}^{-1}$ para o clone GT1 e $35 \mathrm{~g} \mathrm{~kg}^{-1}$ para o clone Tjir 1

Viegas (1985) encontrou valores de $\mathrm{N}$ foliar na faixa de $29,7-33,6 \mathrm{~g} / \mathrm{kg}$ em mudas de seringueiras com 220 dias de idade.

Os teores médios de $\mathrm{P}$ foliares não apresentaram diferenças significativas pelo teste de Tukey e em todos os tratamentos se observou nivel adequado do nutriente nas folhas segundo interpretação conforme Tabela 13.

Em estudo realizado por Bataglia \& Cardoso (1987), onde se fez um levantamento do estado nutricional dos seringais do estado de São Paulo, verificou-se que os teores foliares de $\mathbf{P}$ encontrados nas amostras colhidas em seringal plantados no mesmo tipo de solo ( $\mathrm{Pml}$ ), estão no nível de $1,7 \mathrm{mg} \mathrm{kg}^{-1}$, o que é menor aos encontrados neste trabalho (Tabela 14).

Falcão, (1996) observou que os teores foliares de $\mathrm{P}$ foram afetados pela adubação nitrogenada, provocando um decréscimo do mesmo. Entretanto, Berniz (1987), observou valores mais elevados de $\mathrm{P}$ nas folhas para o tratamento que recebeu adubação nitrogenada. 
Tabela 14. Influência dos tratamentos sobre os teores de macronutrientes em folhas de seringueira amostradas em fevereiro de 1996.

\begin{tabular}{|c|c|c|c|c|c|c|c|c|c|c|c|}
\hline & & \multicolumn{10}{|c|}{ Macronutrientes nas Folhas } \\
\hline & & \multicolumn{2}{|l|}{$\mathrm{N}$} & $\mathrm{P}$ & \multicolumn{2}{|l|}{$\mathrm{K}^{+}$} & \multicolumn{2}{|l|}{$\mathrm{Ca}^{++}$} & \multicolumn{2}{|l|}{$\mathrm{Mg}^{++}$} & $\mathrm{S}$ \\
\hline $\mathrm{T}_{1}$ & $\mathrm{~N}_{0} \mathrm{P}_{0} \mathrm{~K}_{0}$ & 31 & $a b$ & 2,2 & 10 & $a b$ & 17 & $a b$ & 6 & $\mathrm{ab}$ & 2,7 \\
\hline $\mathrm{T}_{4}$ & $\mathrm{~N}_{0} \mathrm{P}_{1} \mathrm{~K}_{1}$ & 27 & $a b$ & 2,1 & 10 & b & 25 & $\mathrm{a}$ & 5 & $\mathrm{ab}$ & 2,6 \\
\hline $\mathrm{T}_{5}$ & $\mathrm{~N}_{1} \mathrm{P}_{1} \mathrm{~K}_{1}$ & 31 & $a b$ & 2,2 & 12 & $a b$ & 19 & $a b$ & 5 & $\mathrm{ab}$ & 2,7 \\
\hline $\mathrm{T}_{6}$ & $\mathrm{~N}_{2} \mathrm{P}_{1} \mathrm{~K}_{1}$ & 32 & $a b$ & 2,2 & 12 & $a b$ & 18 & $a b$ & 5 & $a b$ & 2,5 \\
\hline $\mathrm{T}_{7}$ & $\mathrm{~N}_{3} \mathrm{P}_{1} \mathrm{~K}_{1}$ & 31 & $a b$ & 2,0 & 11 & $a b$ & 19 & $a b$ & 6 & $a b$ & 2,5 \\
\hline $\mathrm{T}_{3}$ & $\mathrm{~N}_{1} \mathrm{P}_{0} \mathrm{~K}_{\mathrm{I}}$ & 30 & $a b$ & 2,1 & 12 & $a b$ & 20 & $a b$ & 5 & $a b$ & 2,4 \\
\hline $\mathrm{T}_{5}$ & $\mathrm{~N}_{1} \mathrm{P}_{1} \mathrm{~K}_{1}$ & 31 & $a b$ & 2,2 & 12 & $a b$ & 19 & $a b$ & 5 & $a b$ & 2,7 \\
\hline $\mathrm{T}_{8}$ & $\mathrm{~N}_{1} \mathrm{P}_{2} \mathrm{~K}_{3}$ & 31 & $a b$ & 2,5 & 12 & $a b$ & 21 & $a b$ & 6 & $a b$ & 2,7 \\
\hline $\mathrm{T}_{9}$ & $\mathrm{~N}_{1} \mathrm{P}_{3} \mathrm{~K}_{1}$ & 28 & $\mathrm{~b}$ & 2,2 & 11 & $a b$ & 23 & $a b$ & 6 & $a b$ & 2,6 \\
\hline $\mathrm{T}_{2}$ & $\mathrm{~N}_{1} \mathrm{P}_{1} \mathrm{~K}_{0}$ & 30 & $a b$ & 2,0 & 9 & b & 22 & $\mathbf{a}$ & 7 & a & 2,8 \\
\hline $\mathrm{T}_{5}$ & $\mathrm{~N}_{1} \mathrm{P}_{1} \mathrm{~K}_{1}$ & 31 & $a b$ & 2,2 & 12 & $a b$ & 19 & $a b$ & 5 & $a b$ & 2,7 \\
\hline$T_{10}$ & $\mathrm{~N}_{1} \mathrm{P}_{1} \mathrm{~K}_{2}$ & 30 & $a b$ & 2,3 & 13 & $a b$ & 20 & $a b$ & 5 & $a b$ & 2,7 \\
\hline $\mathrm{T}_{11}$ & $\mathrm{~N}_{1} \mathrm{P}_{1} \mathrm{~K}_{3}$ & 31 & $a b$ & 2,1 & 14 & $a b$ & 18 & $a b$ & 5 & $a b$ & 2,6 \\
\hline$T_{12}$ & $\mathrm{~N}_{2} \mathrm{P}_{1} \mathrm{~K}_{2}$ & 30 & $a b$ & 2,1 & 13 & $a b$ & 21 & $a b$ & 5 & $a b$ & 2,6 \\
\hline$T_{13}$ & $\mathrm{~N}_{3} \mathrm{P}_{1} \mathrm{~K}_{2}$ & 32 & $\mathrm{a}$ & 2,1 & 10 & $\mathrm{~b}$ & 17 & $a b$ & 5 & $a b$ & 2,5 \\
\hline $\mathrm{T}_{14}$ & $\mathrm{~N}_{2} \mathrm{P}_{1} \mathrm{~K}_{3}$ & 31 & $a b$ & 2,2 & 16 & $\mathrm{a}$ & 15 & $b$ & 5 & $a b$ & 2.6 \\
\hline $\mathrm{T}_{15}$ & $\mathrm{~N}_{2} \mathrm{P}_{2} \mathrm{~K}_{2}$ & 29 & $a b$ & 2,2 & 12 & $a b$ & 19 & $a b$ & 5 & $a b$ & 2,6 \\
\hline $\mathrm{T}_{16}$ & $\mathrm{~N}_{3} \mathrm{P}_{3} \mathrm{~K}_{3}$ & 31 & $a b$ & 2,1 & 14 & $a b$ & 17 & $a b$ & 4 & $\mathrm{~b}$ & 2.5 \\
\hline
\end{tabular}

Médias seguidas de mesma letra não diferem entre si estatisticamente pelo teste de Tukey ao nível de 5\% de probabilidade 
Tabela 15. Influência dos tratamentos sorb os teores de micronutrientes em folhas de seringueira amostradas em fevereiro de 1996.

\begin{tabular}{|c|c|c|c|c|c|c|c|}
\hline & & \multicolumn{6}{|c|}{ Micronutrientes nas Folhas } \\
\hline & & $\mathrm{B}$ & $\mathrm{Cu}$ & $\mathrm{Fe}$ & $\mathrm{Mn}$ & $\mathrm{Zn}$ & \\
\hline $\mathrm{T}_{1}$ & $\mathrm{~N}_{0} \mathrm{P}_{0} \mathrm{~K}_{0}$ & 21 & 11 & 151 & 460 & 103 & $\mathrm{~b}$ \\
\hline $\mathrm{T}_{4}$ & $\mathrm{~N}_{0} \mathrm{P}_{1} \mathrm{~K}_{1}$ & 26 & 10 & 221 & 616 & 245 & $\mathrm{a}$ \\
\hline$T_{5}$ & $N_{1} P_{1} K_{1}$ & 22 & 11 & 212 & 504 & 150 & $a b$ \\
\hline$T_{6}$ & $\mathrm{~N}_{2} \mathrm{P}_{1} \mathrm{~K}_{1}$ & 25 & 11 & 164 & 519 & 123 & $a b$ \\
\hline $\mathrm{T}_{7}$ & $\mathrm{~N}_{3} \mathrm{P}_{1} \mathrm{~K}_{1}$ & 24 & 10 & 135 & 599 & 121 & $a b$ \\
\hline $\mathrm{T}_{3}$ & $\mathrm{~N}_{1} \mathrm{P}_{0} \mathrm{~K}_{1}$ & 23 & 10 & 190 & 578 & 158 & $a b$ \\
\hline $\mathrm{T}_{5}$ & $N_{1} P_{1} K_{1}$ & 22 & 11 & 212 & 504 & 150 & $a b$ \\
\hline $\mathrm{T}_{8}$ & $\mathrm{~N}_{1} \mathrm{P}_{2} \mathrm{~K}_{1}$ & 24 & 11 & 156 & 546 & 135 & $a b$ \\
\hline $\mathrm{T}_{9}$ & $\mathrm{~N}_{1} \mathrm{P}_{3} \mathrm{~K}_{1}$ & 24 & 11 & 186 & 644 & 178 & $a b$ \\
\hline$T_{2}$ & $\mathrm{~N}_{1} \mathrm{P}_{1} \mathrm{~K}_{0}$ & 23 & 10 & 166 & 480 & 129 & $a b$ \\
\hline$T_{5}$ & $\mathrm{~N}_{1} \mathrm{P}_{1} \mathrm{~K}_{1}$ & 22 & 11 & 212 & 504 & 150 & $a b$ \\
\hline $\mathrm{T}_{10}$ & $\mathrm{~N}_{1} \mathrm{P}_{1} \mathrm{~K}_{2}$ & 25 & 11 & 146 & 513 & 129 & $a b$ \\
\hline$T_{11}$ & $\mathrm{~N}_{1} \mathrm{P}_{1} \mathrm{~K}_{3}$ & 28 & 12 & 210 & 578 & 141 & $a b$ \\
\hline $\mathrm{T}_{12}$ & $\mathrm{~N}_{2} \mathrm{P}_{1} \mathrm{~K}_{2}$ & 22 & 11 & 205 & 678 & 193 & $a b$ \\
\hline $\mathrm{T}_{13}$ & $\mathrm{~N}_{3} \mathrm{P}_{1} \mathrm{~K}_{2}$ & 20 & 11 & 193 & 559 & 145 & $a b$ \\
\hline $\mathrm{T}_{14}$ & $\mathrm{~N}_{2} \mathrm{P}_{1} \mathrm{~K}_{3}$ & 21 & 13 & 134 & 443 & 87 & $\mathrm{~b}$ \\
\hline$T_{15}$ & $\mathrm{~N}_{2} \mathrm{P}_{2} \mathrm{~K}_{2}$ & 20 & 10 & 180 & 608 & 148 & $a b$ \\
\hline$T_{16}$ & $\mathrm{~N}_{3} \mathrm{P}_{3} \mathrm{~K}_{3}$ & 19 & 11 & 200 & 658 & 163 & $a b$ \\
\hline
\end{tabular}

Médias seguidas de mesma letra não diferem entre si estatisticamente pelo teste de Tukey ao nível de $5 \%$ de probabilidade 
Os teores médios de potássio foram afetados significativamente pela adubação potássica. Os maiores teores de $\mathrm{K}$ foram encontrados nos tratamentos $14\left(\mathrm{~N}_{2} \mathrm{P}_{1} \mathrm{~K}_{3}\right), 11\left(\mathrm{~N}_{1} \mathrm{P}_{1} \mathrm{~K}_{3}\right)$ e $16\left(\mathrm{~N}_{3} \mathrm{P}_{3} \mathrm{~K}_{3}\right) ; 16,14,14 \mathrm{~g} \mathrm{~kg}^{-1}$, respectivamente, e os menores teores foram encontrados nos tratamentos $4\left(\mathrm{~N}_{\mathrm{O}} \mathrm{P}_{1} \mathrm{~K}_{1}\right), 2\left(\mathrm{~N}_{1} \mathrm{P}_{1} \mathrm{~K}_{0}\right)$ e $13\left(\mathrm{~N}_{3} \mathrm{P}_{1} \mathrm{~K}_{2}\right) ; 10,9,13 \mathrm{~g} \mathrm{~kg}^{-1}$, respectivamente. Estes teores foliares de $\mathrm{K}$ encontrados estão dentro da faixa tida como adequada por Bataglia \& Cardoso, (1987), Malavolta et al. (1989), Shorrocks, (1979).

Bataglia \& Cardoso, (1987), fazendo um levantamento do estado nutricional das seringueiras no cultivadas estado de São Paulo, coletou folhas de seringueira cultivadas sob Pml e verificou que os teores médios de $\mathrm{K}$ eram de 13,0 g $\mathrm{kg}^{-1}$, teores estes encontrados somente nos tratamentos que receberam a dose de 160 e $320 \mathrm{~kg}$ de $\mathrm{K}_{2} \mathrm{O}$ ha $^{-1}$. O mesmo autor, comparando seringais com diferentes níveis de produtividade verificou que os nutrientes que possivelmente estão mais contribuindo para essas diferenças seriam o $\mathrm{N}$ e $\mathrm{K}$, pois seringais com produtividade abaixo de $1000 \mathrm{~kg} / \mathrm{ha}$ ano de borracha seca apresentaram níveis de $\mathrm{N}$ e $\mathrm{K}$ significativamente mais baixos que seringais com produção superior.

Os teores foliares de $\mathrm{Mg}$ foram reduzidos pela adubação (N P K), e o tratamento no qual este efeito foi mais evidente foi o $T_{16}\left(N_{3} P_{3} K_{3}\right)$. Segundo Malavolta et al.(1989), tal fato se deve a inibição competitiva entre $\mathrm{Mg}$, Ca e K no momento da absorção, e também em função do raio iônico destes elementos. Entretanto, os teores de Mg estão altos se considerados a tabela 13, com exceção do $\mathrm{T}_{16}$, que somente este tratamento se apresentou dentro da faixa adequada. Tal fato possa ser explicado, pela alta capacidade desta planta em absorver potássio do solo mesmo em baixas concentrações como no tratamentol (controle).

A relação $\mathrm{K} / \mathrm{Mg}$ média do experimento é de $2,23 / 1$, e a relação no $T_{16}$ foi de 2,5/1, que é abaixo da relação adequada 4,1/1, (Tabela 13). Verifica-se então que a adubação potássica não está afetando os teores foliar de $\mathrm{Mg}$. Os teores de $\mathrm{Ca}$ estão bem acima dos teores adequados para a cultura (Tabela 13). Observa-se pela Tabela 14 que os teores de $\mathrm{Ca}$ estão sendo mais influenciados pela adubação nitrogenada do que pela adubação com o supersimples, pois quando se usa doses 
baixas de $\mathrm{N}$ se observa altos teores de $\mathrm{Ca}$ foliar. $\mathrm{O}$ tratamento que apresentou $\mathrm{O}$ menor teor de Ca foliar foi o $\mathrm{T}_{14}\left(\mathrm{~N}_{2} \mathrm{P}_{1} \mathrm{~K}_{3}\right)$, e o tratamento que apresentou o maior teor foi o $\mathrm{T}_{4}\left(\mathrm{~N}_{0} \mathrm{P}_{1} \mathrm{~K}_{0}\right)$ e $\mathrm{T}_{2}\left(\mathrm{~N}_{1} \mathrm{P}_{1} \mathrm{~K}_{0}\right)$.

Os teores foliares de enxofre estão dentro da faixa adequada (Tabela 13). Não se verificou influência da adubação com superfosfato simples nos teores foliares de S, sendo esta a fonte de S utilizada. Falcão (1996), verificou aumento nos teores foliares de $\mathrm{S}$ em função da adubação fosfatada feita com superfosfato simples.

Os teores foliares dos micronutrientes não foram afetados pela adubação NPK, e todos estão dentro da faixa adequada (Tabela 13), com exceção do Zn que se apresenta acima dos teores adequados para a seringueira (Tabela 15). 


\subsection{Efeito da adubação nitrogenada, fosfatada e potássica no perímetro do caule e na espessura da casca do caule da seringueira.}

$\mathrm{Na}$ Tabela 16 encontram-se os valores do teste $\mathrm{F}$, médias gerais e coeficientes de variação do perímetro do caule e da espessura da casca medidos aos 12 anos e aos 13 anos de idade da seringueira.

A adubação potássica promoveu um efeito linear no desenvolvimento do caule e na espessura da casca aos 12 anos ao nível de $10 \%$, não se observou efeito da adubação nitrogenada e fosfatada. Adicionalmente, Pusparajah et al. (1983) observaram que a adubação nitrogenada aplicada sem adubação potássica reduziu o desenvolvimento e a produção e, Syvanadian et al. (1975) observaram que a carência de potássio na fase de desenvolvimento pode limitar a área foliar e reduzir a atividade fotossintética das folhas, resultando em um incremento mais lento da circunferência do caule.

Quanto a adubação fosfatada e nitrogenada as respostas observadas neste trabalho, diferem das encontradas por Kalan(1970), Pannoje \& Potty (1975), Kitamura (1992), que encontraram resposta a adubação fosfatada no desenvolvimento da seringueira.

A taxa de desenvolvimento do tronco deste seringal em $\mathrm{cm} / \mathrm{ano}$, a partir do $4^{\circ}$ ano de idade, pode ser observada na figura 7 , onde verifica-se um desenvolvimento mais intenso nos primeiros anos após a instalação do experimento e que o mesmo decresce a medida que a seringueira foi ficando mais velha. Analisando a figura podem-se observar dois padrões de crescimento, sendo um até o oitavo ano, onde o crescimento médio do $4^{\underline{0}}$ ao $8^{\underline{o}}$ ano foi de $8,5 \mathrm{~cm} / \mathrm{ano}$ e do $8^{\circ}$ ao $13^{0}$ um crescimento médio do tronco de $2,9 \mathrm{~cm} /$ ano. Esse resultado pode ser atribuído ao fato da seringueira, responder mais nos primeiros anos após a instalação do experimento, por não ter sido adubada nos primeiros 4 anos, bem como, após a entrada em sangria, a planta passar a deslocar nutrientes para a produção em prejuízo do crescimento. 
Tabela 16. Valores do teste $\mathrm{F}$ das regressões, médias gerais e coeficientes de variação referente a espessura de casca e circunferência do tronco.

Efeitos das Regressões Tronco 12 anos Casca 12 anos Tronco 13 anos Casca 13 anos

\begin{tabular}{lcccc}
\hline & $6,28^{* * *}$ & $3,19^{* *}$ & $3,63^{* *}$ & $2,43^{*}$ \\
Efeito linear & 1,46 & 0,42 & 0,65 & 1,16 \\
Efeito quadrático & 0,05 & 0,81 & 0,04 & 0,97 \\
Interação & 0,29 & 1,25 & 0,63 & $1,95^{*}$ \\
Efeito $\mathrm{N}^{(1)}$ & 1,14 & 0,65 & 0,62 & 0,95 \\
Efeito $\mathrm{P}_{2} \mathrm{O}_{5}{ }^{(1)}$ & $2,13^{*}$ & $1,71^{*}$ & 0,84 & $1,96^{*}$ \\
Efeito $\mathrm{K}_{2} \mathrm{O}^{(1)}$ & & & & 7,77 \\
& 62,90 & 7,11 & 64,44 & 3,64 \\
Média gerais & & & \\
C.V. $(\%)$ & 4,83 & 5,32 & 4,20 & \\
& & & & \\
\hline
\end{tabular}

${ }^{*},{ }^{* *} \mathrm{e}^{* * *}$ - nivel de significância de $10 \%, 5 \%$ e $1 \%$ respectivamente

(1) - Segundo modelo de superfície de resposta de $2^{\mathrm{a}}$ ordem nos nutrientes $\mathrm{N}, \mathrm{P}_{2} \mathrm{O}_{5}$ e $\mathrm{K}_{2} \mathrm{O}$

(2) - Médias gerais: tronco e casca $(\mathrm{cm})$ 
A Figura 8a ilustra o desenvolvimento da espessura da casca em relação as doses de $\mathrm{K}_{2} \mathrm{O}$ aplicadas no solo. Este aumento de espessura de casca é muito importante, pois é um dos principais parâmetros que se correlaciona com a produção das plantas. O desenvolvimento da espessura da casca do caule da seringueira tem uma relação direta com o aumento do número e do tamanho nos vasos laticíferos, além da reserva de amido, fatores esses que influenciam o potencial produtivo das plantas.

Syvanadian (1975) relatou a importância da adubação da seringueira ressaltando que embora as plantas adubadas e não adubadas apresentavam produções diferentes mesmo com valores equivalentes do crescimento do tronco. Tal fenômeno foi justificado pelo fato das plantas apresentarem o tamanho e o número de vasos laticíferos, além da reserva de amido contido na casca, totalmente diferentes.

Considerando que os 16 tratamentos constituem 16 formulações diferentes, e visando obter-se maiores informações agronômicas, procedeu-se o teste de Tukey ao nivel de $5 \%$ de probabilidade. A Tabela 17 apresenta estes resultados para os valores da espessura de casca e do perímetro do tronco aos 12 e 13 anos após o plantio da seringueira. Não se constatou diferenças estatísticas, mas se observou que a maior espessura de casca e o maior perímetro do tronco foi encontrado no tratamento $11\left(\mathrm{~N}_{1} \mathrm{P}_{1} \mathrm{~K}_{3}\right)$ aos 12 anos de idade. Aos 13 anos de idade este tratamento apresentou a maior espessura de casca.

Por outro lado, a análise de regressão, realizada para as doses crescentes de nitrogênio, fósforo e potássio, mostraram que as doses de nitrogênio e fósforo não influenciaram de forma significativa o perímetro do caule e a espessura de casca das plantas. Entretanto, a Figura 8A ilustra o desenvolvimento da espessura da casca em função das doses crescentes de $\mathrm{K}_{2} \mathrm{O}$ e a Figura $8 \mathrm{~B}$ ilustra o perímetro do caule influenciado pela adubação potássica na seringueira aos 12 e 13 anos. Nota-se um efeito mais pronunciado da adubação potássica no perímetro do tronco, que na espessura da casca. 
Analisando os dados de espessura de casca e perímetro do tronco, verifica-se que a adubação potássica influenciou positivamente o incremento destes parâmetros.

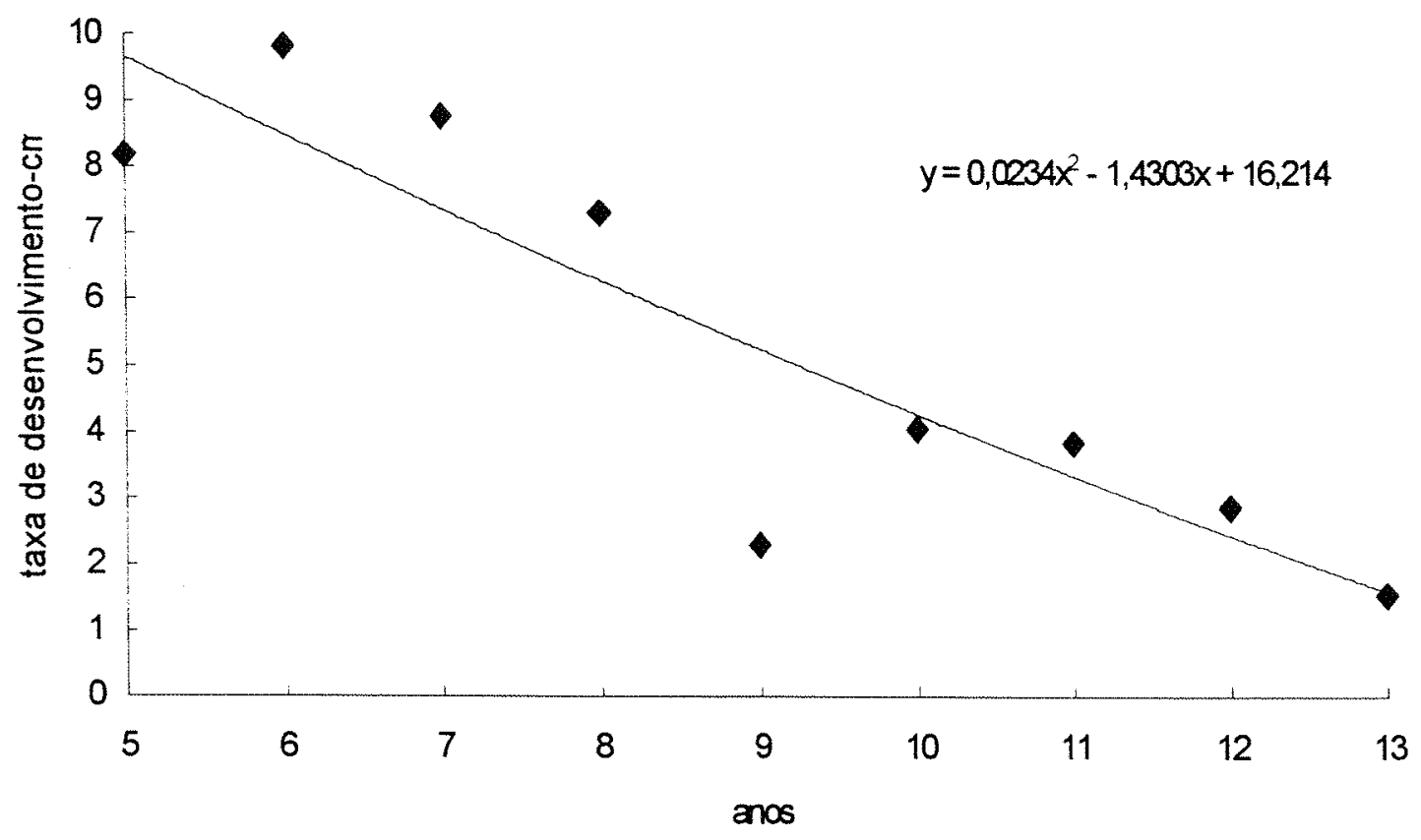

Figura 7. Taxa de desenvolvimento da seringueira em função dos anos 

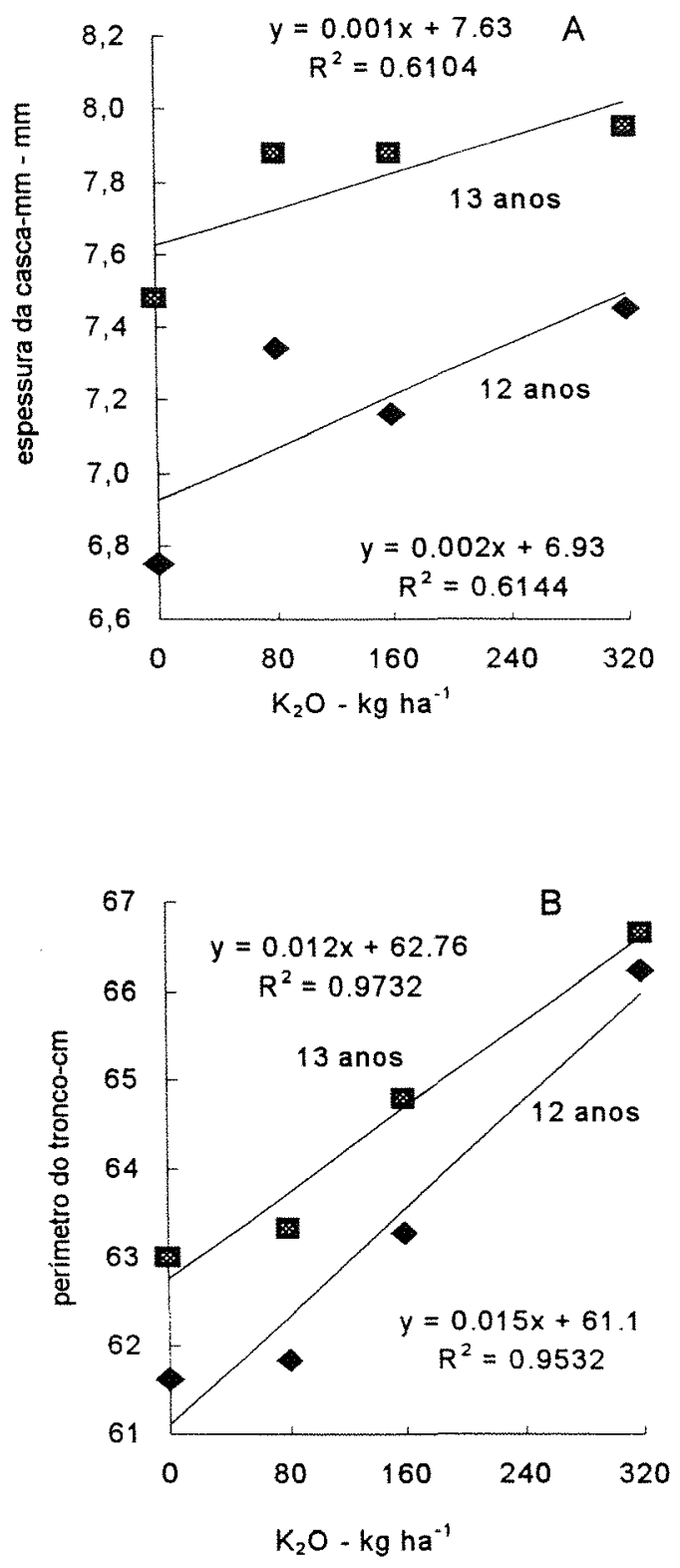

Figura 8. Influência da adubação potássica nos parâmetros (A) espessura de casca e (B) perímetro do tronco. 
Tabela 17. Médias gerais dos valores referentes a espessura de casca e perímetro do tronco (medidas Fevereiro /96 e fevereiro /97)

\begin{tabular}{llcccc}
\hline Tratamentos & $\begin{array}{c}\text { Espessura de } \\
\text { casca }\end{array}$ & $\begin{array}{c}\text { Perímetro do } \\
\text { tronco }\end{array}$ & $\begin{array}{c}\text { Espessura de } \\
\text { casca }\end{array}$ & $\begin{array}{c}\text { Perímetro de } \\
\text { tronco }\end{array}$ \\
\hline $\mathrm{T}_{1}$ & $\mathrm{~N}_{0} \mathrm{P}_{0} \mathrm{~K}_{0}$ & $\mathrm{~mm}$ & $\mathrm{~cm}$ & $\mathrm{~mm}$ & $\mathrm{~cm}$ \\
& & 7,16 & 58,71 & 7,85 & 62,83 \\
$\mathrm{~T}_{4}$ & $\mathrm{~N}_{0} \mathrm{P}_{1} \mathrm{~K}_{1}$ & 7,11 & 61,71 & 7,88 & 63,25 \\
$\mathrm{~T}_{5}$ & $\mathrm{~N}_{1} \mathrm{P}_{1} \mathrm{~K}_{1}$ & 7,34 & 61,83 & 7,88 & 63,33 \\
$\mathrm{~T}_{6}$ & $\mathrm{~N}_{2} \mathrm{P}_{1} \mathrm{~K}_{1}$ & 6,98 & 63,90 & 7,68 & 66,53 \\
$\mathrm{~T}_{7}$ & $\mathrm{~N}_{3} \mathrm{P}_{1} \mathrm{~K}_{1}$ & 6,92 & 62,50 & 7,55 & 64,25 \\
& & & & & \\
$\mathrm{~T}_{3}$ & $\mathrm{~N}_{1} \mathrm{P}_{0} \mathrm{~K}_{1}$ & 6,98 & 59,75 & 7,65 & 61,75 \\
$\mathrm{~T}_{5}$ & $\mathrm{~N}_{1} \mathrm{P}_{1} \mathrm{~K}_{1}$ & 7,34 & 61,83 & 7,88 & 63,33 \\
$\mathrm{~T}_{8}$ & $\mathrm{~N}_{1} \mathrm{P}_{2} \mathrm{~K}_{1}$ & 7,34 & 63,08 & 7,95 & 64,95 \\
$\mathrm{~T}_{9}$ & $\mathrm{~N}_{1} \mathrm{P}_{3} \mathrm{~K}_{1}$ & 6,92 & 61,77 & 7,55 & 62,83 \\
& & & & & \\
$\mathrm{~T}_{2}$ & $\mathrm{~N}_{1} \mathrm{P}_{1} \mathrm{~K}_{0}$ & 6,75 & 61,61 & 7,48 & 63,00 \\
$\mathrm{~T}_{5}$ & $\mathrm{~N}_{1} \mathrm{P}_{1} \mathrm{~K}_{1}$ & 7,34 & 61,83 & 7,88 & 63,33 \\
$\mathrm{~T}_{10}$ & $\mathrm{~N}_{1} \mathrm{P}_{1} \mathrm{~K}_{2}$ & 7,16 & 63,27 & 7,88 & 64,78 \\
$\mathrm{~T}_{11}$ & $\mathrm{~N}_{1} \mathrm{P}_{1} \mathrm{~K}_{3}$ & 7,45 & 66,23 & 7,95 & 66,65 \\
& & & & & \\
$\mathrm{~T}_{12}$ & $\mathrm{~N}_{2} \mathrm{P}_{1} \mathrm{~K}_{2}$ & 7,07 & 63,19 & 7,80 & 64,75 \\
$\mathrm{~T}_{13}$ & $\mathrm{~N}_{3} \mathrm{P}_{1} \mathrm{~K}_{2}$ & 6,91 & 65,19 & 7,75 & 66,77 \\
$\mathrm{~T}_{14}$ & $\mathrm{~N}_{2} \mathrm{P}_{1} \mathrm{~K}_{3}$ & 7,26 & 64,29 & 7,85 & 64,78 \\
$\mathrm{~T}_{15}$ & $\mathrm{~N}_{2} \mathrm{P}_{2} \mathrm{~K}_{2}$ & 7,12 & 63,90 & 7,80 & 64,00 \\
$\mathrm{~T}_{16}$ & $\mathrm{~N}_{3} \mathrm{P}_{3} \mathrm{~K}_{3}$ & 7,43 & 65,50 & 7,85 & 66,57 \\
\hline
\end{tabular}

Médias seguidas de mesma letra não diferem entre si estatisticamente pelo teste de Tukey ao nível de $5 \%$ de probabilidade 


\subsection{Flutuação mensal da produção de borracha seca}

A Figura 9, apresenta a flutuação da produtividade média mensal de borracha seca de todos os tratamentos, em gramas por planta, no período de outubro de 1995 a junho de 1996. Nos meses de agosto e setembro de 1995 as plantas não foram sangradas, devido a desfolha natural das plantas e ao novo reenfolhamento. Nos meses de outubro e novembro a produção está em fase de crescimento, enquanto no mês de dezembro observou-se uma queda da mesma, fato este que se deve a alta pluviosidade deste mês, nesta região, não permitindo que se realizasse as sangrias. Nos demais meses não ocorreu perda da produção devido as chuvas.

Entretanto, ao analisar a Figura 10, onde a demonstração da produtividade é em gramas por planta em cada sangria, verifica-se que a produção é crescente de outubro a fevereiro, e de fevereiro a abril esta se mantém alta, voltando a diminuir nos meses de maio e junho, sendo que neste último mês e encerrou-se a sangria. A queda prematura de folhas ocorrido neste ano, se deve principalmente ao ataque de ácaro.

Segundo Bernardes et al.(1990), variações na produção de látex, ocorrem de dia para dia, e quando a árvore é sangrada em horas diferentes do dia. Tais variações podem ser atribuídas à mudanças nas condições ambientais. Quando a variação de produtividade é considerada por períodos maiores, efeitos sazonais relacionados às condições climáticas bem como a idade das folhas e a densidade da copa, passam a ser importantes. O mesmos autores concluiram que a correlação entre produtividade e densidade da copa foi perturbada pelo estádio de desenvolvimento das folhas e que o período de maior depressão da produção foi quando as folhas novas estavam se desenvolvendo e consequentemente competindo por fotossintetizados.

Cunha (1963), observou que as menores produções mensais foram verificadas quando as árvores, depois da queda de folhas iniciam a nova brotação, o que ocorreu em setembro, na região de Campinas. 


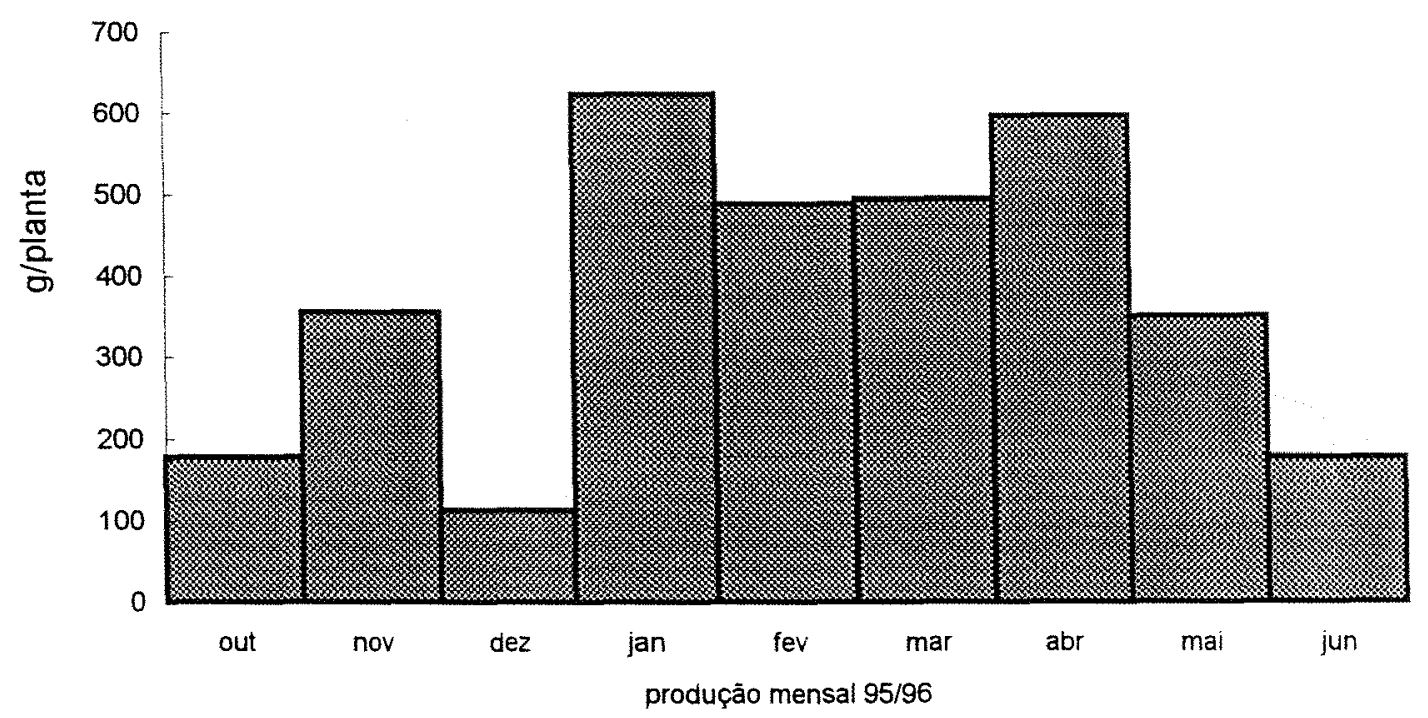

Figura 9. Variação da produção mensal em gramas de borracha seca por planta durante o ano agrícola de $95 / 96$

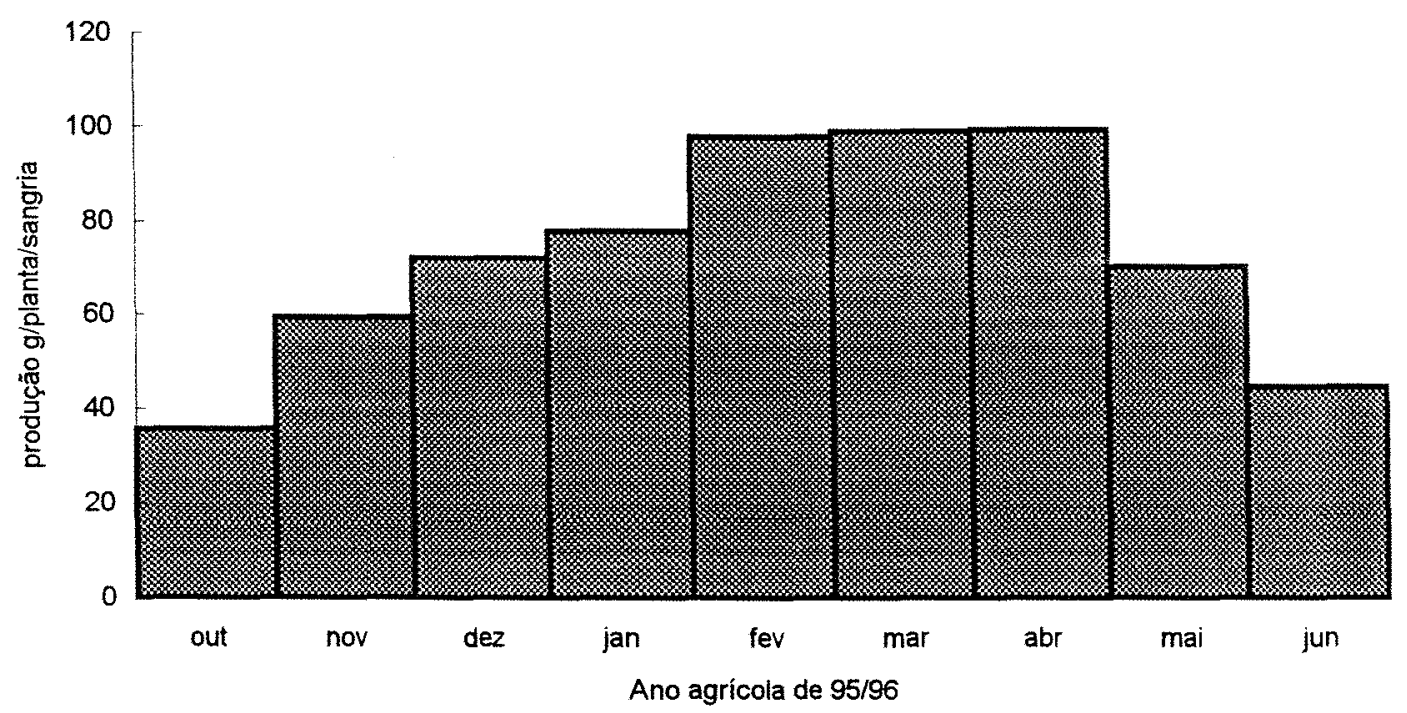

Figura 10. Variação da produção média de borracha seca em $\mathrm{g} / \mathrm{planta} / \mathrm{sangria}$ durante o ano agrícola de $95 / 96$, no sistema $\mathrm{S} / 2, \mathrm{~d} / 4,6 \mathrm{~d} / 7$ 
Martinez (1970) e Cortez (1986) verificaram que a produtividade mensal da seringueira teve uma variação semelhante àquela apresentada na Figura 10

Para Tonnelier \& Gener $^{3}$ (1979) citados porBernardes 1990, um período de descanso anual não implica em perda de produtividade. Os citados anteriores mostraram que dois meses de descanso durante o período de desfolhamento $\mathrm{e}$ enfolhamento, ou outro período, tal como durante a época de chuvas intensas, quando a sangria é normalmente interrompida, há um efeito positivo a longo prazo, na produtividade e no estado geral das plantas.

\subsection{Influência da adubação NPK na produtividade de borracha seca e exportação de nutrientes}

A Tabela 18 apresenta os valores do teste $\mathrm{F}$ da regressão, coeficiente de variação e a produtividade média mensal em g/planta no ano agrícola 95/96 Analisando estes dados, verifica-se que houve efeito quadrático da adubação potássica nos meses de março, abril, maio e junho e na produção anual. A Figura 11 ilustra este efeito no mês de abril (figura 11a) e no mês de junho (figura 11b).

Verifica-se que o efeito da adubação na produtividade de borracha seca, concentra-se principalmente nos meses de maior produção, fase esta em que as folhas já estão maduras. A possivel justificativa para resposta da adubação se concentrar nestes meses é o fato de que as folhas e ramos não estarem mais competindo por fotoassimilados, possibilitando usa-los na produção de látex. Como mencionado anteriormente por Bernardes et al. (1990) a formação de folhas e desenvolvimento de ramos constitui uma fonte de dreno muito grande, competindo diretamente com a elaboração de latex

\footnotetext{
${ }^{3}$ Tonnelier, M. e Gener. P. Interest et choix d'une periode d'arret de saignée de l'Hevea. Caoutchouc et Platique. nº590.p.83-88.1979.
} 


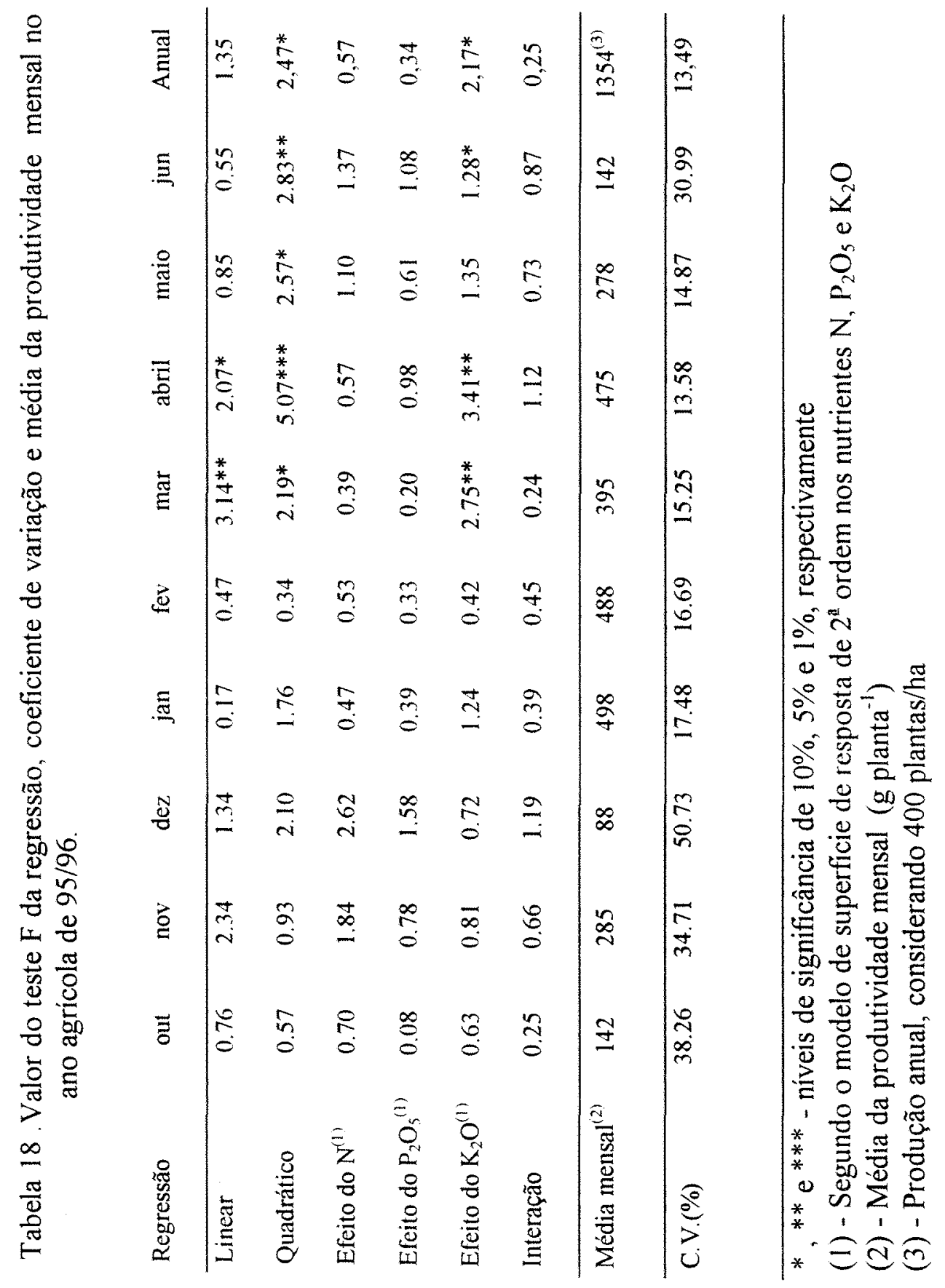



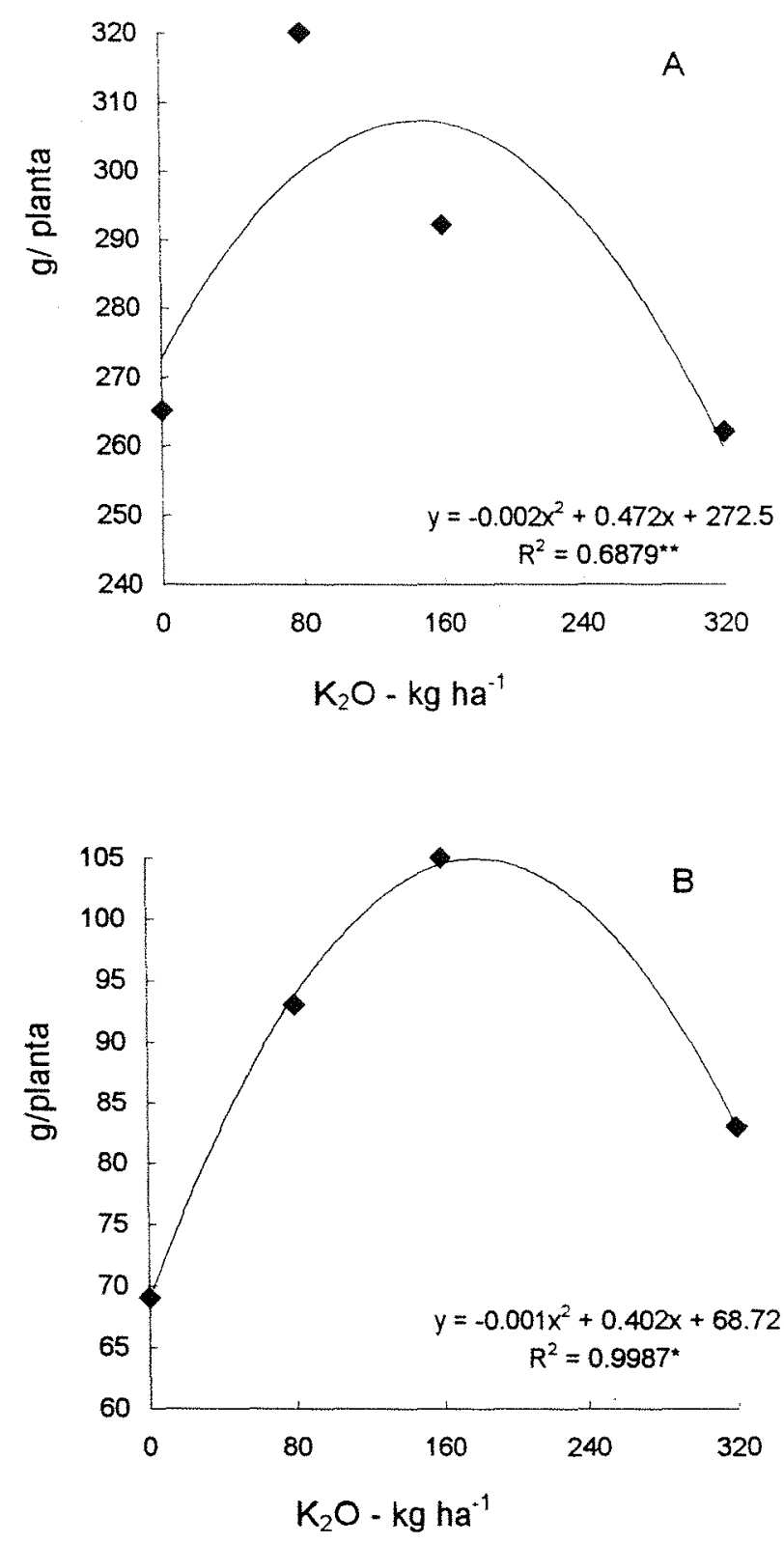

Figura 11. Efeito da adubação potássica sobre a produção de borracha seca nos meses (A) abril e (B) junho. 
Os dados médios de produção de borracha seca em função dos tratamentos, estão apresentados na tabela 19. Pelo teste de média verifica-se que somente no mês de abril houve diferença significativa entre as produtividades ao nivel de $5 \%$. A maior produtividade foi observado no tratamento $8\left(\mathrm{~N}_{1} \mathrm{P}_{2} \mathrm{~K}_{1}\right)$ e a menor produção no tratamento $16\left(\mathrm{~N}_{3} \mathrm{P}_{3} \mathrm{~K}_{3}\right)$, tratamento este que recebeu a maior dose de fertilizante, mostrando que uma adubação indiscriminada da seringueira pode refletir em queda na produção.

A importância do equilíbrio dos nutrientes contidos nos fertilizantes aplicados ao solo plantados com a seringueira foi observado por Pushparajah (1969). Neste trabalho o autor verificou que um excesso de nitrogênio sobre potássio na fórmula recomendada, induziu uma depressão na produção

A Tabela 20 apresenta os valores médios da produção anual de borracha seca em $\mathrm{Kg} / \mathrm{ha}$ e g/árvore. No primeiro caso foram consideradas 400 plantas/ha. Verifica-se que pelo teste de média não se observou diferenças estatisticas ao nível de $5 \%$ entre os tratamentos.

A Figura 12 apresenta a relação entre a adubação potássica, produção de borracha seca anual e teor foliar de potássio. Através de cálculos matemáticos, verifica-se que o ponto de inflexão da curva de produtividade é na dose de $155 \mathrm{~kg} / \mathrm{ha}$ que a produção é máxima, e a concentração de potássio nas folhas que proporciona esta produção máxima é de $12,1 \mathrm{~g} \mathrm{~kg}^{-1}$.

A Figura 13 apresenta a relação entre adubação potássica, produção de borracha seca e teor de $\mathrm{K}$ no solo. Através dos cálculos verifica-se que o teor de $\mathrm{K}$ no solo que proporcionou a maior produção é de $3,18 \mathrm{mmol} / \mathrm{dm}^{3}$.

Analisando os dados de folha verifica-se que este teor de $12,1 \mathrm{~g} \mathrm{~kg}^{-1}$ está dentro da faixa adequada de nutriente para a seringueira segundo a tabela 13, que preconiza como teores adequados variando de 10 a $15 \mathrm{~g} \mathrm{~kg}^{-1}$. Já os teores de $\mathrm{K}$ no solo estão concordando com os encontrados no Boletim 100 do IAC (Bataglia \& Gonçalves, 1996) para seringueira sendo teores adequados maiores que 1,5 $\mathrm{mmol}_{\mathrm{c}}$ $\mathrm{dm}^{-3}$. 
Tabela 19. Influência dos tratamentos nas produções de borracha seca mensais referentes ao ano agrícola 95/96

\begin{tabular}{|c|c|c|c|c|c|c|c|c|c|c|c|}
\hline & & out & nov & $\operatorname{dez}$ & jan & fev & $\operatorname{mar}$ & $a b r$ & & mai & jun \\
\hline $\mathrm{T}_{1}$ & $\mathrm{~N}_{0} \mathrm{P}_{0} \mathrm{~K}_{0}$ & 79 & 176 & 43 & 230 & 202 & 186 & 223 & $a b$ & 133 & 70 \\
\hline $\mathrm{T}_{4}$ & $\mathrm{~N}_{0} \mathrm{P}_{1} \mathrm{~K}_{1}$ & 79 & 174 & 70 & 263 & 194 & 202 & 233 & $a b$ & 125 & 55 \\
\hline $\mathrm{T}_{5}$ & $\mathrm{~N}_{1} \mathrm{P}_{1} \mathrm{~K}_{l}$ & 72 & 162 & 61 & 259 & 178 & 202 & 256 & $a b$ & 145 & 74 \\
\hline $\mathrm{T}_{6}$ & $\mathrm{~N}_{2} \mathrm{P}_{1} \mathrm{~K}_{1}$ & 59 & 122 & 35 & 254 & 206 & 217 & 235 & $a b$ & 161 & 90 \\
\hline$T_{-}$ & $\mathrm{N}_{3} \mathrm{P}_{1} \mathrm{~K}_{1}$ & 60 & 131 & 37 & 225 & 180 & 197 & 244 & $a b$ & 131 & 56 \\
\hline $\mathrm{T}_{3}$ & $\mathrm{~N}_{1} \mathrm{P}_{0} \mathrm{~K}_{1}$ & 79 & 135 & 38 & 244 & 215 & 214 & 246 & $a b$ & 140 & 77 \\
\hline $\mathrm{T}_{5}$ & $\mathrm{~N}_{1} \mathrm{P}_{1} \mathrm{~K}_{3}$ & 72 & 162 & 61 & 259 & 178 & 202 & 256 & $a b$ & 145 & 74 \\
\hline $\mathrm{T}_{8}$ & $\mathrm{~N}_{1} \mathrm{P}_{2} \mathrm{~K}_{1}$ & 78 & 161 & 54 & 263 & 223 & 211 & 281 & a & 166 & 83 \\
\hline $\mathrm{T}_{9}$ & $\mathrm{~N}_{1} \mathrm{P}_{3} \mathrm{~K}_{\mathrm{l}}$ & 70 & 150 & 42 & 247 & 191 & 206 & 246 & a & 145 & 61 \\
\hline $\mathrm{T}_{2}$ & $\mathrm{~N}_{1} \mathrm{P}_{1} \mathrm{~K}_{0}$ & 72 & 136 & 38 & 242 & 190 & 207 & 212 & $a b$ & 138 & 55 \\
\hline $\mathrm{T}_{5}$ & $\mathrm{~N}_{1} \mathrm{P}_{1} \mathrm{~K}_{1}$ & 72 & 162 & 61 & 259 & 178 & 202 & 256 & $a b$ & 145 & 74 \\
\hline$T_{10}$ & $\mathrm{~N}_{1} \mathrm{P}_{1} \mathrm{~K}_{2}$ & 93 & 170 & 52 & 275 & 198 & 204 & 234 & $a b$ & 137 & 84 \\
\hline $\mathrm{T}_{11}$ & $\mathrm{~N}_{1} \mathrm{P}_{1} \mathrm{~K}_{3}$ & 63 & 123 & 38 & 235 & 183 & 171 & 210 & $a b$ & 134 & 66 \\
\hline $\mathrm{T}_{12}$ & $\mathrm{~N}_{2} \mathrm{P}_{1} \mathrm{~K}_{2}$ & 55 & 121 & 34 & 255 & 177 & 205 & 237 & $a b$ & 137 & 73 \\
\hline$T_{13}$ & $\mathrm{~N}_{3} \mathrm{P}_{1} \mathrm{~K}_{2}$ & 74 & 114 & 35 & 265 & 198 & 212 & 274 & $a b$ & 158 & 84 \\
\hline$T_{14}$ & $\mathrm{~N}_{2} \mathrm{P}_{1} \mathrm{~K}_{3}$ & 61 & 109 & 32 & 235 & 205 & 178 & 219 & $a b$ & 133 & 78 \\
\hline $\mathrm{T}_{15}$ & $\mathrm{~N}_{2} \mathrm{P}_{2} \mathrm{~K}_{2}$ & 88 & 158 & 49 & 263 & 214 & 201 & 266 & $a b$ & 150 & 87 \\
\hline $\mathrm{T}_{16}$ & $\mathrm{~N}_{3} \mathrm{P}_{3} \mathrm{~K}_{3}$ & 62 & 132 & 51 & 230 & 176 & 158 & 192 & b & 122 & 58 \\
\hline
\end{tabular}

Médias seguidas de mesma letra não diferem entre si estatisticamente pelo teste de Tukey ao nível de $5 \%$ de probabilidade. 
Tabela 20. Influência dos níveis de N, P e K sobre a produtividade de borracha seca anual

\begin{tabular}{|c|c|c|c|c|c|c|c|}
\hline & \multicolumn{2}{|c|}{ TRATAMENTOS } & \multirow{3}{*}{$\mathrm{K}_{2} \mathrm{O}$} & \multicolumn{4}{|c|}{ BORRACHA SECA } \\
\hline & \multirow[t]{2}{*}{$\mathrm{N}$} & \multirow{2}{*}{$\begin{array}{l}\mathrm{P}_{2} \mathrm{O}_{5} \\
\mathrm{~kg} \mathrm{ha}^{-1}\end{array}$} & & \multirow[b]{2}{*}{$\mathrm{kg} \mathrm{ha}^{-1}$} & \multicolumn{2}{|c|}{ safra $95 / 96$} & \\
\hline & & & & & & $\mathrm{g}$ arvore $^{-1}$ & \\
\hline$\overline{T_{1}}$ & 0 & 0 & 0 & 1342 & $a^{1}$ & 3.35 & a \\
\hline$T_{4}$ & 0 & 40 & 80 & 1394 & a & 3.47 & a \\
\hline $\mathrm{T}_{5}$ & 80 & 40 & 80 & 1409 & a & 3.52 & a \\
\hline $\mathrm{T}_{6}$ & 160 & 40 & 80 & 1379 & $\mathrm{a}$ & 3.45 & a \\
\hline $\mathrm{T}_{7}$ & 320 & 40 & 80 & 1261 & $\mathrm{a}$ & 3.19 & a \\
\hline $\mathrm{T}_{3}$ & 80 & 0 & 80 & 1389 & $\mathrm{a}$ & 3.47 & $\mathrm{a}$ \\
\hline $\mathrm{T}_{5}$ & 80 & 40 & 80 & 1409 & $\mathrm{a}$ & 3.52 & $\mathrm{a}$ \\
\hline $\mathrm{T}_{8}$ & 80 & 80 & 80 & 1522 & $\mathrm{a}$ & 3.81 & a \\
\hline $\mathrm{T}_{9}$ & 80 & 160 & 80 & 1358 & $\mathrm{a}$ & 3.39 & a \\
\hline $\mathrm{T}_{2}$ & 40 & 40 & 0 & 1291 & a & 3.23 & $\mathrm{a}$ \\
\hline $\mathrm{T}_{5}$ & 40 & 40 & 80 & 1409 & a & 3.52 & a \\
\hline$T_{10}$ & 40 & 40 & 160 & 1446 & $\mathrm{a}$ & 3.66 & $a$ \\
\hline$T_{11}$ & 40 & 40 & 320 & 1223 & $\mathbf{a}$ & 3.11 & $\mathrm{a}$ \\
\hline$T_{12}$ & 160 & 40 & 160 & 1294 & $\mathrm{a}$ & 3.23 & $\mathrm{a}$ \\
\hline $\mathrm{T}_{13}$ & 320 & 40 & 160 & 1413 & $\mathrm{a}$ & 3.53 & $a$ \\
\hline $\mathrm{T}_{14}$ & 160 & 40 & 320 & 1250 & $\mathrm{a}$ & 3.13 & a \\
\hline $\mathrm{T}_{15}$ & 320 & 80 & 160 & 1476 & $\mathrm{a}$ & 3.69 & a \\
\hline$T_{16}$ & 160 & 160 & 320 & 1182 & $\mathrm{a}$ & 2.95 & $\mathrm{a}$ \\
\hline
\end{tabular}

${ }^{1}$ Médias, na coluna, seguidas de mesma letra não diferem estatisticamente (Tukey a 5\%) 


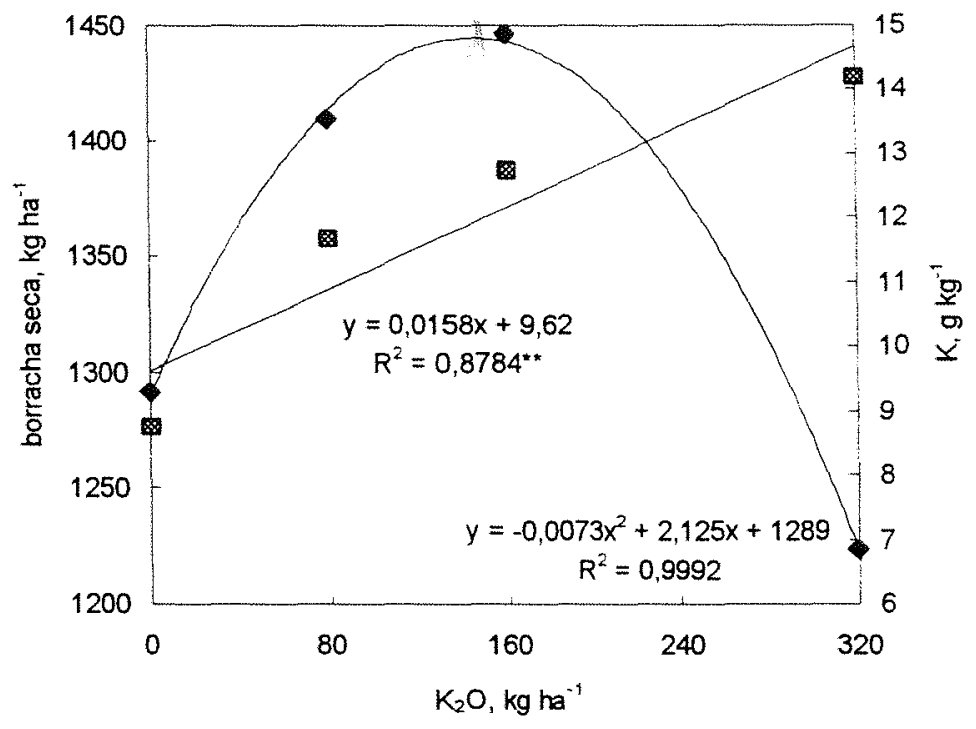

Figura 12. Produtividade de borracha seca e teor foliar de $\mathrm{K}$ em função de doses de $\mathrm{K}$.

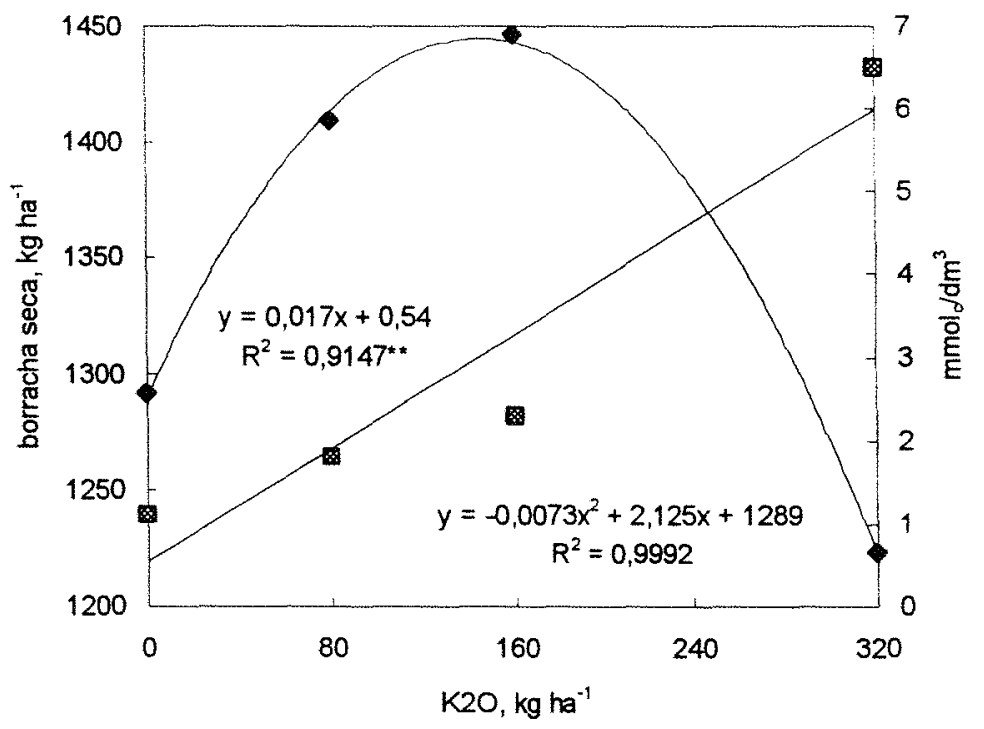

Figura 13. Produtividade de borracha seca e teor trocávelde $\mathrm{K}$ no solo em função de doses de $\mathrm{K}$. 
A Tabela 21 apresenta os valores do teste $F$ das regressões, médias gerais e coeficiente de variação referente a exportação de nutriente pela borracha seca com o soro. Observa-se que nâo há efeito isolado da adubação nos teores de nutrientes da borracha. O que também é observado na tabela 22, que apresenta os teores médios destes nutrientes na borracha, onde se aplicou o teste de Tukey para compará-las.

Os teores médios de nutrientes exportados através da sangria são apresentados na tabela 22 ,onde observa-se que os valores são baixos. O nutriente que é exportado em maior quantidade é o $\mathrm{N}(6,6 \mathrm{~kg} / 1000 \mathrm{~kg}$ de borracha produzido), seguido do $\mathrm{K}(6,1 \mathrm{~kg} / \mathrm{t})$ e depois pelo $\mathrm{P}(3,85 \mathrm{~kg} / \mathrm{t}), \mathrm{Mg}(1,13 \mathrm{~kg} / \mathrm{t}), \mathrm{S}(0,54 \mathrm{~kg} / \mathrm{t}), \mathrm{Ca}$ $(0,19 \mathrm{~kg} / \mathrm{t})$. O teor de Ca na borracha é muito baixo, fato este também observado por Haag 1987. As quantidades de micronutrientes exportados em $1000 \mathrm{~kg}$ de borraha seca são: Cu (18 g/t), Fe (57g/t), Mn (3 g/t) e Zn (257g/t). 


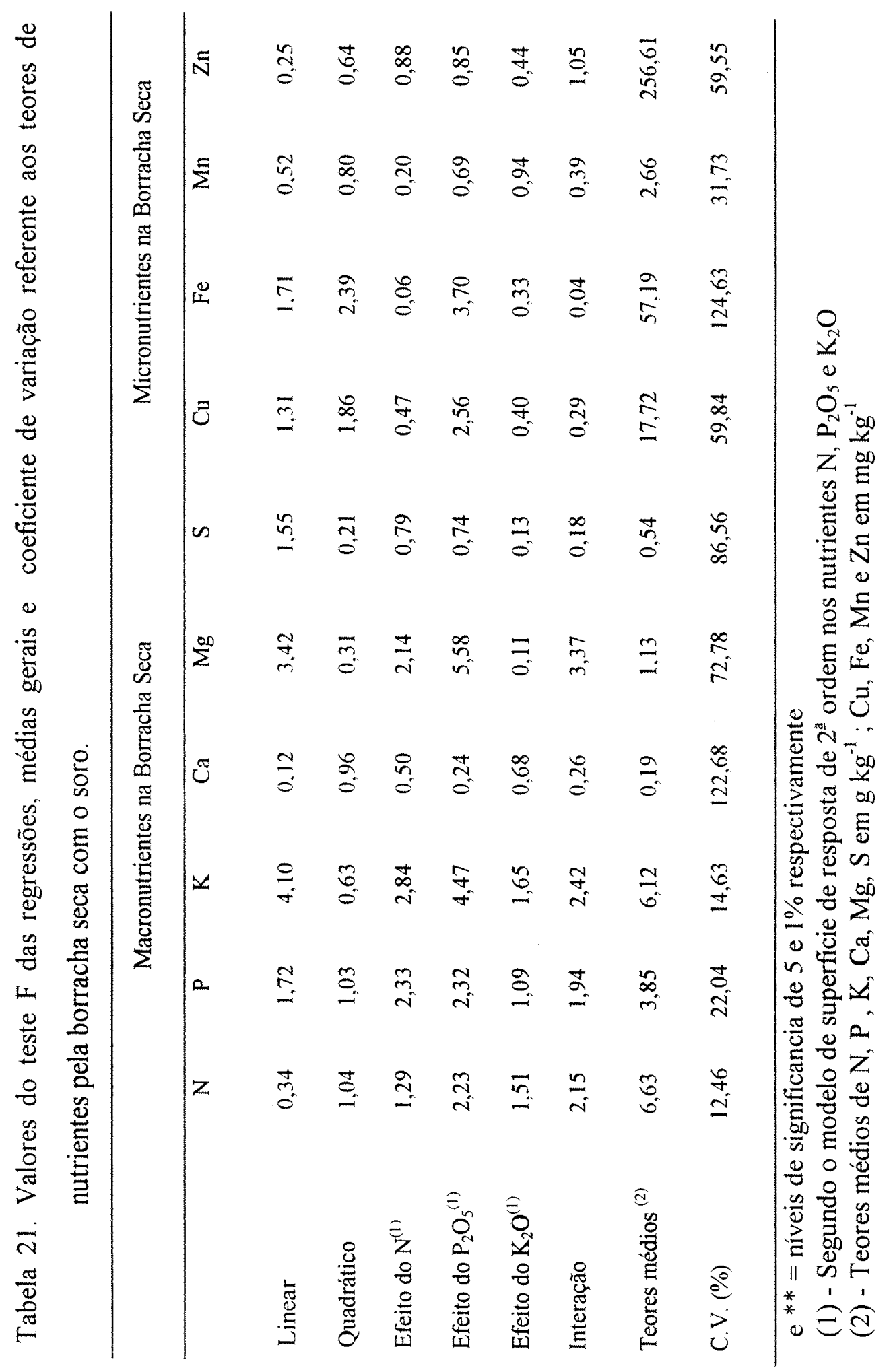




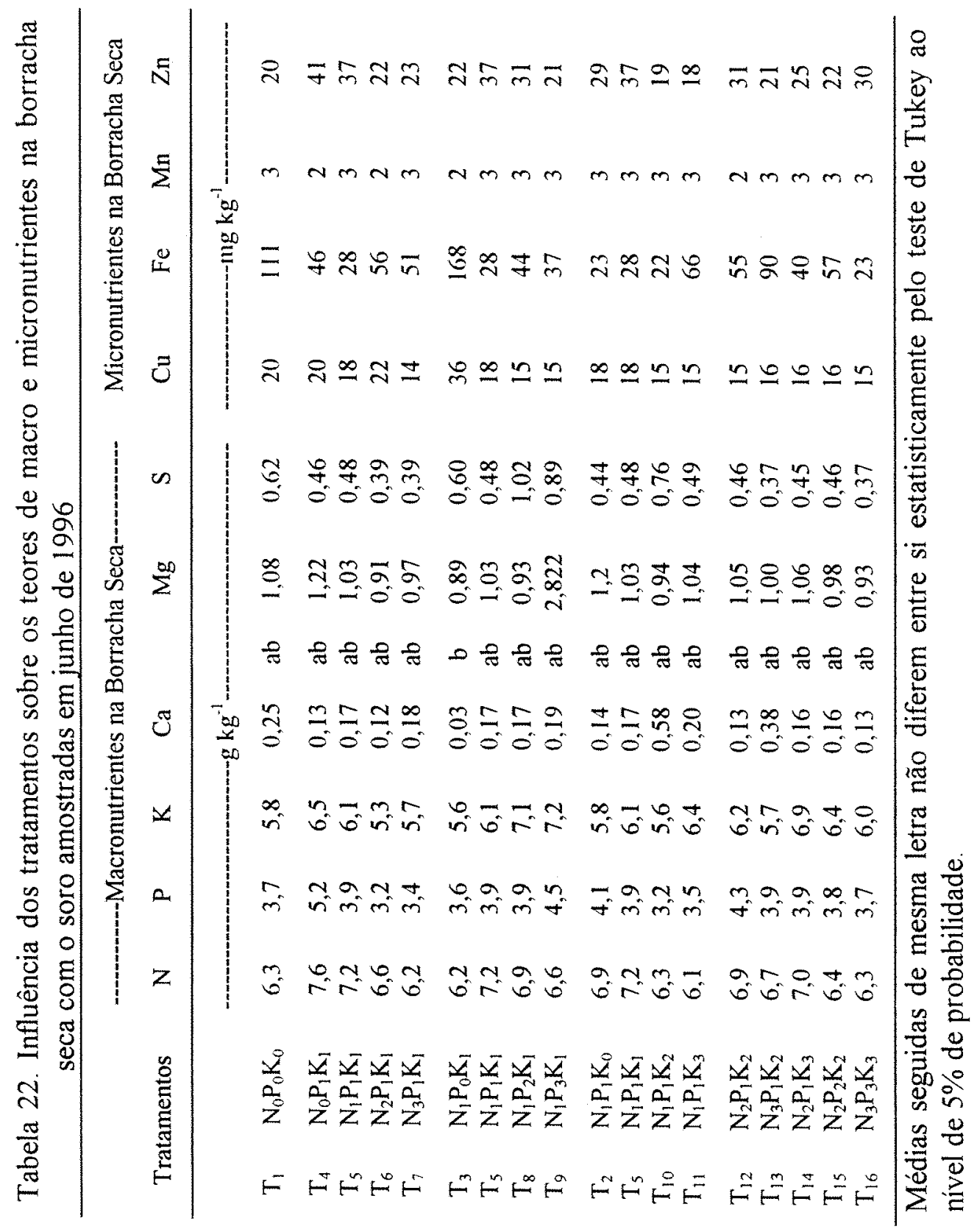


A Tabela 23 apresenta os teores de nutrientes da borracha seca encontrados por outros autores.

Tabela 23. Teores de macronutrientes encontrados na borracha seca.

\begin{tabular}{|c|c|c|c|c|c|c|}
\hline Autores & $\mathrm{N}$ & $\mathrm{P}$ & $\mathrm{K}$ & $\mathrm{Ca}$ & $\mathrm{Mg}$ & S \\
\hline RRIM (1980) & 6,76 & 1,65 & 5,97 & - & 1,22 & - \\
\hline HAAG et al.(1990) & 4,75 & 0,43 & 0,50 & 0,008 & 0,05 & 0,17 \\
\hline PUSHPARAJAH (1977) & 6,30 & 1,46 & 5,58 & - & 1,37 & - \\
\hline
\end{tabular}

Os teores de $\mathrm{P}$ da borracha no presente trabalho, estão acima dos teores encontrado por diferentes autores (Tabela 23). O teor de Ca apesar de ser baixo, ainda é maior que os teores da Tabela 23 , e os teores de nitrogênio estão semelhantes aos teores encontrados por outros autores. Os teores de $\mathrm{K}$ encotrados são superiores aos encontrados por Haag et al. (1990), e semelhantes aos reportados por Pushparajah (1977) e RRIM (1980).

Analisando os dados da tabela 23 se verifica que os teores de nutrientes na borracha determinados por Haag et al. (1990) estão, com exceção do $\mathrm{N}$, bem abaixo dos demais, o que pode ser influenciado pelo método de amostragem, pois quando se determina os teores de nutrientes da borracha sem o soro estes são bem inferiores se comparados aos mesmos determinados com o soro.

Pelos dados apresentados verifica-se que a adubação NPK não interfere nos teores de nutrientes da borracha. Observa-se desse modo que, a exportação de nutrientes será maior, nos tratamentos que apresentarem maior produção. 
RRIM (1980) verificou que o uso de estimulação com ethephon a 10\% motivou um aumento da produtividade em $1180 \mathrm{~kg} \mathrm{ha}^{-1}$ em relação as seringueiras não estimuladas. Este fato aumentou significativamente a drenagem de $\mathrm{N}, \mathrm{P}, \mathrm{K}$ e $\mathrm{Mg}$ em $14,5,14$ e $2 \mathrm{~kg} /$ ha respectivamente.

Pushparajah (1977), fazendo um balanço da adubação NPK aplicado no seringal concluiu que a adubação inadequada faz com que haja um "empobrecimento" das árvores que estão sendo sangradas, pois uma parte dos nutrientes é exportada pela produção e outra é imobilizada pelo crescimento das plantas.

Não foi observado efeito significativo das adubações na produção de borracha seca. Tal fato pode ser relacionado a baixa exportação de nutrientes pela borracha. Analisando o tratamento que proporcionou a maior produção $\mathrm{T}_{8}\left(\mathrm{~N}_{1} \mathrm{P}_{2} \mathrm{~K}_{1}\right)$ verifica-se que a exportação anual de nutrientes foi: $\mathrm{N}(10,1), \mathrm{P}(5.86), \mathrm{K}(9,32), \mathrm{Ca}$ $(0,29), \mathrm{Mg}$ (1.72), S (0.82) em kg ha ${ }^{-1}, \mathrm{Cu}$ (27), Fe (87), Mn (4), Zn (390). Entretanto, esta exportação não é a única fonte de dreno, pois a planta desloca nutrientes para o crescimento de ramos, folhas, troncos e raizes.

Como mencionado anteriormente a seringueira apresenta a senescência anual das folhas, que retornam ao solo, formando a serrapilheira, sendo rica em $\mathrm{N}$ e $\mathrm{K}$. Os ramos inferiores, com o crescimento da planta, caem e se decompõem no solo retornando os nutrientes ao sistema solo-planta. 


\subsection{Influência da adubação NPK na \% do corte seco do painel da seringueira}

A seca do painel, como foi discutido anteriormente, é um disturbio fisiológico, sendo mencionado por alguns autores, que o mesmo possa ter alguma relaçãocom a adubação, principalmente a potássica.

A Tabela 24 apresenta os valores do teste $F$ das regressões médias gerais e coeficientes de variação referente a $\%$ de corte seco do painel, avaliado em abril de 1996 e fevereiro de 1997. Verifica-se que a adubação não promoveu qualquer influência sob este parâmetro, mas é importante frisar que houve um aumento médio de incidência de secamento de um ano para o outro, sendo que o índice de secamento passou de $7,65 \%$ aos 12 anos e para $17,63 \%$ aos 13 anos de idade da seringueira.

Falcão (1996), em estudo realizado nesta mesma área experimental, avaliou alguns parâmetros fisiológicos do látex e concluiu que os valores de fósforo inorgânico de alguns tratamentos estavam acima do teor adequado que seria $(>10 \mathrm{e}<$ $20 \mathrm{mM}$ ). A tabela 25 apresenta as médias gerais dos valores de \% do corte seco do painel e os valores de $\mathrm{P}$ inorgânico encontrados para estes tratamentos. Onde se verifica que o clone PB 235, citado como um clone resistente a seca do painel por Gonsalves et al.(1983), não se mostra resistente a tal distúrbio fisiológico, discordando deste autor.

Falcão (1996), concluiu também que os tratamentos que apresentaram valores $\mathrm{P}$ inorgânico acima de $20 \mathrm{mM}$, estariam sendo superexplotados. E um dos principais fatores ligados a super explotação é o secamento de painel. Pelos dados apresentados verifica-se que o aumento na \% de secamento de painel, pode ter de fato alguma relação com o teor de $\mathrm{P}$ inorgânico do látex. Estudos futuros a respeito deste distúrbio fisiológico, devem levar em consideração este parâmetro para a confirmação de tal resposta.

A grande vantagem de se analisar o $\mathrm{P}$ inorgânico no latex seria na prevenção ao secamento de painel, pois medidas, como menor freqüência de sangria, menor concentração de ethephon e menor número de aplicação por ano, paralisação 
da sangria por um período do ano, adubação adequada do seringal, seriam medidas que poderia diminuir a incidência de tal distúrbio fisiológico.

Tabela 24. Valores do teste $\mathrm{F}$ das regressões, médias gerais e coeficientes de variação referente a $\%$ de corte seco do painel, avaliado em abril de 96 e fev/97.

\begin{tabular}{lcc}
\hline \multicolumn{1}{l}{ Regressão } & Abril/96 & Fev/97 \\
\hline Linear & 2,61 & 1,06 \\
Quadrático & 0,74 & 0,07 \\
Efeito do $\mathrm{N}^{(1)}$ & 0,44 & 0,15 \\
Efeito do $\mathrm{P}_{2} \mathrm{O}_{5}^{(1)}$ & 1,31 & 0,49 \\
Efeito do $\mathrm{K}_{2} \mathrm{O}^{(1)}$ & 0,31 & 0,08 \\
Interação & 0,61 & 0,20 \\
& & 17,63 \\
Médias & $(2)$ & \\
C.V. (\%) & 7,65 & 73,64 \\
\hline ** & 133,84 & \\
\hline
\end{tabular}

$\mathrm{e}^{* *}=$ niveis de significancia de 5 e $1 \%$ respectivamente

(1)Segundo modelo de superficie de resposta de $2^{\underline{a}}$ ordem nos nutrientes $\mathrm{N}, \mathrm{P}_{2} \mathrm{O}_{6}$ e $\mathrm{K}_{2} \mathrm{O}$

(2) $\%$ de secamento de painel 
Tabela 25. Influência da adubação na incidência de seca do painel, avaliado em abril/96 e fev/97 e valores de $\mathrm{P}$ inorgânico encontrado nestes tratamentos em Jul/95.

\begin{tabular}{|c|c|c|c|c|}
\hline & & $\%$ de corte seco abril/96 & $\%$ de corte seco fev/97 & P inorg ${ }^{(1)}$ \\
\hline $\mathrm{T}_{1}$ & $\mathrm{~N}_{0} \mathrm{P}_{0} \mathrm{~K}_{0}$ & 0.8 & 14,0 & 18,86 \\
\hline $\mathrm{T}_{4}$ & $\mathrm{~N}_{0} \mathrm{P}_{1} \mathrm{~K}_{1}$ & 5,0 & 11,8 & 29,45 \\
\hline $\mathrm{T}_{5}$ & $\mathrm{~N}_{1} \mathrm{P}_{1} \mathrm{~K}_{1}$ & 6,6 & 16,0 & 23,78 \\
\hline $\mathrm{T}_{6}$ & $\mathrm{~N}_{2} \mathrm{P}_{1} \mathrm{~K}_{1}$ & 6.7 & 12,3 & 17.30 \\
\hline $\mathrm{T}_{7}$ & $\mathrm{~N}_{3} \mathrm{P}_{1} \mathrm{~K}_{1}$ & 3,3 & 19,3 & 15.72 \\
\hline $\mathrm{T}_{3}$ & $\mathrm{~N}_{1} \mathrm{P}_{0} \mathrm{~K}_{1}$ & 0,8 & 11,8 & 16,27 \\
\hline $\mathrm{T}_{5}$ & $\mathrm{~N}_{1} \mathrm{P}_{1} \mathrm{~K}_{1}$ & 6,6 & 16,0 & 23,78 \\
\hline $\mathrm{T}_{8}$ & $\mathrm{~N}_{1} \mathrm{P}_{2} \mathrm{~K}_{1}$ & 15,0 & 22,5 & 20,59 \\
\hline $\mathrm{T}_{9}$ & $\mathrm{~N}_{1} \mathrm{P}_{3} \mathrm{~K}_{1}$ & 7,5 & 20,0 & 21,49 \\
\hline $\mathrm{T}_{2}$ & $\mathrm{~N}_{1} \mathrm{P}_{1} \mathrm{~K}_{0}$ & 3,3 & 16,5 & 15,82 \\
\hline $\mathrm{T}_{5}$ & $\mathrm{~N}_{1} \mathrm{P}_{1} \mathrm{~K}_{1}$ & 6,6 & 16,0 & 23.78 \\
\hline $\mathrm{T}_{10}$ & $\mathrm{~N}_{1} \mathrm{P}_{1} \mathrm{~K}_{2}$ & 11,7 & 30,8 & 19,00 \\
\hline $\mathrm{T}_{11}$ & $\mathrm{~N}_{1} \mathrm{P}_{1} \mathrm{~K}_{3}$ & 9,2 & 14,0 & 20,88 \\
\hline $\mathrm{T}_{12}$ & $\mathrm{~N}_{2} \mathrm{P}_{1} \mathrm{~K}_{2}$ & 13,4 & 19,3 & 19.13 \\
\hline$T_{13}$ & $\mathrm{~N}_{3} \mathrm{P}_{1} \mathrm{~K}_{2}$ & 4,2 & 16,8 & 15,29 \\
\hline $\mathrm{T}_{14}$ & $\mathrm{~N}_{2} \mathrm{P}_{1} \mathrm{~K}_{3}$ & 10,9 & 16,5 & 19,89 \\
\hline $\mathrm{T}_{15}$ & $\mathrm{~N}_{2} \mathrm{P}_{2} \mathrm{~K}_{2}$ & 8,3 & 13,3 & 22,56 \\
\hline $\mathrm{T}_{16}$ & $\mathrm{~N}_{3} \mathrm{P}_{3} \mathrm{~K}_{3}$ & 15,8 & 27,5 & 21,57 \\
\hline
\end{tabular}

(1) valores encontrados por Falcão (1996) 


\section{CONCLUSÕES}

O perímetro do tronco, medido aos 12 e 13 anos de idade da seringueira, e a espessura da casca, medida aos 12 anos de idade da seringueira, aumentaram linearmente com as doses de potássio.

A produção de borracha seca teve um comportamento quadrático em função

das doses de potássio. A produção máxima ocorreu com a dose de potássio de 155 $\mathrm{kg} / \mathrm{ha}$ e então decresceu com a dose de potássio de $180 \mathrm{~kg} / \mathrm{ha}$. Associado à produção máxima o teor foliar foi de $12,1 \mathrm{~g} / \mathrm{kg}$ e o teor de potássio no solo extraido pela resina trocadora de ions foi de $3,2 \mathrm{mmol} / \mathrm{dm}^{3}$.

A cada $1000 \mathrm{~kg}$ de borracha seca são exportados $6,6 \mathrm{~kg}$ de $\mathrm{N} ; 3,9 \mathrm{~kg}$ de P; $6,1 \mathrm{~kg}$ de $\mathrm{K} ; 190 \mathrm{~g}$ de $\mathrm{Ca} ; 1,1 \mathrm{~kg}$ de $\mathrm{Mg} ; 540 \mathrm{~g}$ de $\mathrm{S} ; 18 \mathrm{~g}$ de $\mathrm{Cu} ; 57 \mathrm{~g}$ de Fe; $3 \mathrm{~g}$ de $\mathrm{Mn} ; 257 \mathrm{~g}$ de $\mathrm{Zn}$.

A incidência de seca de painel não teve qualquer relação com a adubação de nitrogênio, fósforo e potássio aplicada ao solo.

O clone PB 235 se mostrou suscetível a seca de painel. 


\section{REFERÊNCIAS BIBLIOGRÁFICAS}

BAHIA . Secretaria da Indústria e Comércio. A seringueira na Bahia. Salvador, 1959. $114 \mathrm{p}$.

- BARROS, N.F. DE; ALVES, V.M.C. Adubação de seringueira. Informe Agropecuário, v.11, n.121, p.29-34, jan. 1985 .

BARROS,J.C.M.; CASTRO, A.M.G..Visita nos centros de pesquisa e produção de borracha natural na República da China. Brasília: Superintendência da Borracha, 1983.33p.

BATAGLIA, O.C.; CARDOSO, M. Situação nutricional dos seringais de São Paulo. In: SIMPÓSIO dA CUlTURA dA SERINGUEIRA, 2, Piracicaba, 1897. Anais... Piracicaba: USP/ESALQ, Dept. Agricultura, 1990. p.89-97.

BATAGLIA, O.C.; CARDOSO, M.; IGUE, T. ; RAIJ, B.V. Desenvolvimento da seringueira em solos do Estado de São Paulo. Pesquisa Agropecuária Brasileira, v.22, n.4, p.419-424, abr. 1987.

BATAGLIA, O.C.; GONSALVES, P. Recomendações de adubação e calagem para o Estado de São Paulo. Campinas: Instituto Agronômico, 1996. 243p. (Boletim Técnico, 100). 
BERNARDES, M. S.; VIRGENS FILHO, A. D.; CASTRO, P. R. C. Fatores condicionantes dos sistemas de explotação da seringueira para o estado de São Paulo. In: SIMPÓSIO DA CULTURA DA SERINGUEIRA, 2, Piracicaba, 1987. Anais... Piracicaba: ESALQ, Depto. Agricultura, 1990 p.273-333.

BERNARDES, M. S. (ed) Sangria da Seringueira, Piracicaba, ESALQ/FEALQ, 1990, 206p.

BERNARDES, M. S.; CASTRO, P. R. C.; MARTINS, A. N. A formação de copa e resistência de árvores ao vento: Modelo da seringueira. Piracicaba, FEALQ, 1996, $88 \mathrm{p}$.

BERNIZ, J.M.J. Influência de N,P,K, em seringueira jovem (Hevea brasiliensis Muell. Arg.). Viçosa, 1987. 59p. Tese (Doutorado).- Universidade Federal de Viçosa.

BOAVEnTURA, M. A. M.; GONÇALVES, P.S.; CARDOSO, M. et al Controle e explotação de árvores afetadas pala seca do painelem seringais de cultivo Agronômico, v. 41, n.2, p. 110-21, 1989.

BOLTON, J.C. The response of imature Hevea brasiliensis to fertilizers in Malaya. I. Experiments in Shale-derived soils. Journal of the Rubber Research Institute of Malaysia, v.18, n.2, p.67-79, 1964.

BOUYCHOU, J. E. La biologie de l'Hevea. Gen. des Caoutchoucs et des plastiques. v.40, p. 933-1001, 1963.

BOUYCHOU, J. E. Manuel du Planteur d' hevea; la biologie de l'hevea. Paris: Societé Parisiensi D'Imprimerie, 1951. p. 8 - 9. 
BOX, G.E.P.; HUNTER, W.G. JR.; HUNTER, J.S. Statistics for experimenters: an introdution to design, data analysis and model building. New York: Wiley Interscience, $1973.653 \mathrm{p}$.

BRASIL. Ministério da Agricultura. Levantamento de reconhecimentodos solos do estado de São Paulo. Contribuição a carta de solos do Brasil. Boletim do Serviço Nacional de Pesquisas Agronômicas, n.12, p. 198-203, 1960.

BRASIL. Superintendência da Borracha. Plano nacional da Borracha: O gênero Hevea . Brasilia: SUDHEVEA, 1971. v.7

BREMNER, J. M. Inorganic forms of nitrogen. In: Black, C. A. ed.Methods of soil analysis. Part. 2. Madison: American Society of Agronomy, 1965 p. 1179- 1237

CABALA- ROSAND, F.P.; MAIA, F. Adubação de plantas enviveiradas de seringueira. Informe Técnico 1972/ 1973. Itabuna: Centro de pesquisas do Cacau, p. 12

CAMARGO, A.P. Estudo das possibilidades de desenvolvimento da cultura da seringueira no Estado de São Paulo. Governo do Estado de São Paulo, Campinas: IAC, 1958.

- CARDOSO, M. Instruções para a cultura da seringueira. 2.ed. Campinas: Instituto Agronômico, 1980. 42p. (Boletim, 196)

- CARVAlHo, C. J. R. Indução de Floração Precoce em Clones de Hevea brasiliensis X Hevea benthamiana. Pesquisa Agropecuária Brasileira, v.15, n. 4, p. 405-411, 1980. 
CORTEZ, A.; BLACK, G.A.Considerações sobre os centros produtores do sudeste da Asia, Malásia e Indonésia. In: Cultura da Seringueira.14p. 1954.

CORTEZ, J. V. História e Expanção da Cultura da Seringueira no Estado de São Paulo. In: SIMPÓSIO SOBRE A CULTURA DA SERINGUEIRA NO ESTADO DE SÃo PAULO, 1, Campinas, 1986. Anais. Campinas: Fundação Cargil ,1986 p.119.

CUNHA, J.F. A Seringueira (Hevea brasiliensis) na região de Campinas, sua adaptação e produtividade. Bragantia, v.22, n. 35, p. 445-460, 1963.

CUNHA, M.M.; YEOW, K.H. Soil and nutrient status in relation to soil type. Planters Bulletin, p.170-177, 1966.

DIJKMAN, M.J. Hevea: thirty years of research in the Far-East. Miami:University of miami Press, 1951.

DOLMAT, M. T. Manuring of Hevea under ethephon stimulation. In: RUBBER RESEARCH INSTITUTE OF MALAYSIA. Training manual on tapping, tapping systems and yield stimulation of Hevea. Kuala Lumpur: RRIM, 1980. p.193 - 203.

EMPRESA BRASILEIRA DE PESQUISA AGROPECUÁRIA. EMBRAPA. Relatório Técnico Anual- 1978-1979, Planaltina: CPAC/EMBRAPA, 1979, 170p.

FALCÃO, N. S. F. Adubação NPK afetando o desenvolvimento do caule da seringueira e parâmetros fisiologicos do látex. Piracicaba, 1996. 134p. Tese (Doutorado) Escola Superior de Agricultura Luiz de Queiroz, Univesidade de São Paulo. 
GOMES, F. P. Curso de estatística experimental. 8. ed. São Paulo: Nobel, 1978. $430 \mathrm{p}$.

GONSALVES, P. ; SOUZA, J.R.; SOUZA, R.A. Retrospectiva e atualidades do melhoramento genético da seringueira (Hevea spp.) no Brasil e em Países Asiáticos. Manaus, EMBRAPA CNPSD/EMBRAPA, 1983. 69p.

HAAG, H.P. Nutrição e adubação da seringueira no Brasil. Campinas, Fundação Cargill, 1973. 116.

HAAG, H.P.; BUENO, N.; PEREIRA; J. P. Alguns aspectos recentes da nutrição da seringueira no Brasil. In: SIMPÓSIO DA CULTURA DA SERINGUEIRA, 2, Piracicaba, 1987. Anais... Piracicaba: ESALQ, Depto. Agricultura, 1990. p.59-88.

HAAG, H.P.; DECHEN, A. R. Nutrição Mineral da Seringueira: marcha de absorção de nutrientes. Campinas, Fundação Cargil, 1982. 86p.

INTERNATIONAL RUBBER STUDY GROUP. Rubber Statistical Bulletin. vol.1, n. 52 , p. 52 , nov. 1996

JOBBE-DURVAL, B. Contribuition a l'etude des phenomenes d'encoches seches d'Hevea brasiliensis Muell Arg. Epidemiologie, facteurs de risque et methodes de lutte, Paris: IRCA, 1986. 62p.

KALAN, M.A. Effect of fertilizer application on growth and leaf nutrient control of some important Hevea brasiliensis clones. Rubber Board Bulletin, v.16, n.1, p. $19-29,1970$. 
KITAMURA, M.C. Influência dos níveis de nitrogênio, fósforo, potássio e magnésio no desenvolvimento da seringueira jovem (Hevea brasiliensis Muell. Arg.) em um solo sob cerrado de Mato Grosso do Sul. Lavras, 1992. 90p. Dissertação (M.S.) Escola Superior de Agricultura de Lavras

MAINSTONE, B. J. Residual effects of type of ground cover and duration of nitrogenous fertiliser treatment applied before tapping on the growth and yield of Hevea brasiliensis. Planter Bulletin Rubber Research Institute Malaysia, v. 68, p.130-8, 1969.

MALAVOLTA, E.; VITTI,G. C.; OLIVEIRA, S. A.. Avaliação do estado nutricional das plantas. Piracicaba: POTAFOS,. 1989. $201 \mathrm{p}$.

MARTINEZ, A. A. Cultura da seringueira. São Paulo: CATI, 1970. 34p.

MEDRADO, M. J. S. COSTA, J. D. Clones de seringueira para a região do planalto paulista. Informativo Técnico. ESALQ, n.9, p.1-12, 1990.

MENEZES, J.A.; VASCONCELOS FILHO, A. P.; MANDARINO, E. P. Cadastro dos seringais do estado da Bahia: atualização e análise. Ilhéus: CEPLAC, 1975. 104p.

MIRANDA, E.R.; ROSAND, P.C.; SANTANA, C.J.L. Requerimentos nutricionais e adubação do cultivo da seringueira. Boletim Técnico, CEPLAC/CEPEC, n.33, p. $1-32,1975$.

MOHD, T. B. D. Role of legume covers - the effects of yeild and growth. In: RUBBER RESEARCH INSTITUTE OF MALAYSIA. Training manual on soil management and nutrition of Hevea. Kuala Lumpur: RRIM, 1979, p.111-8. 
MORAES, V.H.F., Rubber. In: ALVIM, P. T; KOZLOWSKI, T. T. Ecophysiology of tropical crops. New York: Academic Press, 1977. p. 315-331.

MURBACH, M. R. Influência do manejo da entrelinha da seringueira nas propriedades físicas e químicas do solo. Jaboticabal, 1994. 62p Monografia (Graduação)Faculdade de Ciências Agrárias e Veterinária, Universidade Estadual Paulista, "Júlio de Mesquita Filho".

ORTOLANI, A. A.; et al. Aptidão agroclimática para regionalização da heveicultura no Brasil. In: SEMINÁRIO BRASILEIRO SOBRE RECOMENDAÇÕES DE CLONES DE SERINGUEIRA, 1, Brasilia, 1983. Anais. Brasilia: SUDHEVEA, 1983. p. 19-28.

PAKIANATHAN, S. W. Physiology of latex flow and water relations: In. RUBBER RESEARCH INSTITUTE OF MALAYSIA. Training manual on tapping, tapping systems and yield stimulation of Hevea Kuala Lumpur, RRIM, 1980. p. $27-41$

PANNOJE, K.J.; POTTY, S.N. Responses of Hevea brasiliensis to fertilizer in South India. In: INTERNATIONAL RUBBER RESEARCH INSTITUTE OF MALAYSIA PLANTERS CONFERENCE, Kuala Lumpur, 1975. Proceedings. Kuala Lumpur: RRIM, 1975. v.3, p. 84-105.

PARAJONTHY, K. Brown bast and explotationof dry trees. In: RUBBER RESEARCH INSTITUTE OF MALAYSIA. Training on tapping, tapping systems and yield stimulation of Hevea, Kuala Lumpur: RRIM, 1980. p. 56-65. 
PARAJONTHY, K. GOMES, J.B. YEANG, H. Y. Physiological aspects of brown bast development. In: RUBBER RESEARCH. INSTITUTE OF MALAYSIA. PLANTERS' CONFERENCE. Kuala Lumpur: 1975 Proceedings. Kuala Lumpur: RRIM, 1975. p.1-22.

PUSHPADAS, M. V.; AHAMMED, M. Nutritional requirements and manurial recommendations. In: PILLAR, P.N.R., ed. Handbook of natural rubber production in India. Kottayan: Rubber Research Institute of India, 1980

PUSHPARAJAH, E. Nutritional status and fertilizer requirements of Malaysia on soil for Hevea brasiliensis. Chent State, 1977. 275p. Thesis (D.S.) - University of Ghent Belgium.

PUSHPARAJAH, E. Response in Growthand yield of Hevea brasiliensis to fertilizer application on Regan series soil. Journal Rubber Research Institute of Malaysia, v.21, n.2, p. 165, 1969.

PUSHPARAJAH, E. TAN, K. T. Fators influencing leaf nutrient levels in rubber. In: RUBBER RESEARCH INSTITUTE OF MALAYSIA PLANTERS' CONFERENCE, Kuala Lumpur, 1975. Proceedings. Kuala Lumpur: RRIM, 1975. p. 140 .

PUSHPARAJAH, E.; CUNHA, M.M. Fertilizer response in Hevea brasiliensis in relation to soil type and leaf nutrient status. In: CONGRESS OF SOIL SCIENCE. Adelaide, 1968. Transactions. p.85-93. 
PUSHPARAJAH, E.; CHAN, H. Y. ; SIVANADYAN, K. Recent development for reduced fertilizer applications for Hevea. In: RUBBER RESEARCH INSTITUTE OF MALAYSIA PLANTERS CONFERENCE, Kuala Lumpur, 1975. Proceedings. Kuala Lumpur: RRIM, 1983. p.313.

RAIJ, B. VAN. Fertilidade do solo e adubação. São Paulo: Agronômica Ceres, 1991. p. $90-95$.

RAIJ, B. Van; SILVA, N.M.; BATAGLIA, O.C.; QUAGGIO, J.A.; HIROCE, R.; CANTARELA, H.; BELlNAZZI JR., R.; DECHEN, A.R.; TRANI. P. E. Recomendações de adubação e calagem para o Estado de São Paulo. Campinas: Instituto Agronômico, 1985. 107p.(Boletim Técnico, 100).

RAIJ, B. Van; QUAGGIO, J. A. Métodos de análises de solos para fins de fertilidade do solo. Campinas: Instituto Agronômico, 1983. 31p. (Boletim Técnico, 81).

RAIJ, B. VAN; QUAGGIO, J.A.; CANTARELA, H. FURLANI, A. M. C. Recomendações de adubação e calagem para o Estado de São Paulo. Campinas: Instituto Agronômico, 1996. 285p.(Boletim Técnico, 100).

REIS, E. L.; CABALA-ROSAND, P. Eficiência dos fertilizantes aplicados nas fases pré e pós-sangria da seringueira. Revista Theobroma, v.18, n.3, p.189-200, jul./set. 1988.

REIS, A.C.F dos. O seringal e o seringueiro. Rio de Janeiro, Ministério da Agricultura, 1953. 194p. 
REIS, E.L. Influência da aplicação de nitrogênio, fósforo e potássio sobre o desenvolvimento da seringueira (Hevea brasiliensis Muell. Arg.) no sul da Bahia. Piracicaba, 1979. 61p. Dissertação (Mestrado) - Escola Superior de Agricultura Luiz De Queiroz, Universidade de São Paulo.

REIS, E. L.; ROSAND, P. C.; SANTANA, C. J. L. Indicações de adubação da seringueira no Sul da Bahia. Ilhéus: CEPLAC/SUDHEVEA, 1984a p.16.

REIS, E. L.; SOUZA, L.F.S. ; MELLO, F.A.F. Influência da aplicação de nitrogênio, fósforo e potássio sobre o desenvolvimento da seringueira (Hevea brasiliensis Muell. Arg.) no sul da Bahia. Revista Theobroma, v.14, n.1, p. 45-52, $1984 b$.

REIS, E.L.; SANTANA, C.J.; ROSAND, P.C. Influência da calagem e adubação na produção da seringueira no sul da Bahia. Revista Theobroma, v.14, n.1, p.33-44, $1984 c$.

RODRIGUES, F. M.; TINÓCO, P. B. Densidade inicial de exploração em seringal de cultivo. Comunicado Técnico CNPSD/EMBRAPA. n. 35, p. 1-7, 1984

RUBBER RESEARCH INSTITUTE OF INDIA. Handbook of natural rubber production in India. KottaYam: RRII, 1980, 668p.

RUBBER RESEARCH INSTITUTE OF MALAYSIA. Wind Damage. Planters' Bulletin of the Rubber research institute of Malaysia. v.43, p. 79-93, 1959

RUBBER RESEARCH INSTITUTE OF MALAYSIA. Cycle of nutrients in rubber plantation. Planters Bulltin of the Rubber Reasearch Institute of Malaysia, v. 115, n.220, p. 225-33, 1971. 
RUBBER RESEARCH INSTITUTE OF MALAYSIA. Tapping Systems and yield stimulation of Hevea. Kuala Lumpur: RRIM, 1980. p. 287.

RUBBER RESEARCH INSTITUTE OF MALAYSIA. Manual for diagnosing nutritional requirements for Hevea . Kuala Lumpur: RRIM, 1990.

SANTANA, C. J. L.; MIRANDA, E. R.; CABALA-ROSAND, F. P. Resposta da seringueira no sul da Bahia a doses crescentes de nitrogênio, fósforo e potássio. Informe Técnico. CEPEC. p.55-57, 1977/78.

SÃO PAULO. Secretaria da Agricultura. Cultura da seringueira. São Paulo: Departamento de Produção Vegetal, 1958.

SARRUGE, J.R.; HAAG, H.P. Análises químicas em plantas. Piracicaba: ESALQ, Departamento de Química, 1974. 56p.

SHORROCKS, V.M. Leaf analysis as a guide to the nutrition of Hevea brasiliensis. 5 . Leaf sampliing technique for the nature rubber. Journal of Rubber Research Institute of Malaysia, v.17, p. 167-190, 1962.

SHORROCKS, V.M. Deficiências minerais em Hevea e plantas de cobertura associadas. Brasília: Superintendência da Borracha, 1979.76p.

SOUZA, P. S. A exploração dos seringais de cultivo no polo seringalista de Ituberá. Anais: Encontro nacional sobre Explotação e organização de seringais de cultivo. SUDHEVEA. p. 79-86. 1986. 
SYVANADIAN, K. Reduced imaturity period of Hevea brasiliensis. In: RUBBER RESEARCH CONFERENCE, Kuala Lumpur: 1975. Proceedings. Kuala Lumpur: RRIM . 1975, v.3, p.147-157

SYVANADIAN, K. Efficient use de fertilisers. In: RUBBER RESEARCH INSTITUTE OF MALAYSIA. Training manual on soils, soil management and nutrition of Hevea. Kuala Lumpur: RRIM, 1979. p. 163-180.

VIEGAS, I. J. Doses de NPK em viveiro de Hevea spp. na obtenção de plantas aptas para a enxertia em Latossolos Amarelo Testura média, na ilha de Mosqueiro-PA. Piracicaba, 1985. Dissertação ( Mestrado). Escola Superior de Agricultura Luiz de Queiroz, Univervidade de São Paulo

VIRGENS FILHO, A. C.; BERNARDES, M. S.; CASTRO, P. R. C. Recente enfoque sobre a exploração precose da seringueira (hevea spp). In: SIMPÓSIO DA CULTURA DA SERINGUEIRA, 2, Piracicaba 1987. Anais... Piracicaba: ESALQ Depto Agricultura, 1990. p. 333-348.

VIRGENS FILHO, A.C. Sangria e coleta do látex em seringueira. In: SIMPÓSIO SOBRE A CULTURA DA SERINGUEIRA NO ESTADO DE SÃO PAULO, 1, Piracicaba, 1986 Anais... Campinas : Fundação Cargil, 1986. p. 270-318.

VIRGENS FILHO,A. C. Ecofisiologia da seringueira. Piracicaba: ESALQ/USP, (Relatório - Disciplina Fitotecnia).

WISNIEWSKY,A. Aspectos econômicos: geopolíticos, da heveicultura. Belém: 1979. $19 \mathrm{p}$. 
WONG C. B. Discriminatory fertilizer use for Hevea. In: RUBBER RESEARCH INSTITUTE OF MALAYSIA. Course on soils management of soil and nutrition of Hevea. Kuala Lumpur: RRIM, 1977. p. 162-173 